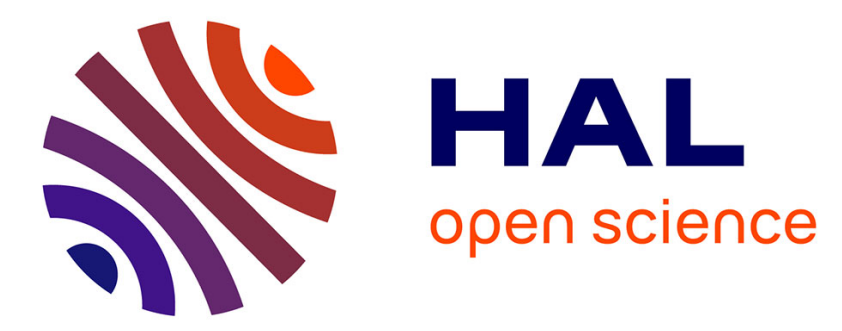

\title{
Unraveling the Martian water cycle with high-resolution global climate simulations
}

Alizée Pottier, François Forget, Franck Montmessin, Thomas Navarro, Aymeric Spiga, Ehouarn Millour, André Szantai, Jean-Baptiste Madeleine

\section{- To cite this version:}

Alizée Pottier, François Forget, Franck Montmessin, Thomas Navarro, Aymeric Spiga, et al.. Unraveling the Martian water cycle with high-resolution global climate simulations. Icarus, 2017, 291, pp.82-106. 10.1016/j.icarus.2017.02.016 . hal-01497681

\section{HAL Id: hal-01497681 \\ https://hal.sorbonne-universite.fr/hal-01497681}

Submitted on 29 Mar 2017

HAL is a multi-disciplinary open access archive for the deposit and dissemination of scientific research documents, whether they are published or not. The documents may come from teaching and research institutions in France or abroad, or from public or private research centers.
L'archive ouverte pluridisciplinaire HAL, est destinée au dépôt et à la diffusion de documents scientifiques de niveau recherche, publiés ou non, émanant des établissements d'enseignement et de recherche français ou étrangers, des laboratoires publics ou privés. 


\title{
Unraveling the Martian water cycle with high-resolution global climate simulations
}

\author{
Alizée Pottier $^{\mathrm{a}, \mathrm{b}, *}$, François Forget ${ }^{\mathrm{b}}$, Franck Montmessin ${ }^{\mathrm{a}}$, Thomas Navarro ${ }^{\mathrm{b}}$, Aymeric Spiga ${ }^{\mathrm{b}}$, Ehouarn \\ Millour $^{\mathrm{b}}$, André Szantai ${ }^{\mathrm{b}}$, Jean-Baptiste Madeleine ${ }^{\mathrm{b}}$ \\ ${ }^{a}$ LATMOS/IPSL, UPMC Univ. Paris 06 Sorbonne Universités, UVSQ, CNRS, Guyancourt, France \\ ${ }^{b}$ Laboratoire de Météorologie Dynamique/IPSL/CNRS, UPMC Univ. Paris 06, Sorbonne Universités, Paris, France
}

\begin{abstract}
Global climate modeling of the Mars water cycle is usually performed at relatively coarse resolution (200$300 \mathrm{~km}$ ), which may not be sufficient to properly represent the impact of waves, fronts, topography effects on the detailed structure of clouds and surface ice deposits. Here, we present new numerical simulations of the annual water cycle performed at a resolution of $1^{\circ} \times 1^{\circ}(\sim 60 \mathrm{~km}$ in latitude). The model includes the radiative effects of clouds, whose influence on the thermal structure and atmospheric dynamics is significant, thus we also examine simulations with inactive clouds to distinguish the direct impact of resolution on circulation and winds from the indirect impact of resolution via water ice clouds. To first order, we find that the high resolution does not dramatically change the behavior of the system, and that simulations performed at $\sim 200 \mathrm{~km}$ resolution capture well the behavior of the simulated water cycle and Mars climate. Nevertheless, a detailed comparison between high and low resolution simulations, with reference to observations, reveal several significant changes that impact our understanding of the water cycle active today on Mars. The key northern cap edge dynamics are affected by an increase in baroclinic wave strength, with a complication of northern summer dynamics. South polar frost deposition is modified, with a westward longitudinal shift, since southern dynamics are also influenced. Baroclinic wave mode transitions are observed. New transient phenomena appear, like spiral and streak clouds, already documented in the observations. Atmospheric circulation cells in the polar region exhibit a large variability and are fine structured, with slope winds. Most modeled phenomena affected by high resolution give a picture of a more turbulent planet, inducing further variability. This is challenging for long-period climate studies.
\end{abstract}

Keywords: Mard, atmosphere, Atmospheres, dynamics, Mars, climate, Meteorology

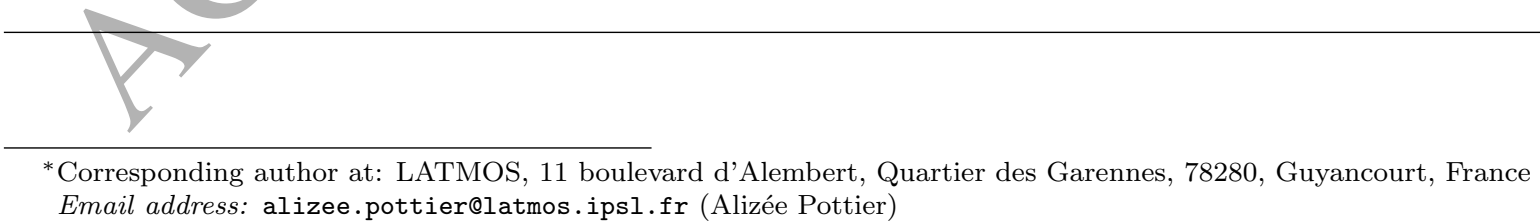

Corresponding author at: LATMOS, 11 boulevard d'Alembert, Quartier des Garennes, 78280, Guyancourt, France 


\section{Introduction}

Since the early days of Mars exploration, diverse, intriguing water ice clouds have been observed on Mars. The occurrence and thickness of clouds depend on locations and seasons. One notable Viking era compilation exists (Tamppari, 2003). There can be high altitude (mesospheric) clouds, tropospheric clouds, 5 thick polar hood cover (Briggs \& Leovy, 1974), or fog and haze in low lands or detached layers (Jaquin et al., 1986), as well as orographic clouds (Briggs et al., 1977). Since then, other missions have enhanced the dataset on cloud coverage, including Mars Global Surveyor (Wang \& Ingersoll, 2002; Pearl et al., 2001), and Mars Express (Zasova et al., 2005; Madeleine et al., 2012b).

Global climate models (GCMs) are useful tools to analyse the seasonal cycle of clouds and their main formation areas. They are able to simulate a realistic spatial and temporal distribution of clouds when the global circulation advects water vapor realistically (Richardson \& Wilson, 2002a; Montmessin et al., 2004). But some questions still remain. For example, unresolved mesoscale circulation patterns in the polar regions, a major source of water, seem to play a very important role in water advection (Tyler \& Barnes, 2014). One of the open questions about the martian water cycle is whether it is in equilibrium or not. The theory tends to show there is a slow loss of water from the north to the south pole, which acts as a cold trap for water with its remaining $\mathrm{CO}_{2}$ ice even in the hottest part of the summer (Richardson \& Wilson, 2002a; Houben et al., 1997; Jakosky \& Farmer, 1982).

Previous model studies of the martian water cycle have usually been carried out at relatively low resolutions, typically about 64 per 48 grid points, or $5.625^{\circ}$ in longitude per $3.75^{\circ}$ in latitude in the global climate model of the Laboratoire de Météorologie Dynamique (LMD) (Madeleine et al., 2012a; Navarro et al., 2014). Other examples in the literature are $6^{\circ}$ in longitude per $5^{\circ}$ in latitude, or $3.6^{\circ}$ per $3^{\circ}$ (Richardson $\&$ Wilson, 2002a), or $5^{\circ}$ in longitude per $4^{\circ}$ in latitude (Urata \& Toon, 2013). These resolutions are sufficient for first order climatic studies as they capture the emergence of synoptic phenomena and can represent baroclinic waves and thermal tides on Mars. With the increase in computational power, studies at higher resolutions are now accessible (see Table 1). More detailed topographical features can have an impact on the circulation. Smaller atmospheric wayes can be resolved, and the transport of water vapor and ice can be improved by limiting numerical diffusion typical of coarser advection schemes and by better representing filamentation processes due to wind shear. On Mars, a few studies with high resolution global climate models have been carried out, although they remain mostly unpublished in the refereed literature, see abstracts by Takahashi 30 et al. (2006, 2011), and see Lewis \& Montabone (2008), and without water cycle. Toigo et al. (2012) have shown that the winter polar circulation is more sensitive to resolution in the northern hemisphere than in the southern one.

This paper addresses the following questions: how can resolution affect atmospheric dynamics and the transport of water vapor above the ground of Mars? What impact does it have on cloud coverage? What 


\begin{tabular}{|l|cc|}
\hline \hline Resolution & Low & High \\
\hline Grid points in longitude & 64 & 360 \\
Grid points in latitude & 48 & 180 \\
Horizontal levels & 29 & 29 \\
Longitudinal length $\left(0^{\circ} \mathrm{N}\right)$ & $333 \mathrm{~km}$ & $59 \mathrm{~km}$ \\
Longitudinal length $\left(45^{\circ} \mathrm{N}\right)$ & $235 \mathrm{~km}$ & $42 \mathrm{~km}$ \\
Longitudinal length $\left(60^{\circ} \mathrm{N}\right)$ & $166 \mathrm{~km}$ & $30 \mathrm{~km}$ \\
Longitudinal length $\left(80^{\circ} \mathrm{N}\right)$ & $58 \mathrm{~km}$ & $10 \mathrm{~km}$ \\
Latitudinal length of a cell & $222 \mathrm{~km}$ & $59 \mathrm{~km}$ \\
\hline \hline
\end{tabular}

Table 1: Table of the main geometric features for the two resolutions of the study: number and size of cells.

insights can be gained into the water cycle and global climate from high-resolution simulations?

In section 2, we present the global climate model used in this study, and describe the simulations that were carried out. In section 3, the impact of the increase in resolution on the dynamics of the atmosphere and on the simulated thermal structure is studied. Then we focus in section 4 on the water cycle, using seasonal simulations performed over a whole year. In particular, planetary wave structures and their effect

40 on clouds and vapor are investigated in section 5 . Finally we study the sublimation processes on the northern polar cap, the main water reservoir, in section 6. Working at high resolution means resolving the cap better, with, for example, a better rendering of Chasma Boreale on topographical profiles. This has an effect on the water cycle and on the climate.

\section{Methodology}

\subsection{The LMD global climate model}

The model used in this study is the martian global climate model of the Laboratoire de Météorologie Dynamique (Forget et al., 1999). It is able to model a comprehensive water cycle for the red planet. The ability to simulate radiatively active clouds is included in the model (Madeleine et al., 2012a) (radiatively active clouds will also be called RAC in this paper). The cloud model includes a microphysical scheme that models the growth of water ice crystals onto dust nucleation cores (Montmessin et al., 2002), and whose effects on the climate are described in Navarro et al. (2014). Fluid mechanics equations for the atmosphere are solved in a finite-difference grid point dynamical core. A spatial polar filter is used in the GCM to remove small scale waves which irrealistically accumulate energy due to the limitation in scale caused by the finite grid cells. The polar filter removes some numerical instabilities. Dust, ice, vapor and condensation nuclei are tracers that can be advected in air parcels. The dust vertical distribution and the dust particle size are computed using a semi-interactive dust scheme (Madeleine et al., 2011). In this paper, the dust 
column opacity is prescribed using observation-derived dust "scenarios" detailed in Montabone et al. (2015). This means that the climate of a particular martian year can be computed. Unless otherwise indicated, the runs presented in this paper were performed with the scenario for Martian year 26 from Montabone et al. (2015). The study of interannual variability of traveling waves and water transport is beyond the scope of this paper.

\subsection{Simulated cases}

The standard resolution grid in previous studies of the water cycle with the LMD GCM makes use of 64 longitude per 48 latitude cells, with 29 vertical layers (Montmessin et al., 2004; Madeleine et al., 2012a; Navarro et al., 2014). Using the same number of vertical layers, with a model top at an altitude of about $80 \mathrm{~km}$, this study aims at comparing these standard low resolution simulations $\left(5.625^{\circ} \times 3.75^{\circ}\right)$ with model runs performed with a higher horizontal resolution $\left(1^{\circ} \times 1^{\circ}\right)$. Closer to the poles, one degree in longitude represents a smaller arc of a circle (Table 1), whereas one degree in latitude represents the same distance on the ground $(59 \mathrm{~km})$. This means that the surface area of a grid cell decreases closer to the poles. A polar filter limits effective longitudinal resolution of waves to the resolution at $60^{\circ} \mathrm{N}$. The improvement in resolution affects the representation of the north polar residual cap (Figure 1). Recent mesoscale modeling by Tyler \& Barnes (2014) is focused on northern summer and underlines the importance of the polar cap representation for cloud and wave structures. We will discuss further this topic in sections 5 and 6 of this paper.

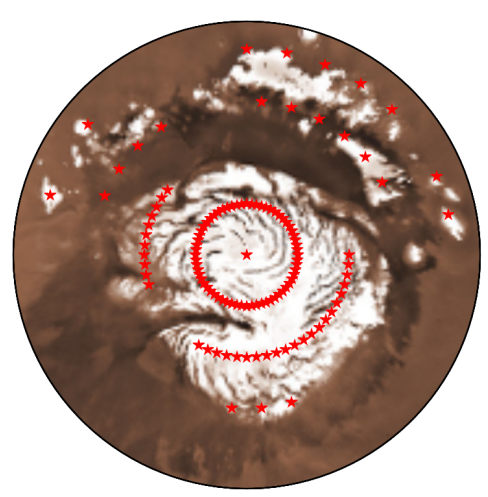

Low resolution, residual northern cap

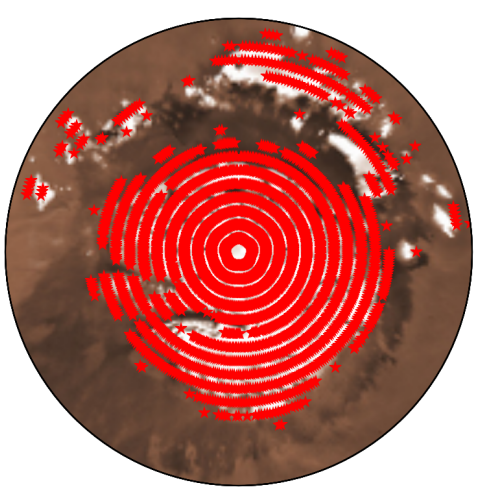

b High resolution, residual northern cap

Figure 1: North polar residual cap in low and high resolutions: main source of water in the Martian water cycle. Each red star represents the center of a grid cell permanently covered by water ice on the surface.

To compute an initial state for the high-resolution simulations, a lower resolution state from a simulation with a stabilized water cycle has been interpolated. The distribution of permanent water ice deposits near 
the north pole was inferred from a thermal inertia map of Mars. Where thermal inertia, taken from data (Mellon et al., 2000; Wilson et al., 2007), is higher than $500 \mathrm{~J} \mathrm{~m}^{-2} \mathrm{~K}^{-1} \mathrm{~s}^{-\frac{1}{2}}$, model cells are set to be part of the water ice deposits. Topography (Smith et al., 2001a) and albedo (Christensen et al., 2001) maps at higher resolution are also used. Figure 1 shows the resulting map of the pole. The northern perennial ice cap has a surface of $A_{\mathrm{HR}}=1.27 \times 10^{6} \mathrm{~km}^{2}$ at high resolution, while it has a surface of $\mathrm{A}_{\mathrm{LR}}=9.91 \times 10^{5} \mathrm{~km}^{2}$ at low resolution. As $\mathrm{A}_{\mathrm{HR}}=1.28 \times \mathrm{A}_{\mathrm{LR}}$, the area of exposed water ice is consequently larger at high resolution. Low resolution runs are converged, while high resolution ones were only run for one year. For high resolution runs, work was done when preparing the runs to make the transition from low to high resolution topography smooth, removing irrealistic amounts of ice deposited where no perennial cap is observed. These areas are key to convergence. At the end of the year, the water vapor amount does not diverge that much compared to the beginning.

To understand the scales involved, Figure 2 shows two maps of the total cloud ice column at the time of the northern summer solstice $\left(\mathrm{L}_{\mathrm{s}}=90^{\circ}\right)$, in the low and high resolution simulations with radiatively active clouds. The observed fine-scale structure ("patchiness") of clouds is better resolved in the high-resolution run. There is a global increase of cloud thickness. Furthermore, the thick clouds in Hellas ( $>5$ pr. $\mu \mathrm{m})$ fill only the northern part of the basin at low resolution, whereas they encircle the edge of Hellas and spread to the west in the high-resolution simulations. In the area between $60^{\circ} \mathrm{E}$ and $180^{\circ} \mathrm{E}$, east and south of Hellas, there is a wide area of textured clouds that extends as far as the south pole, that are not present in lower resolution runs. More clouds appear over Argyre and overall south of $50^{\circ} \mathrm{S}$. Such maps can be compared to Mars Orbiter Camera pictures depicting water ice clouds in shades of blue (Wang \& Ingersoll, 2002). Clouds on Mars on orbiter pictures during daytime are really textured and are anchored to topographical features like Tharsis Montes. Fog is present inside Valles Marineris and Hellas on MOC orbiter images at a local time of 2 P.M. The fragmentation of clouds in high-resolution runs tends to match MOC images more closely. However the aphelion season in high latitudes in the north and south tends to be too cloudy in the LMD MGCM (clouds are too thick, both during the day and the night), compared to MCS (McCleese et al., 2010) and TES data (Smith et al., 2001b). Faint nighttime low-latitude clouds seem more widespread in observations (MCS data, again) than in the LMD GCM model. Data showing the winter polar hood is difficult to obtain but for example nighttime TES data (Pankine et al., 2013) in northern winter shows that the edge of the polar hood qualitatively agrees with the LMDZ Mars model (simulated clouds having the tendency to spread a bit further south, though). Pankine et al. (2013) could not observe well the core of the polar hood due to a lack of thermal contrast. Figure 2 of Navarro et al. (2014) shows that the simulated polar hood clouds are thicker than indicated in TES diurnal observations. We will discuss in section 4 how resolution affects this result.

To better pinpoint resolution effects, low (LR) and high resolution (HR) versions of the model were also run with radiatively inactive water ice clouds (or IC). This means that the clouds do not interact with the 


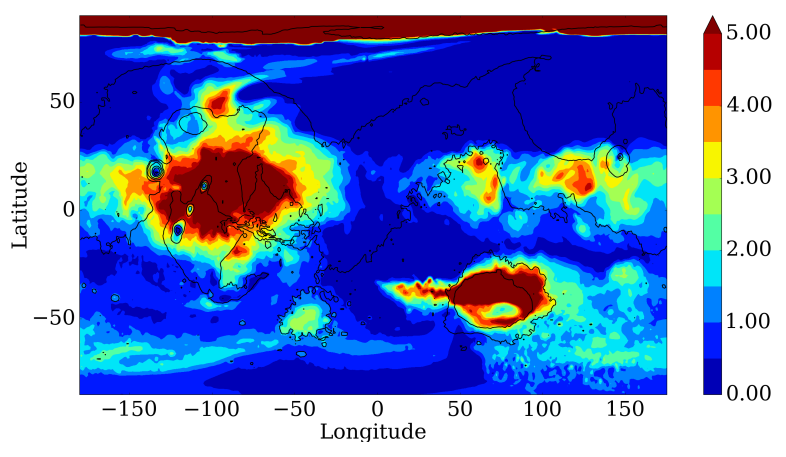

a High resolution model

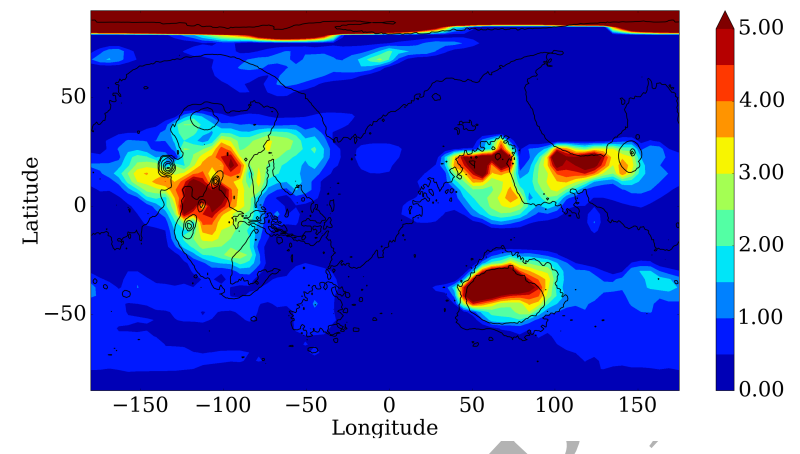

b Low resolution model

Figure 2: A comparison of two maps of the column of atmospheric water ice (in pr. $\mu \mathrm{m}$ ) at the northern summer solstice as modeled by the LMD Mars GCM at high and low resolution (see Table 1). Midnight is at longitude 0. Contours of MOLA topography (black lines) show main surface features at $1^{\circ} \times 1^{\circ}$ for both maps.

ambiant infrared and visible radiation in the atmosphere of the planet. The non-linear thermodynamical effects caused by the interaction between airborne ice particles and light are suppressed (Navarro et al., 2014). The modification of water sources at the different resolutions changes the water cycle, but these changes are amplified by the radiative effect of clouds, owing to positive and negative feedbacks between atmospheric dynamics, cloud formation, and the impact thereøf on the thermal structure. The inactive runs conducted in this study, at both high and low resolutions, help untangle the phenomena. Inactive runs are less realistic (Madeleine et al., 2012a; Navarro et al., 2014), as will be confirmed later in the paper.

\section{Vertical structure: atmospheric profiles and thermal tides}

The aim of this section is to review/the impact of resolution on the average vertical structure of the atmosphere, studying temperature profiles, and the link with cloud content, vapor profiles, and dust loading. Profiles, averaged over all longitudes (zonal mean) and over twenty days, are studied. They help quantify exactly the effect of resolution, with or without radiatively active clouds.

\subsection{Runs without radiatively active clouds}

Overall, high-)and low-resolution cases without radiatively active clouds (or HRIC and LRIC cases) are quite similar, except for the polar warming in the polar night, which is known to be model dependent (see Figures 8 and 9 of Forget et al. (1999)) and notably sensitive to resolution (Toigo et al., 2012).

Figure 3 shows temperature and water vapor profiles from LRIC and HRIC runs. The yearly average profiles of temperature for the whole planet are very similar, with a slightly colder higher atmosphere $(40-100 \mathrm{~km})$ in the high resolution case. The temperature inversion is a consequence of the adiabatic heating of the air advected by the Hadley cell. The temperature inversion within the tropics is reinforced 
with a $7 \mathrm{~K}$ increase in high altitudes at high resolution. At the South pole at its winter solstice, the high resolution model is colder at high altitudes. This is confirmed at $\mathrm{L}_{\mathrm{s}}=270^{\circ}$ : the air is warmer at high altitudes above the winter pole in low resolution, which means the Hadley cell circulation slightly decreases in activity with the increase in resolution in the IC case. The annual averages of the dust profiles in the atmosphere (figure not shown) show little difference from run to run because of the prescribed dust loading read in the dust scenarios from data. Relative shifts could however happen between high and low altitudes. IC runs do not show any significant relative increase in dust loading in middle-to-high altitudes (10 to $40 \mathrm{~km})$ and cannot explain the differences in temperature.

Yearly averaged cloud formation seems confined within the $10-40 \mathrm{~km}$ height range with a peak around $15 \mathrm{~km}$ and $35 \mathrm{~km}$, within the altitude range of clouds in published simulations and observations (Madeleine et al., 2012b; Wilson \& Guzewich, 2014). Within the tropics there is an increase in vapor content in the lowest layers, and a smaller increase in cloud content. The southern polar hood at the winter solstice is thicker than at low resolution.

Terrestrial planets with a diurnal cycle and an atmosphere like the Earth or Mars are subject to diurnal and semi-diurnal (harmonics of the diurnal cycle) waves. The sun heats periodically different areas of the planet and the atmospheric system responds to this forcing by producing waves. Lindzen (1970) presents an early discussion of the application of the Earth tidal theory to Mars. Tidal waves have been studied on Mars, for example, recently, using Mars Climate Sounder data (Kleinböhl et al., 2013). These thermal tides are a key element of the global atmospheric dynamics on Mars. Overall, the latitudinal structure of the thermal tides is found to be almost insensitive to horizontal model resolution with an alternance of extrema where afternoon temperature is higher than night temperature and the reverse. On Figure 4, the zonal mean temperature at 3 P.M. minus the temperature at 3 A.M. (the local times observed by Mars Climate Sounder) is shown in an altitude versus latitude plot for high and low resolutions (without active clouds). The time period is a snapshot of $\mathrm{L}_{\mathrm{s}}=180^{\circ}$. This structure evolves slowly during the year. These graphs are comparable to similar plots derived from MCS data (Figure 4 of Guzewich et al. (2012), or Figure 3 of Lee et al. (2009))

\subsection{Runs with radiatively active clouds}

The IC runs show a rather unrealistic cloud cover. At first clouds were thought not to affect the martian climate, being only a byproduct of its effect on the water cycle. However, cloud coverage affects the climate, as waterice clouds interact mostly with thermal radiation, absorbing and scattering it. There is a quantifiable effect on air and surface temperature via the greenhouse effect when the clouds are thick or high enough or both (Madeleine et al., 2012a). For example, RAC in summer in the northern hemisphere are responsible for higher nighttime surface temperatures under the aphelion cloud belt due to the supplementary infrared radiation (Wilson et al., 2007). Temperature inversions above Tharsis where clouds are the thickest show 


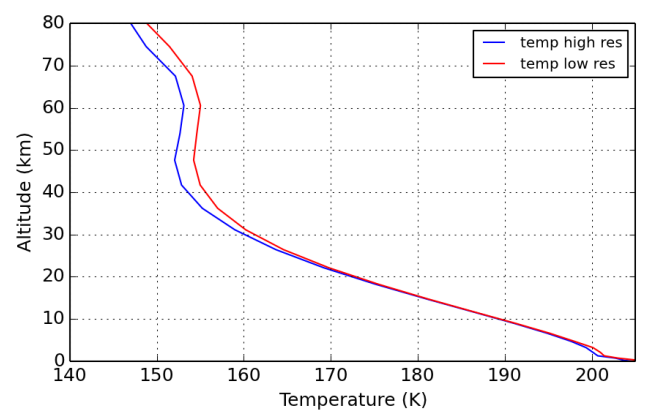

a $\mathrm{T}$, yearly average, all latitudes

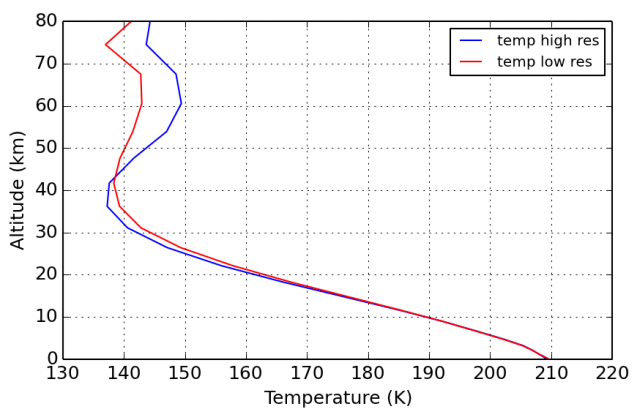

c $\mathrm{T}, 30^{\circ} \mathrm{N}$ to $30^{\circ} \mathrm{S}, 20$-sols mean around $\mathrm{L}_{\mathrm{s}}=90^{\circ}$

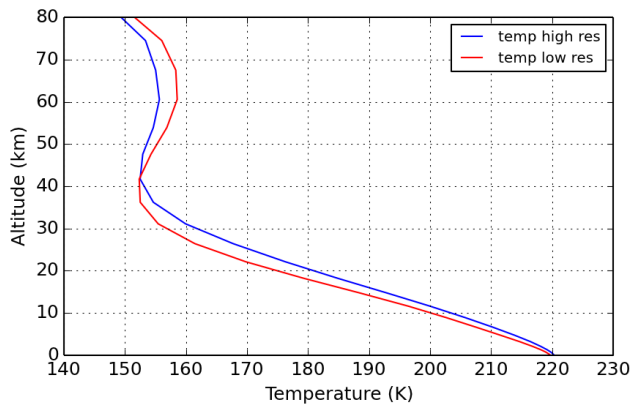

e T, $75^{\circ}$ to $90^{\circ} \mathrm{N}, 20$-sols meán around $\mathrm{L}_{\mathrm{s}}=90^{\circ}$

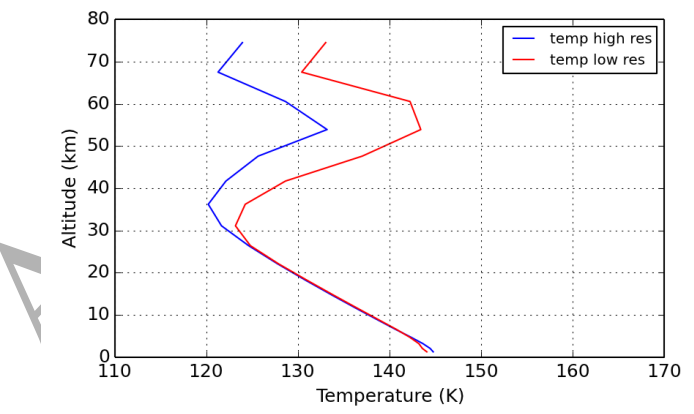

g T, $75^{\circ}$ to $90^{\circ} \mathrm{S}, 20$-sols mean around $\mathrm{L}_{\mathrm{S}}=90^{\circ}$

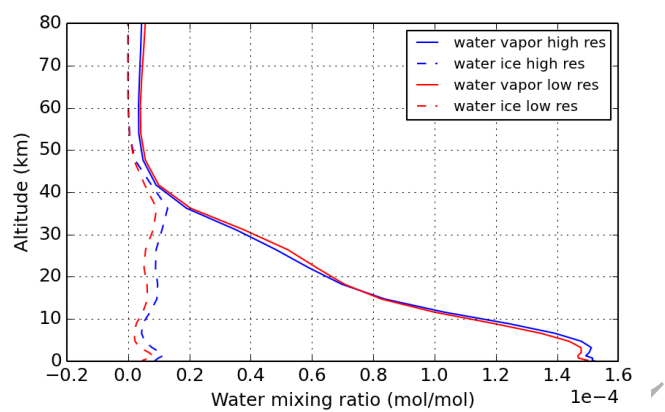

b $\mathrm{H}_{2} \mathrm{O}$, yearly average, all latitudes

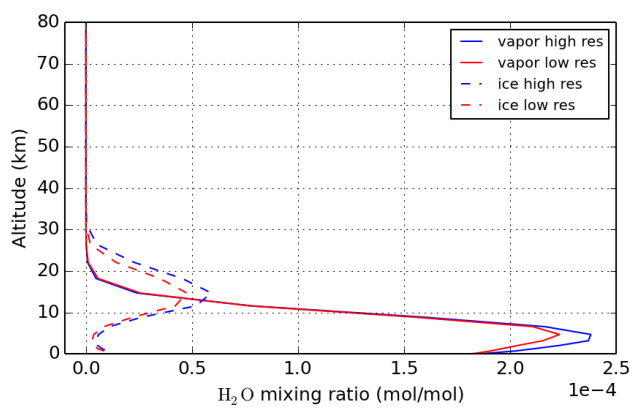

d $\mathrm{H}_{2} \mathrm{O}, 30^{\circ} \mathrm{N}-30^{\circ} \mathrm{S}, 20$-sols mean at $\mathrm{L}_{\mathrm{s}}=90^{\circ}$

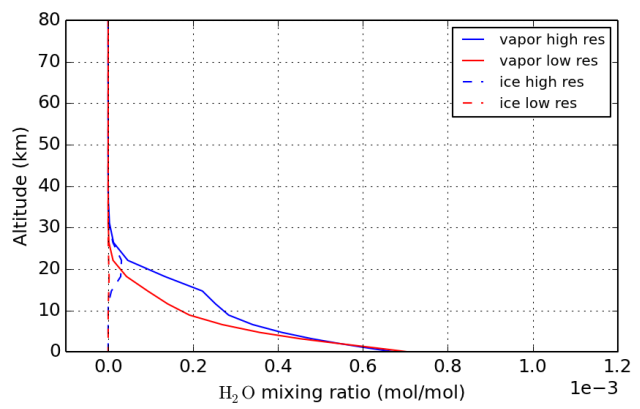

f $\mathrm{H}_{2} \mathrm{O}, 75^{\circ}-90^{\circ} \mathrm{N}, 20$-sols mean at $\mathrm{L}_{\mathrm{S}}=90^{\circ}$

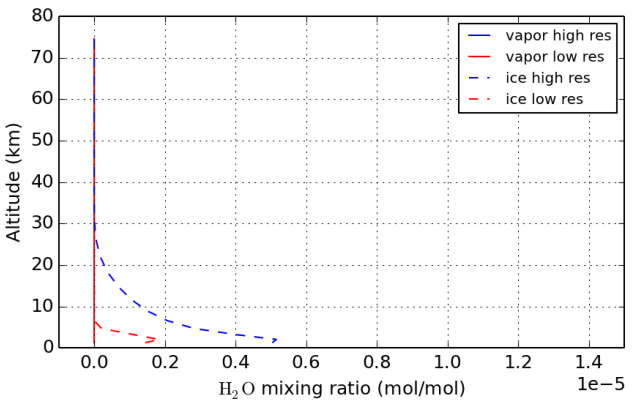

h $\mathrm{H}_{2} \mathrm{O}, 75^{\circ}-90^{\circ} \mathrm{S}, 20$-sols mean at $\mathrm{L}_{\mathrm{S}}=90^{\circ}$

Figure 3: Vertical profiles of temperature $\mathrm{T}(\mathrm{K})$, water mixing ratio of ice and vapor $(\mathrm{mol} / \mathrm{mol})$, zonally averaged, simulations with inactive clouds. Blue curves: high-resolution run, red curves: low-resolution run. 


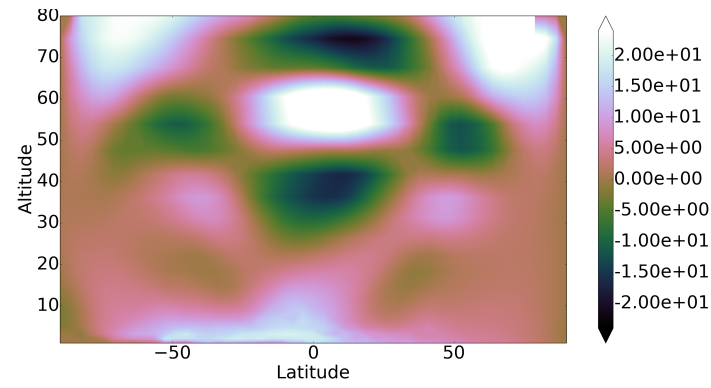

a Low resolution, inactive clouds

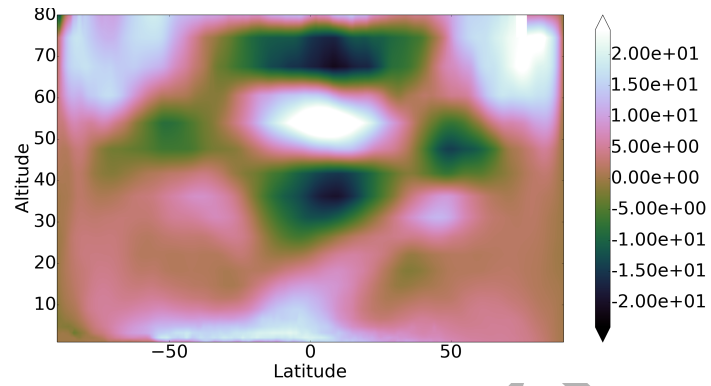

b High resolution, inactive clouds

Figure 4: Zonal mean of the temperature at $3 \mathrm{pm}$ minus the temperature at $3 \mathrm{am}(\mathrm{K})$. Diurnal tidal wave. $\mathrm{L}_{\mathrm{s}}=180^{\circ}$, northern hemisphere autumn equinox.

the link between tropical temperature structure and water ice clouds (Wilson \& Guzewich, 2014). Using RAC, what are the effects on the climate of the increased resolution? A first answer emerges from the study of the panels of Figure 5, which show temperature (a, c, e, g) and water vapor (b, d, f, h) profiles from LRRAC and HRRAC runs.

For simulations with RAC, a comparison made at the poles shows that the change in polar topography and ice distribution is reflected in the atmosphere as the water sublimates. There is more water released in the atmosphere (Figure 5f) at high resolution, the origin of which is surface ice sublimation. The increased ice sublimation results from a longer period of absence of polar hood, and better evacuation of water from the polar areas by air circulation within atmospheric cells and winds over the cap (see later subsections for details). While the LR profile exhibits a drop in water vapor near the ground, reflected in an increase in cloud mass below $10 \mathrm{~km}$, clouds are less thick at high resolution and their peak is higher in altitude. This reflects the earlier and more gradual disappearance of the polar hood (described in subsection 4). This affects temperature (Figure 5e): the polar hood cools the lower levels more intensively at low resolution, and both the low altitude and high altitude temperature inversions are not present at high resolution, while the temperature gradient is also less steep.

The increase of water vapor inventory has an effect on the aphelion tropical climate (Figure $5 \mathrm{c}$ ), because thicker and more spatially extended clouds form by adiabatic cooling out of the wetter air masses traveling from the pole to the northern tropics (Figure 5d). The temperature profile is warmed up to an altitude of $50 \mathrm{~km}$ and is then colder above in the high-resolution run. This results from a strengthening of the Hadley cell circulation, induced by the radiative effect of clouds (Wilson et al., 2008; Madeleine et al., 2012a), that in turn increases the cloud cover.

Averaged over the whole year and the whole planet (Figure 5b), the main result is an overall wetter atmosphere, in HR simulations, as more water is advected from the north polar cap. The air is noticeably drier in the upper atmosphere without the radiatively active clouds. This produces thicker clouds that also 


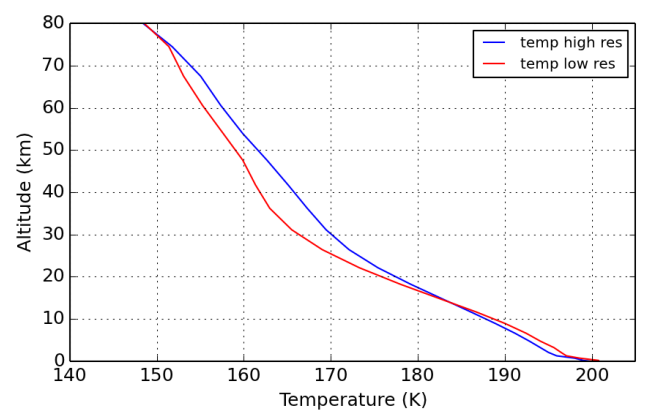

a $\mathrm{T}$, yearly average, all latitudes

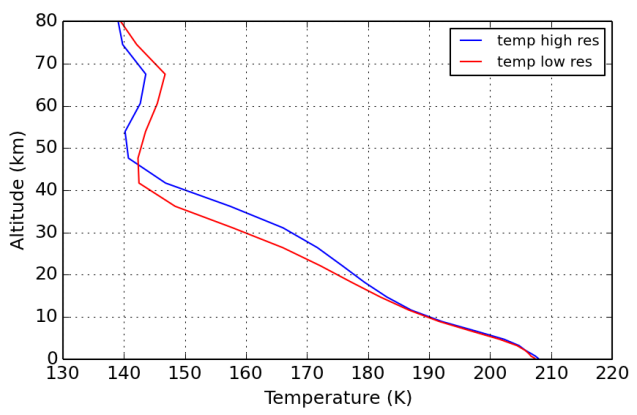

c $\mathrm{T}, 30^{\circ} \mathrm{N}$ to $30^{\circ} \mathrm{S}, 20$-sols mean around $\mathrm{L}_{\mathrm{s}}=90^{\circ}$

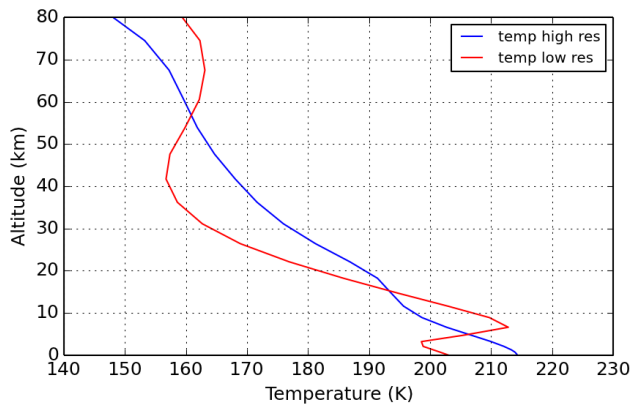

e T, $75^{\circ}$ to $90^{\circ} \mathrm{N}, 20$-sols mean around $\mathrm{L}_{\mathrm{s}}=90^{\circ}$

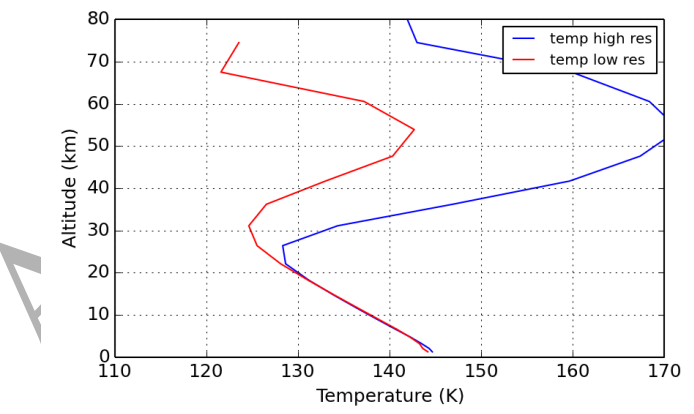

g T, $75^{\circ}$ to $90^{\circ} \mathrm{S}, 20$-sols mean around $\mathrm{L}_{\mathrm{s}}=90^{\circ}$

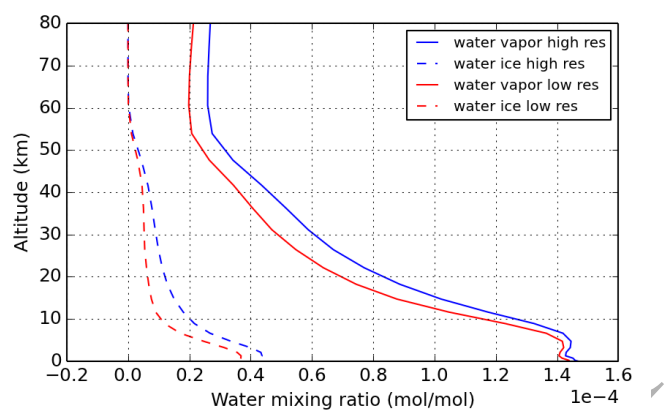

b $\mathrm{H}_{2} \mathrm{O}$, yearly average, all latitudes

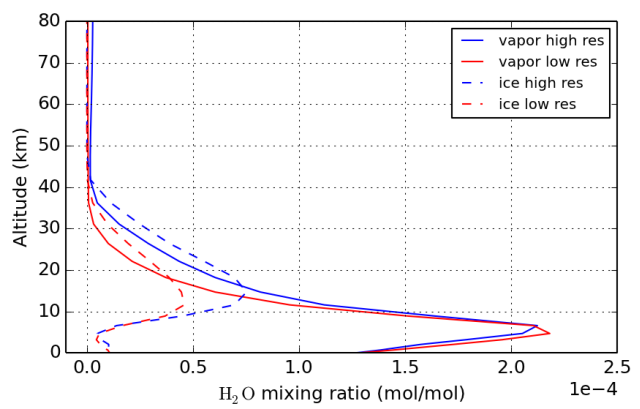

d $\mathrm{H}_{2} \mathrm{O}, 30^{\circ} \mathrm{N}-30^{\circ} \mathrm{S}, 20$-sols mean at $\mathrm{L}_{\mathrm{s}}=90^{\circ}$

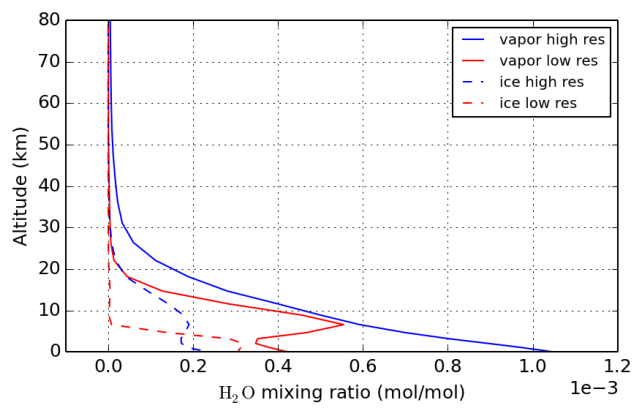

f $\mathrm{H}_{2} \mathrm{O}, 75^{\circ}-90^{\circ} \mathrm{N}, 20$-sols mean at $\mathrm{L}_{\mathrm{S}}=90^{\circ}$

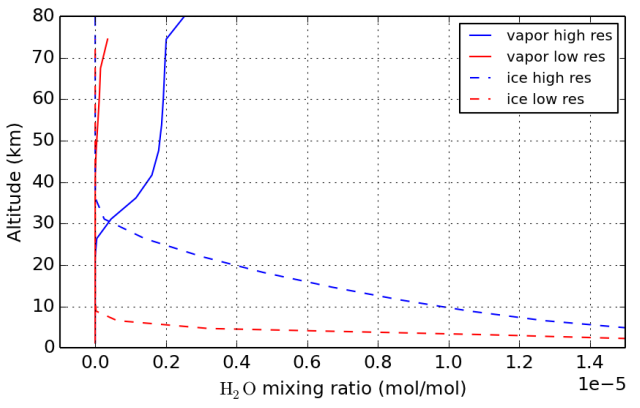

h $\mathrm{H}_{2} \mathrm{O}, 75^{\circ}-90^{\circ} \mathrm{S}, 20$-sols mean at $\mathrm{L}_{\mathrm{S}}=90^{\circ}$

Figure 5: Vertical profiles of temperature $\mathrm{T}(\mathrm{K})$, water mixing ratio of ice and vapor $(\mathrm{mol} / \mathrm{mol})$, zonally averaged, simulations with radiatively active clouds. Blue curves: high-resolution run, red curves: low-resolution run. 


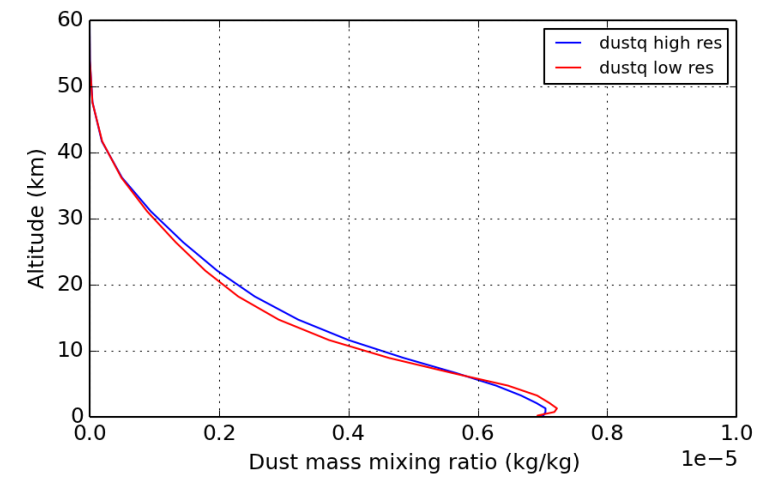

a Yearly average, all latitudes, active clouds

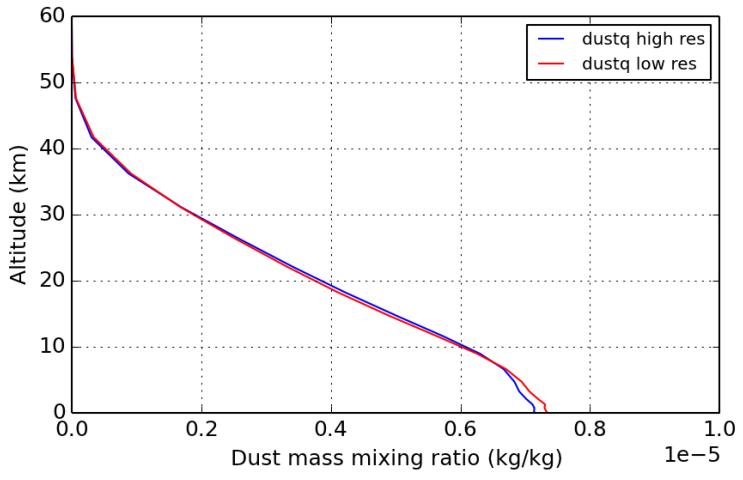

b Tropics, active clouds

Figure 6: Profiles of dust mixing ratio $(\mathrm{kg} / \mathrm{kg})$, averaged over a year and zonally, as a function of altitude above areoid. Blue curves: high-resolution run, red curves: low-resolution run.

cover more area, especially during the aphelion season with its cloud belt (Figure 5d, see section 4). These clouds have an impact on the Hadley cell circulation, which is strengthened. This results in dust transported to higher altitudes, with a dust depletion at lower altitudes, as can be seen on the yearly averaged dust profile shown on Figure 6a and b. The dust-cloud feedback is described in Kahre et al. (2015). However, the globally averaged vertical distribution of dust is only very slightly changed.

The winter south pole has more water vapor (at high resolution) incoming through high latitudes from the Northern hemisphere, that condenses as clouds below $40 \mathrm{~km}$. There was no water transport of this magnitude in both previously studied LRIC and HRIC runs. Ice is consequently deposited by sedimentation onto the seasonal cap (see Figure 5h). The low altitude temperature gradient remains the same (following $\mathrm{CO}_{2}$ condensation temperature) while at high altitude there is an increase of $30 \mathrm{~K}$ of the peak temperature. A temperature of $170 \mathrm{~K}$ over the South Pole has been observed in the data, later in the soutern winter: see Figure 25 of Kleinböhl et al. (2009).

The strengthening of the temperature inversion over the South pole in winter is a symptom of the strengthening of the Hadley cell in the HR run. Indeed, this air is adiabatically heated in the descending branch of the cell which rises in the summer hemisphere (Forget et al., 1999). It contrasts with the behavior of the inactive ruhs that get colder in high altitudes in the high resolution runs.

In general, thermal inversion is less marked than in the inactive runs. Cloud and vapor content are enhanced in the active runs as compared to the inactive ones: RAC amplify this change, like catalysts. There is an averaged hotter higher atmosphere in the HR case, which is the opposite of what is observed with IC. Resolution does not change deeply the thermal structure, except in polar areas, (as expected, see 8 of Forget et al. (1999)), as Hadley circulation affects heating in polar areas and thermal effects are the most pronounced here. Let us assess the impact of the increase in resolution on thermal tides, with 
RAC. During the northern fall equinox, the high altitude north-to-south wave amplitude is greater at high resolution, especially the $30^{\circ} \mathrm{S}-30^{\circ} \mathrm{N}$ latitude zone at a height of $80 \mathrm{~km}$ (Figure 7 ). This corresponds to the dominant mode, which has a phase reversal at $22^{\circ} \mathrm{S}$ and $22^{\circ} \mathrm{N}$ (Zurek, 1976; Lee et al., 2009). The difference between the thermal tide of the active and inactive cloud models is reduced at high resolution. Previous works have shown that RAC increase the amplitude of the semidiurnal tide (Wilson et al., 2014). Wilson \& Guzewich (2014) have shown that, as compared to IC simulations, RAC tend to heat the air in the night above $100 \mathrm{~Pa}$, and cool it at $200 \mathrm{~Pa}$ near the base of the cloud deck, during the aphelion season. Here, a noticeable fact is that the vertical wavelength of the thermal tide is increased by about $10 \mathrm{~km}$ in active cloud simulations, showing the thermal effects of the clouds. At high latitudes, between 60 and $80 \mathrm{~km}$, the wave structure shows high-frequency perturbations. The tidal waves in HR simulations are overall consistent with LR simulations with RAC. The waves excited by the alternating sunlight and nighttimes are typically the same, to first order. High in the sky $(>70 \mathrm{~km})$, the zonal wave amplitude is bigger in the high resolution simulation, and below, it tends to be a bit smaller. High resolution also allows fragmentation into smaller scale perturbations at high latitudes/altitudes. With RAC, horizontal resolution does not seem to impact the vertical wavelength of the tide, which is an improvement if we compare to the inactive cases (where the vertical wavelength shrinks when resolution improves).

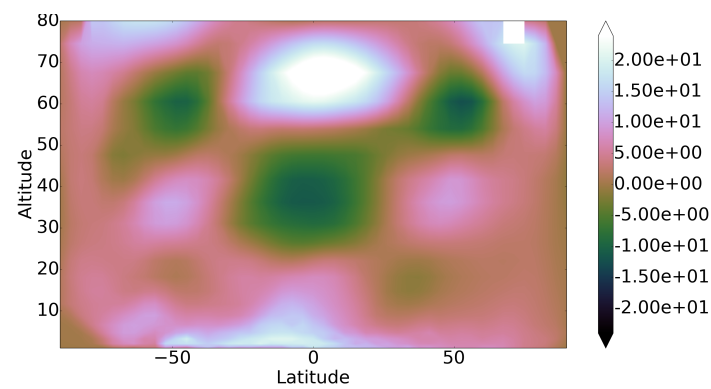

a Low resolution, active clouds

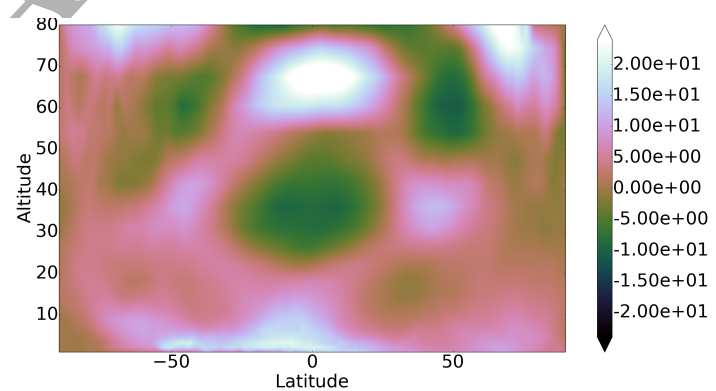

b High resolution, active clouds

Figure 7: Zonal mean of the temperature at $3 \mathrm{pm}$ minus the temperature at 3 am $(\mathrm{K})$. Diurnal tidal wave. $\mathrm{L}_{\mathrm{s}}=180^{\circ}$, northern hemisphere autumn equinox.

\section{Discussion: impact on the water cycle}

In section 3, we discussed the thermal variation in active runs, the strengthening of the Hadley cell circulation, and the consequences on cloud thickness and height. The precise effect on the water cycle, considering the atmosphere of Mars as a system with its reservoirs and transport vectors is discussed here and in the following sections. The column integrated amount of water vapor in the atmosphere, as presented in Figures 8 and 9, is a proxy for water cycle activity on the planet. At high resolution, with active clouds, the martian atmosphere is wetter than at LR from latitudes 0 to $40^{\circ} \mathrm{N}$. The gradient of water distribution 
from north to south in southern summer is less steep at high resolution than at low resolution. This has an impact on the "Clancy" effect, as described in Clancy et al. (1996), explaining the asymmetry between northward and southward global transport of water by the trapping of water by the aphelion cloud belt. That non-linear coupling between circulation and cloud formation describes how the quantity and advection of water in the aphelion summer hemisphere is enhanced as the eccentric orbit affects water vapor saturation altitude.

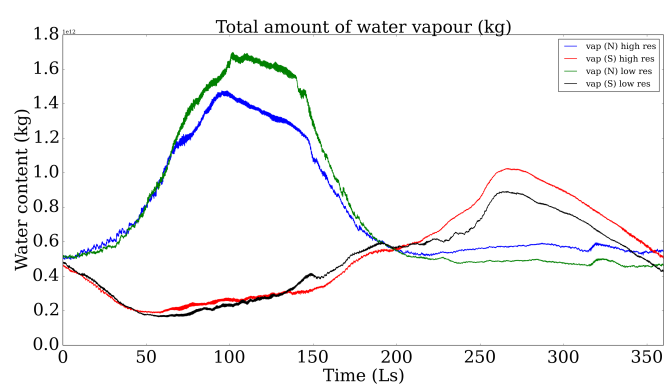

a Vapor content, active clouds

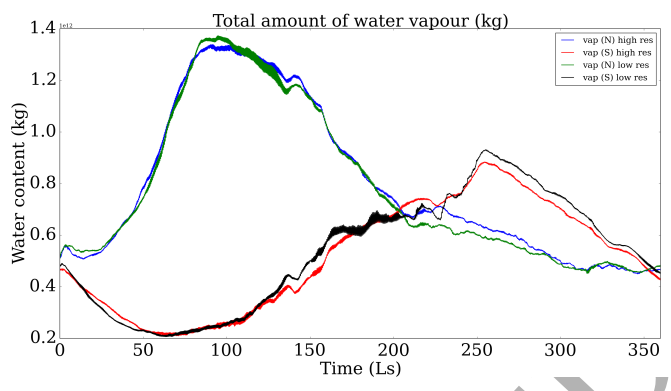

c Vapor content, inactive clouds

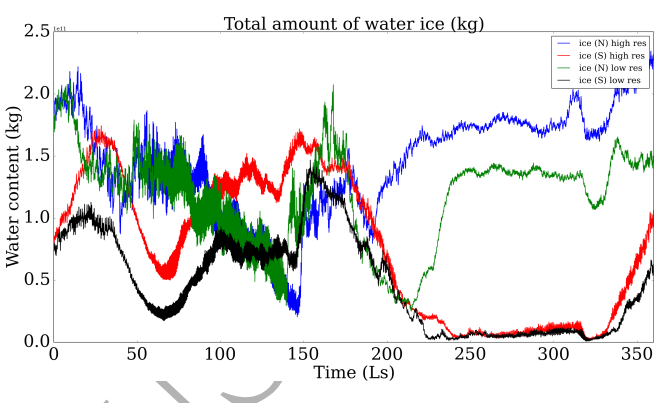

b Ice content, active clouds

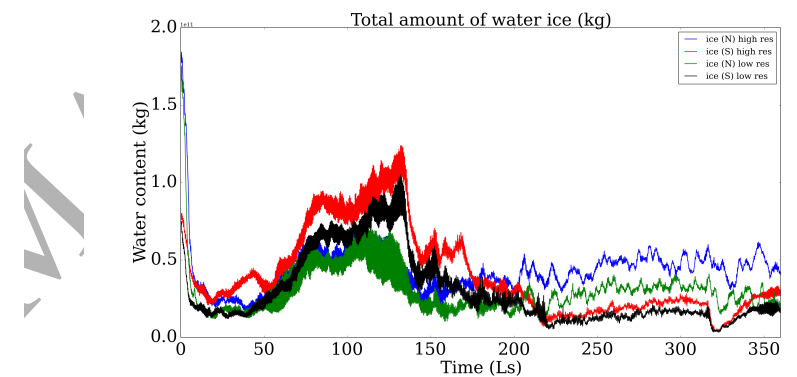

d Ice content, inactive clouds

Figure 8: Total water ice and vapor content (kg) of the two martian hemispheres for one year, for runs with (top) and without (bottom) active clouds. In blue and red are the high-resolution masses of water in the northern and southern hemisphere respectively, while in green and black are the lower resolution northern and southern masses of water.

The total water budget for the two hemispheres allow us to assess the sensitivity to resolution of interhemispheric water distribution for inactive cloud simulations (figures not shown). A comparison can be made, for example, with the same inventory made with Viking data, see Figure 6 of Jakosky \& Farmer (1982). This allows us to understand how the water distribution evolves throughout the year and the differences between the models that were run, at high and low resolutions. The total hemispheric water content illustrates the differences between the two models (see Figure 8). The mass of water vapor has an order of magnitude of $10^{12} \mathrm{~kg}$, while the order of magnitude of the ice mass is $10^{11} \mathrm{~kg}$. As a rule of thumb, ice in the atmosphere represents $10 \%$ of the water available.

On Figure 8a the total amount of water vapor by hemisphere is shown for the RAC simulations. There are two main peaks which originate from the sublimation of the seasonal frost in summer. The first one, in 


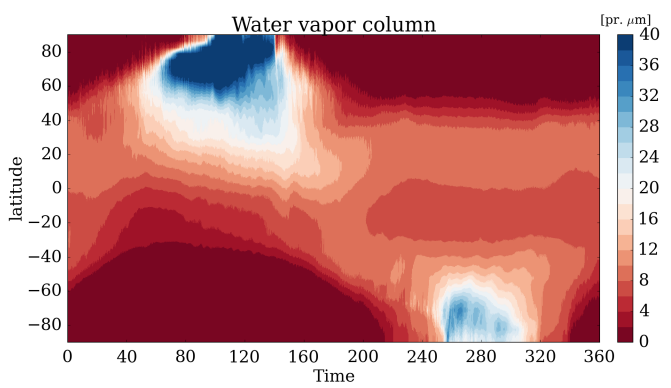

a Low resolution, active clouds

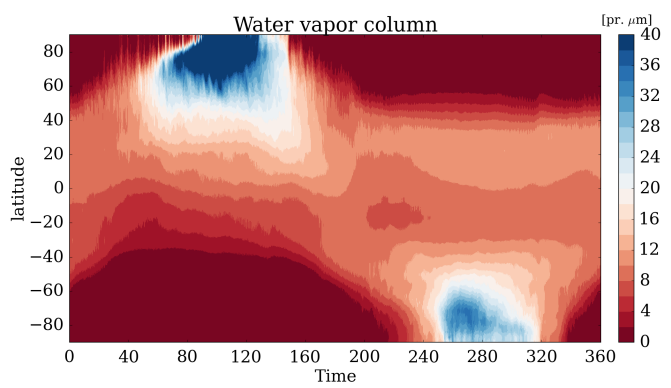

b High resolution, active clouds

Figure 9: Zonal mean of atmospheric water vapor column (precipitable or pr. $\mu \mathrm{m}$ ), latitude versus $L_{\mathrm{S}}$ plot.

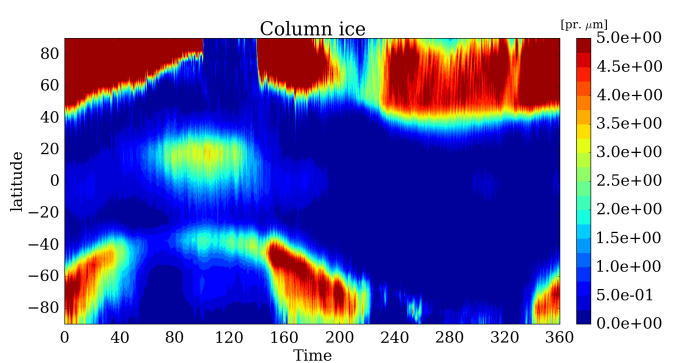

a Low resolution, active clouds

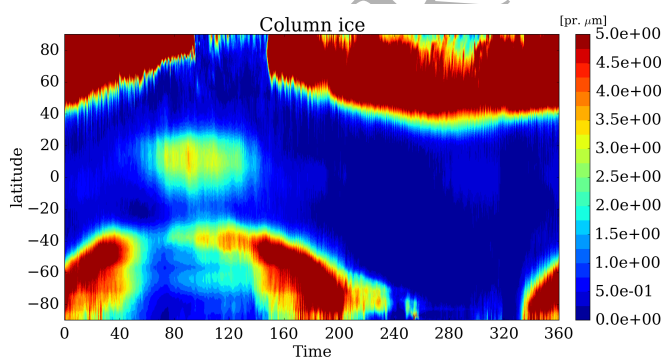

b High resolution, active clouds

Figure 10: Zonal mean of airborne water ice column (pr. $\mu \mathrm{m})$, latitude versus $\mathrm{L}_{\mathrm{s}}$ plot.

the northern hemisphere, happens between $\mathrm{L}_{\mathrm{s}}=60 \%$ and $150^{\circ}$. The second one, in the southern hemisphere, peaks between $\mathrm{L}_{\mathrm{s}}=240^{\circ}$ and $320^{\circ}$. The crossing of curves at $\mathrm{L}_{\mathrm{s}}=200^{\circ}$ corresponds to the shifting of the water dominance from the north to the south as northern polar dusk falls. The high resolution maximum water content is $0.2 \times 10^{12} \mathrm{~kg}$ lower in the north than the lower resolution one. However there is more water vapor available in the southern hemisphere. These graphs can be compared to TES hemispheric water vapor data, figure 8 of Smith (2002), which shows a northern hemisphere maximum of more than $2 \times 10^{12} \mathrm{~kg}$ and a southern hemisphere maximum of $1.5 \times 10^{12} \mathrm{~kg}$. These early results were later adjusted with a $40 \%$ decrease in the northern peak, more in agreement with PFS results (Fouchet et al., 2007). This means the aforementioned maxima become $1.2 \times 10^{12} \mathrm{~kg}$ (north) and $0.9 \times 10^{12} \mathrm{~kg}$ (south) respectively. These values show that the HRRAC simulation is closer to the observations in the northern hemisphere wet season $\left(1.4 \times 10^{12} \mathrm{~kg}\right.$ of vapor at the peak instead of $1.7 \times 10^{12} \mathrm{~kg}$ value of LRRAC simulations $)$. In the southern hemisphere, the HRRAC simulations are too wet with a peak at $1 \times 10^{12} \mathrm{~kg}$ instead of $0.8 \times 10^{12} \mathrm{~kg}$ of the LRRAC simulations. Another set of observations, SPICAM (Trokhimovskiy et al., 2015), giving total mass of water on the whole planet, shows a too dry HRRAC model in the aphelion season $\left(2.1 \times 10^{12} \mathrm{~kg}\right.$ are observed $)$ and a too wet HRRAC model in the southern spring and summer $\left(1.3 \times 10^{12} \mathrm{~kg}\right)$. As for water ice in the clouds (Figure 8b), the most prominent differences take place in the winter of each hemisphere. 
Indeed, there is an increase of $0.5 \times 10^{11} \mathrm{~kg}$ of cloud amount in the south in the HR run as compared to the LR one. And this difference is also found in the northern hemisphere in winter with roughly the same amplitude. The total amount of water ice also begins its northern fall increase earlier with a smaller increase.

Active cloud simulations are drier at low latitudes, either at high or low resolution, as compared to IC runs (Figures 8c and d). Polar ice sublimation is more efficient (as compared to IC runs) in northern and southern summer north of $60^{\circ} \mathrm{N}$ and south of $60^{\circ} \mathrm{S}$. There are more clouds everywhere and during the whole year, these clouds are thicker. This is due to the reduced content of water released in the atmosphere in IC runs. Also, with RAC, when clouds appear at low altitudes, these clouds reflect the incoming sunlight and tend to further cool the atmosphere, resulting in even more clouds. But clouds at high altitudes absorb thermal radiation from the planet and emit at that colder temperature: they should rather have a warming effect. This feedback loop is described in Navarro et al. (2014), for example. Kahre et al. (2015) explores the relationship between this feedback loop and the dust cycle, impacting polar warming.

With active clouds, resolution primarily influences the northern polar hood (see figure 10). At high resolution, the disappearance of the polar hood happens earlier and the cloud-free period around summer solstice lasts longer, possibly because the higher resolution affects daytime duration, with a finer terminator representation. However there are transient polar clouds that are able to form locally. The polar hood is overall thicker. The study of baroclinic waves, in section 5, sheds light on atmospheric dynamics phenomena that can explain these differences. Yet again, it is apparent that the clouds' interaction with incoming and outgoing radiation is key to the organization of the fluxes of water.

Assessing the realism of the polar hood simulations can be difficult. The observed thickness of the polar hood is difficult to assess (see also section 2.2). The thick polar hood clouds of RAC simulations seem unrealistic if we compare them to what we can see of the polar hood (i.e, its edge) in MCS or nighttime TES data (Pankine et al., 2013). But there is an observational bias that must be taken into account: the lack of thermal contrast affects the visibility of clouds from the heart of the polar hood. Temperature data can also be used to try to understand indirectly which simulation is more realistic. Unlike for the tropical clouds, it is not easy to use surface temperature to constrain the characteristics of the polar hood clouds, for three reasons. The ground under the polar hood clouds is covered by $\mathrm{CO}_{2}$ ice. Surface temperature data may be affected by the presence of the clouds. In the regions where the polar hood forms, the difference between the modeled and observed temperatures seems to mostly result from the error in the timing of the modeled $\mathrm{CO}_{2}$ ice cap. The effect of the clouds is small compared to this error. Thus it prevents us from assessing the realism of our cloud simulation. So, we have tried to look at low altitude temperatures to compare them with data. Global low altitude temperatures seems lower in RAC simulations. Thicker clouds seem to have a global cooling effect. However, a more detailed study shows that this depends on the time of the day, and on the altitude and thickness of the clouds. McCleese et al. (2010) (Figure 4) shows polar temperatures in MCS data, with temperature as low as $150 \mathrm{~K}$ at the poles in the dead of winter, and the profile and 
temperature inversion seem close to our results with RAC in the north polar winter (low or high resolution, figure not included in the paper). The temperature maxima seem to have a slightly higher altitude in the data, and the HRIC run, with its colder (170-180 K) temperature maximum, matches better the data than the LRIC. With RAC, the HRRAC and LRRAC are closer to each other, and both agree rather well with the data during the north polar winter, qualitatively. As for the south polar hood, comparing Figure $5 \mathrm{~g}$ and the MCS data, the HRRAC model matches the data better with its peak of temperature inversion at $170 \mathrm{~K}$ rather than the $140 \mathrm{~K}$ of the LRRAC (which is too cold). Madeleine et al. (2012a) has shown that in the LMD GCM the low level clouds cool the atmosphere at the poles (especially at equinoxes). The loss of infrared radiation to space makes the lower atmosphere near the north pole too cold by $15 \mathrm{~K}$ in early spring, for example. This corrects a previous warm bias (so IC simulations are not realistic either with their too thin clouds) (Madeleine et al., 2012a), but replaces it by a cold one.

HR runs tend to be more cloudy, especially in the winter hemisphere. One hypothesis would be that polar hood edge dynamics, with a better resolved latitudinal temperature gradient, allow the formation of smaller ice particles due to smaller supersaturation and slower growth of crystals. These smaller ice particles stay longer in the atmosphere. Stronger baroclinic waves (see later) also inject more easily water toward the pole and thus increase cloud quantity and coverage.

This shows the key part the active clouds take in atmospheric dynamics and their impact on the water budget. Overall there is more water everywhere and at all times, and the behavior of clouds is more erratic and different from one run to another, which is compatible with the presence of a feedback loop between temperature, water vapor and clouds. Indeed, RAC GCM runs are more sensitive to model parameters, because of a positive feedback between cloud formation and temperatures (Navarro et al., 2014), and more unstable.

To further analyze the water cycle behaviour described in the paragraphs above, we show Figures 11 and 12 mean zonal stream functions, and water vapor and ice mixing ratios, all for the HRRAC and LRRAC runs and for all seasons. At $\mathrm{L}_{\mathrm{s}}=0^{\circ}$, at high resolution, there is an intensification of the low- to middle-latitude circulation in the northern hemisphere, and also in the high-latitude cell in that same hemisphere. This results in an increase in the amount of water vapor, especially at higher altitudes. The aphelion cloud belt is thicker, while there are less clouds near the north pole. At $\mathrm{L}_{\mathrm{s}}=90^{\circ}$, the global north-to-south cell is strenghtened with the increase in resolution, which results in more vapor above the north pole, and most of all a wider vertical extension of the polar hood clouds. The aphelion cloud belt is thicker, which tends to reduce the amount of water vapor present at lower latitudes. At $\mathrm{L}_{\mathrm{s}}=180^{\circ}$, polar hoods are thicker and have a greater vertical extension at high resolution. The middle- to low-latitude clouds are also thicker. Polar cells are strengthened. On the whole, there is more water vapor, but it is more spatially confined due to the high-latitude cells. Middle to low latitudes are wetter at high resolution. At $\mathrm{L}_{\mathrm{s}}=270^{\circ}$, again, the planet-scale Hadley cell is strengthened and extends further up at high resolution. More water is released 
at the south pole, the atmosphere is wetter, not only at the pole but also above the middle to low latitudes. All clouds are thicker, except those high above the south pole. The double maxima of water vapor above the south pole merge at high resolution.

To conclude this study of mean meridional circulation, the fact that there is a global strengthening of the Hadley cell circulation is confirmed, especially at solstices. The transition cells of the equinox are more complex, but show globally the same trend of a wetter and clouder atmosphere. Evolutions in cell morphology have consequences on the confinement of vapor and clouds and on the localization of maxima.

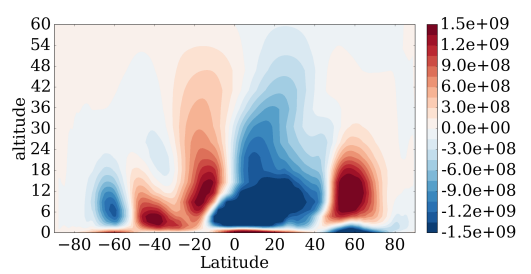

a $\psi, \mathrm{HR}, \mathrm{L}_{\mathrm{s}}=0^{\circ}$

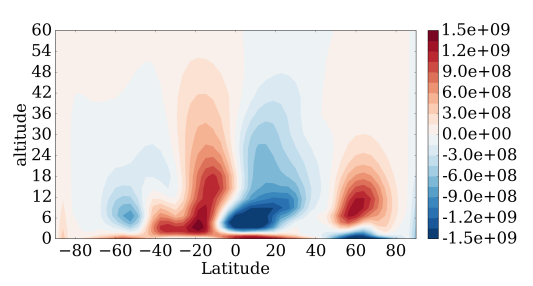

$\mathrm{d} \psi, \mathrm{LR}, \mathrm{L}_{\mathrm{s}}=0^{\circ}$
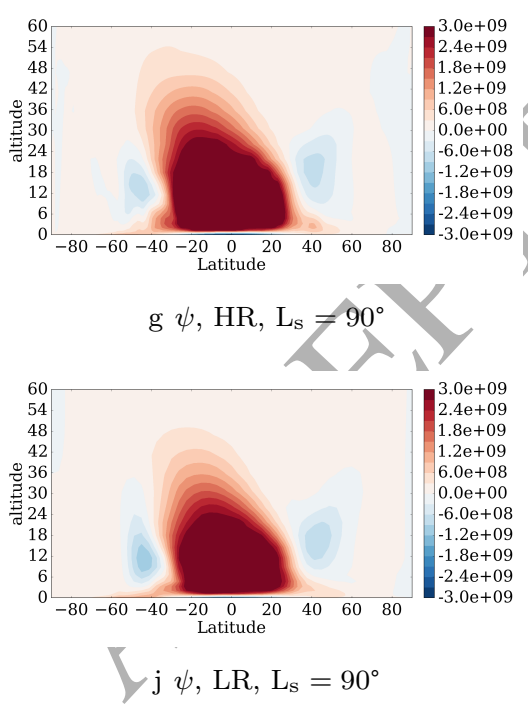

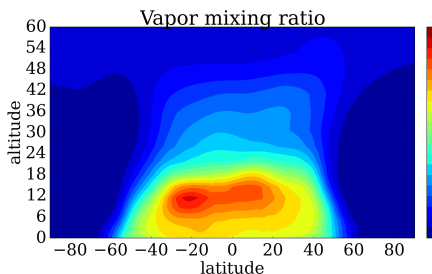

b $q_{\text {vap }}, \mathrm{HR}, \mathrm{L}_{\mathrm{s}}=0^{\circ}$

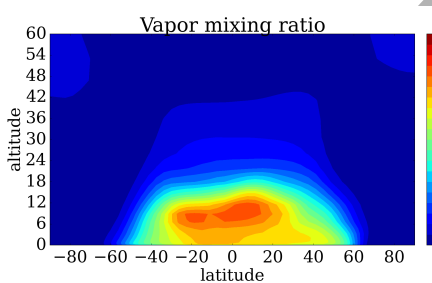

e $q_{\text {vap }}, \mathrm{LR}, \mathrm{L}_{\mathrm{s}}=0^{\circ}$
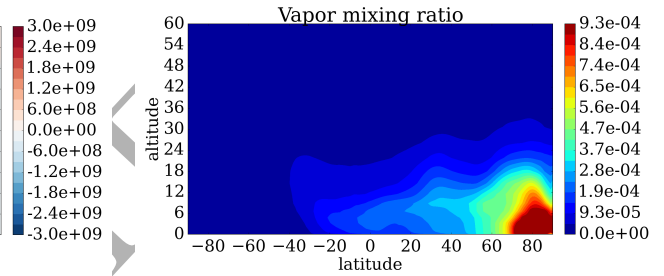

h $q_{\text {vap }}, \mathrm{HR}, \mathrm{L}_{\mathrm{s}}=90^{\circ}$

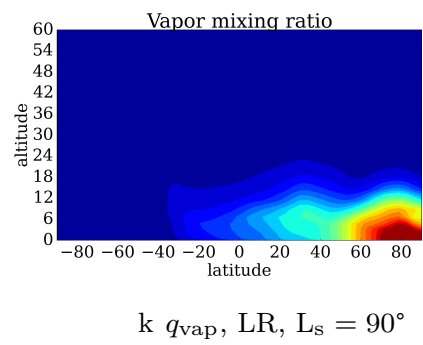

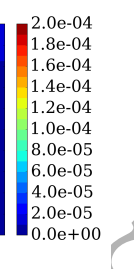

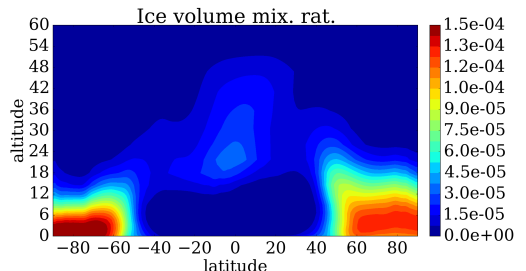

c $q_{\text {ice }}, \mathrm{HR}, \mathrm{L}_{\mathrm{s}}=0^{\circ}$
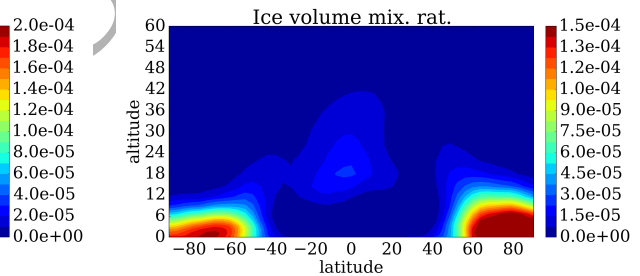

f $q_{\text {ice }}, \mathrm{LR}, \mathrm{L}_{\mathrm{s}}=0^{\circ}$

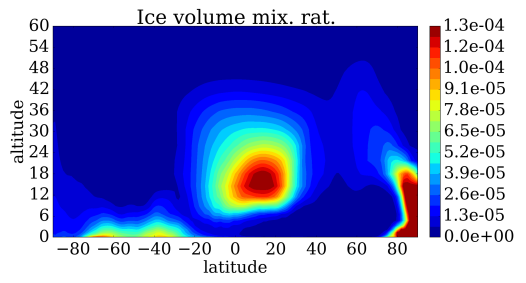

i $q_{\text {ice }}, \mathrm{HR}, \mathrm{L}_{\mathrm{s}}=90^{\circ}$
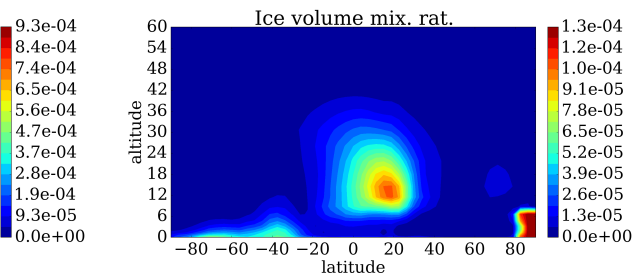

$1 q_{\text {ice }}, \mathrm{LR}, \mathrm{L}_{\mathrm{s}}=90^{\circ}$

Figure 11: Mean zonal stream function $(\mathrm{kg} / \mathrm{s})$, water vapor $\left(q_{\text {vap }}\right)$ and ice $\left(q_{\text {ice }}\right)$ mixing ratio $(\mathrm{mol} / \mathrm{mol})$, for the high- $(\mathrm{HR})$ and low-resolution (LR) runs, for northern spring $\left(L_{s}=0^{\circ}\right)$ and summer $\left(\mathrm{L}_{\mathrm{s}}=90^{\circ}\right)$. Averaged over 24 sols 


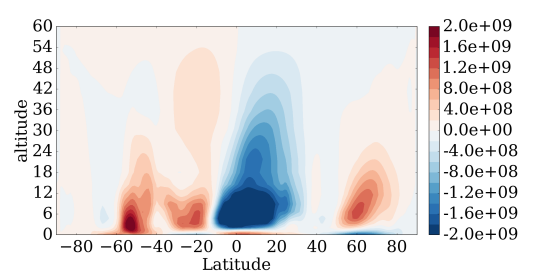

a $\psi, \mathrm{HR}, \mathrm{L}_{\mathrm{s}}=180^{\circ}$

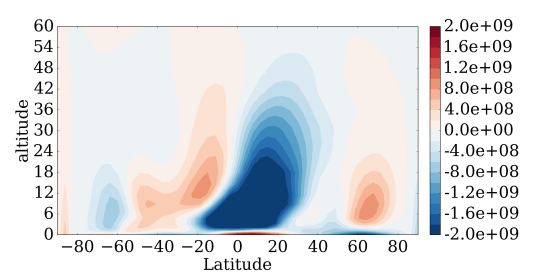

$\mathrm{d} \psi, \mathrm{LR}, \mathrm{L}_{\mathrm{s}}=180^{\circ}$

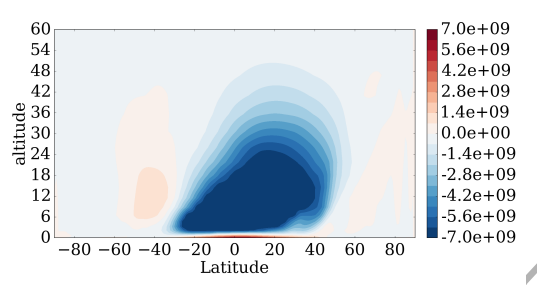

g $\psi, \mathrm{HR}, \mathrm{L}_{\mathrm{s}}=270^{\circ}$

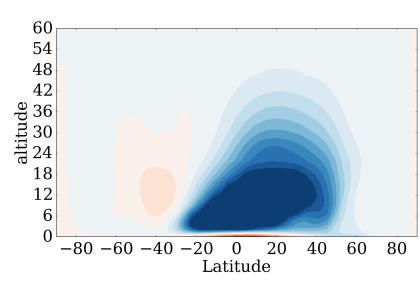

j $\psi, \mathrm{LR}, \mathrm{L}_{\mathrm{s}}=270^{\circ}$

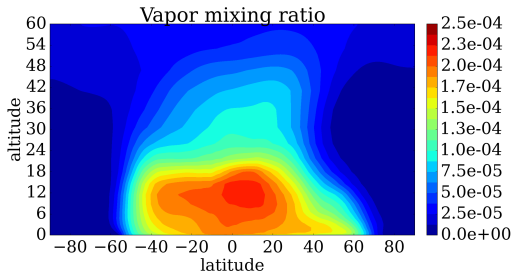

b $q_{\text {vap }}, \mathrm{HR}, \mathrm{L}_{\mathrm{s}}=180^{\circ}$
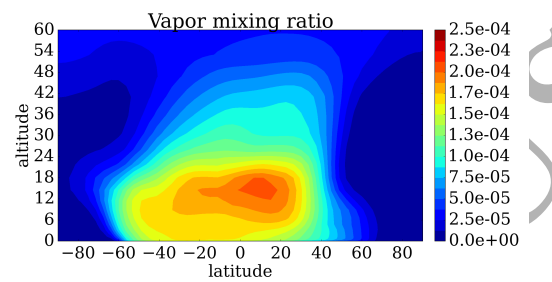

e $q_{\text {vap }}, \mathrm{LR}, \mathrm{L}_{\mathrm{s}}=180^{\circ}$

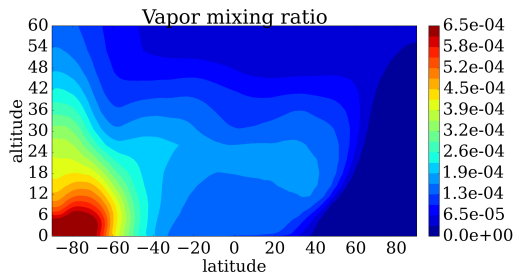

h $q_{\text {vap }}, \mathrm{HR}, \mathrm{L}_{\mathrm{s}}=270^{\circ}$

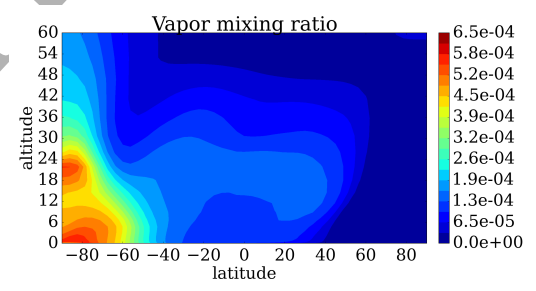

k $q_{\mathrm{vap}}, \mathrm{LR}, \mathrm{L}_{\mathrm{s}}=270^{\circ}$
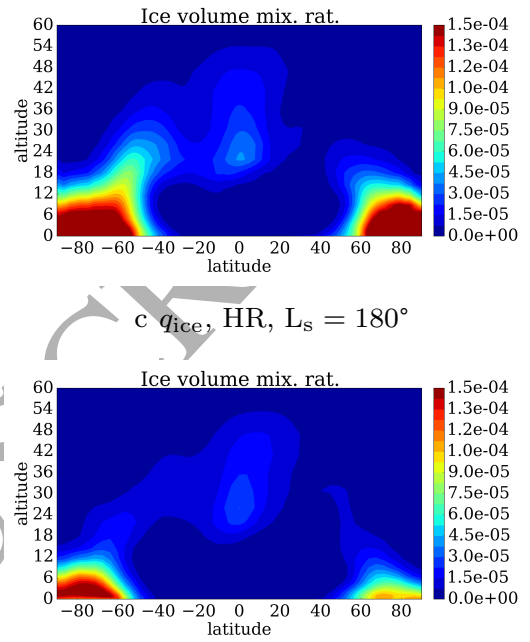

f $q_{\text {ice }}, \mathrm{LR}, \mathrm{L}_{\mathrm{s}}=180^{\circ}$

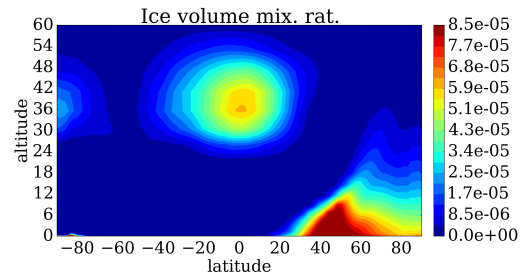

i $q_{\text {ice }}, \mathrm{HR}, \mathrm{L}_{\mathrm{s}}=270^{\circ}$

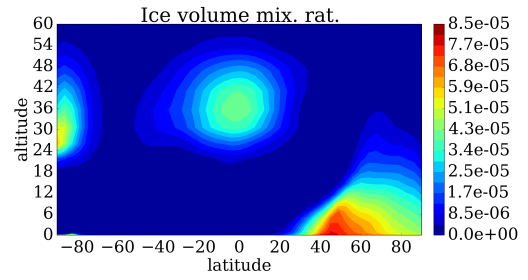

$1 q_{\text {ice }}, \mathrm{LR}, \mathrm{L}_{\mathrm{s}}=270^{\circ}$

Figure 12: Mean zonal stream function $(\mathrm{kg} / \mathrm{s})$, water vapor $\left(q_{\mathrm{vap}}\right)$ and ice $\left(q_{\text {ice }}\right)$ mixing ratio $(\mathrm{mol} / \mathrm{mol})$, for the high- $(\mathrm{HR})$ and low-resolution $(\mathrm{LR})$ runs, for northern fall $\left(L_{s}=180^{\circ}\right)$ and winter $\left(\mathrm{L}_{\mathrm{s}}=270^{\circ}\right)$. Averaged over 24 sols. 


\section{Baroclinic waves and the polar hood} This solsticial pause is most visible in wavenumber 2 to 3 waves (stronger in spring and autumn) while wavenumber one waves are rather prominent near the solstice (Lewis et al., 2016). GCM sensitivity studies

Baroclinic waves shape the water transport on Mars at midlatitudes. In Barnes (1980, 1981), pressure data from the Viking $1\left(22.5^{\circ} \mathrm{N}, 48^{\circ} \mathrm{W}\right)$ lander, and all data types from the lander $2\left(48^{\circ} \mathrm{N}, 226^{\circ} \mathrm{W}\right)$, were used to infer dynamical properties of eastward traveling transient disturbances caused by baroclinic instability $\left(\mathrm{L}_{\mathrm{s}}=180-360^{\circ}\right)$. The two dominant spectral peaks of disturbances were calculated to have wavenumbers during wintertime. Barnes (1981) confirmed the first results, and also detected baroclinic waves centered to the north of the Lander 2 site. The 6-8 sol periodicity has a zonal wavenumber of $1.5-2$, and the higher frequency peak $(2$ to $3 \mathrm{sol}$ ) tends to have a higher wavenumber (3-4). The onset of dust storms seems to strengthen atmospheric heating during the day, and strengthen the diurnal cycle signature, decreasing the signal of baroclinic waves.

The instrument TES aboard the MGS spacecraft provided a more complete dataset for the study of waves. TES nadir temperature data revealed zonal wavenumbers 1 and 2 waves, the former, prominent at the winter solstice, being bimodal, with a slow higher altitude wave (periods of more than $10 \mathrm{sol}$ ) and a fast surface wave (period of 6-7 sol), the latter, dominant in autumn or spring, having periods of 3-4 and 6-7 sol (Banfield et al., 2004). MGS MOC data and MGS radio occultation data confirmed the presence of a dominant eastward-travelling wave with zonal wavemumber 3 , and secondary ones at 2 and 1 , all three having a period of $2.3 \mathrm{sol}$ (Hinson \& Wang, 2010), plus a wavenumber 2 stationary wave (Rossby wave that shapes the polar hood clouds). Shifts in frequencies were observed around $L_{s}=230^{\circ}$ from a period of 2 to 3 sol for zonal wavenumbers 1 to 3 waves (Hinson \& Wang, 2010). In Hinson et al. (2012), MGS TES and Radio Science experiment data were used to analyze the triggering of regional dust storms in the northern hemisphere basins by the zonal wayenumber 3 mode. Indeed, zonal wavenumbers of 1 to 3 exist, with the mode 3 having the smallest periods $(2-3 \mathrm{sol})$, and the mode 1 the longest $(P>6 \mathrm{sol})$. Baroclinic wave modes are anticorrelated; when one is strong, others tend to be weak, and longer waves of zonal wavenumber 1 or 2 tend to have deeper vertical structure than the shorter ones. A mode tends to stay coherent for 15 to 30 sol (Hinson et al., 2012). Traveling dust storms may symmetrically and non-linearly enhance the zonal wavenumber 3 traveling waves under specific conditions according to global climate simulations (Wang et al., 2013).

Lewis et al. (2016) used MGS TES assimilation inside the LMD/UK GCM and explored the repeatable pattern of wave decrease around solstices, when low altitude transient waves reach a minimum around winter solstice, while thermal contrast between the summer hemisphere and the winter pole is maximal. 
are important as the interaction with topography seems to greatly influence the rise of different wavenumbers in spectral studies of the baroclinic waves. Indeed, by modification of near surface flow, the zonal variations of topography weaken transient eddies around solstice in both hemispheres (Mulholland et al., 2016). The intercomparisons between inactive and RAC simulations are revealing as RAC are known to increase lowlevel winds of the eastward propagating waves of periods of 1.5 to $10 \mathrm{sol}$, as their radiative cooling within the polar hood in spring and fall seasons influences the structure of the polar vortex (Wilson, 2011). They are also known to play a role in the dampening of baroclinic waves around winter solstices, due to a decrease of the vertical shear of the westerly jet near the surface around solstices, see also section 5.3 (Mulholland et al., 2016). In this section, we will study Fourier transforms of the waves that are visible in the LRIC, HRIC, LRRAC and HRRAC models to analyze how harmonics of the transient eddies are respectively impacted by horizontal resolution and RAC: Figures 13 and 14 show the Fourier transform of the surface pressure at two latitude ranges for northern fall and winter $\left(\mathrm{L}_{\mathrm{s}}=180^{\circ}\right.$ to $\left.360^{\circ}\right)$ waves.

Impact of radiatively active clouds. At $48^{\circ} \mathrm{N}$ (the Viking lander 2 location, Figure 13), RAC result in the shifting of the dominant frequency and wavenumber from $0.17 \mathrm{sol}^{-1}$ (wavenumber 1 to 2$)$ to $0.4 \mathrm{sol}^{-1}\left(2.5 \mathrm{sol}^{-1}\right.$ period). The frequencies are consistent with the slow and fast waves observed in Viking data, with a trend of higher frequency for higher wavenumbers (Barnes, 1981). At higher latitudes $\left(70^{\circ} \mathrm{N}\right.$ to $80^{\circ} \mathrm{N}$ latitude band, Figure 14) the shifting is opposite as modes from 0.05 to $0.15 \mathrm{sol}^{-1}$ become populated at high resolution, while inhibited in HRIC simulations. At the Xiking lander 2 latitude, and thus further to the south, waves tend to exhibit higher wavenumbers (see for exemplethe $0.17 \mathrm{sol}^{-1}$ waves). The waves propagate more slowly than in the inactive run. Wavenumber 2 waves seem to widen and lean towards wavenumber 1 at higher frequencies. For RAC simulations, westward waves appear (they are only very faintly present in the HRIC run). The wavenumber is -1 (westward), and the peak frequency is at $0.1 \mathrm{sol}^{-1}$ (10 sol). Comparing IC and RAC runs, there are more harmonics in the active run, and more wave frequency dispersion. Irregularities in the baroclinic instabilities are the consequence of the cloud feedback that intercepts outgoing radiation. Non linear effects and positive feedback loops in active clouds seem to favor the wavenumber 1 waves.

Effect of resolution. The recurring most prominent feature of the spectra is the peak at a frequency of $0.17 \mathrm{sol}^{-1}(5.9 \mathrm{sol}$ period), with a wavenumber 1 in most of the cases. There is also an ubiquitous weaker family of waves of wavenumber 2 at a frequency of about 0.38 to 0.55 (2.6 to $\left.1.8 \mathrm{sol}^{-1}\right)$. High resolution populates the spectra with higher frequency and wavenumber oscillations, as a wider range of waves is generated by the increased irregularities and chaos, see for example Figure 13; in IC runs the high frequency peak becomes bimodal at high resolution with frequencies of 0.38 and 0.45 (2.6 and 2.2 sol respectively). The westward waves are enhanced by higher resolution. More frequency dispersion also appears in HR runs 


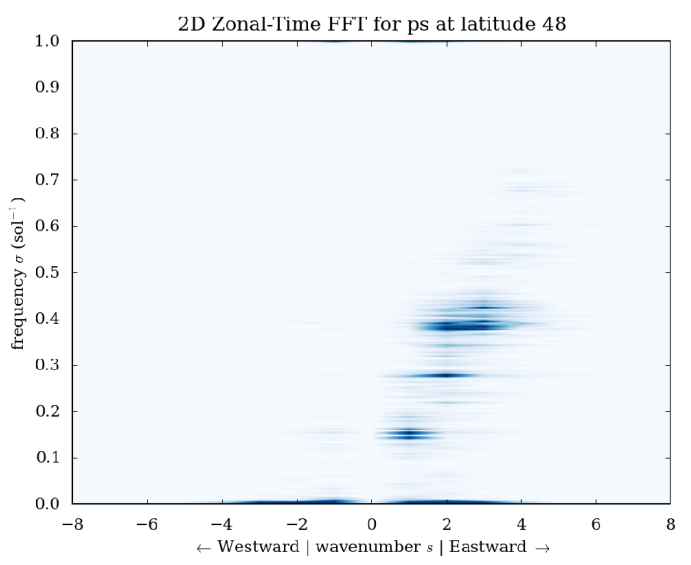

a Low resolution

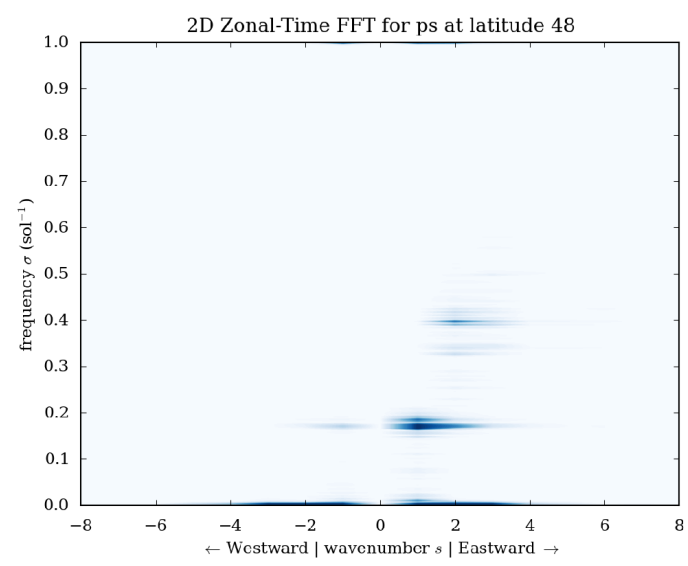

c Low resolution, inactive

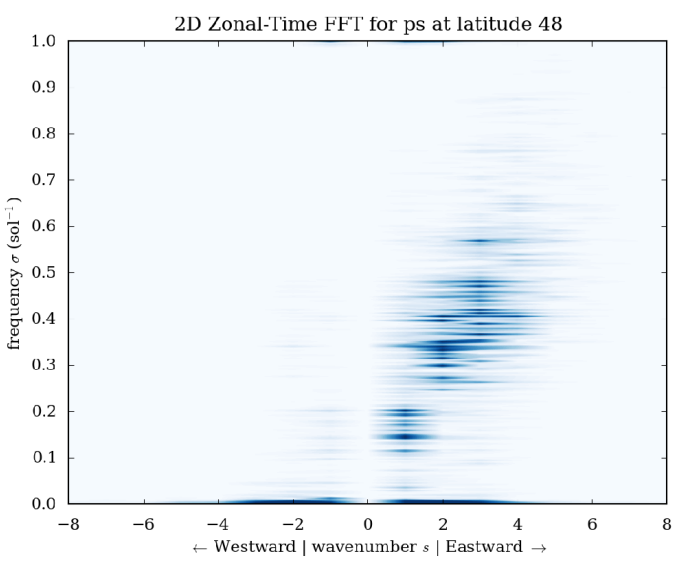

b High resolution

mean

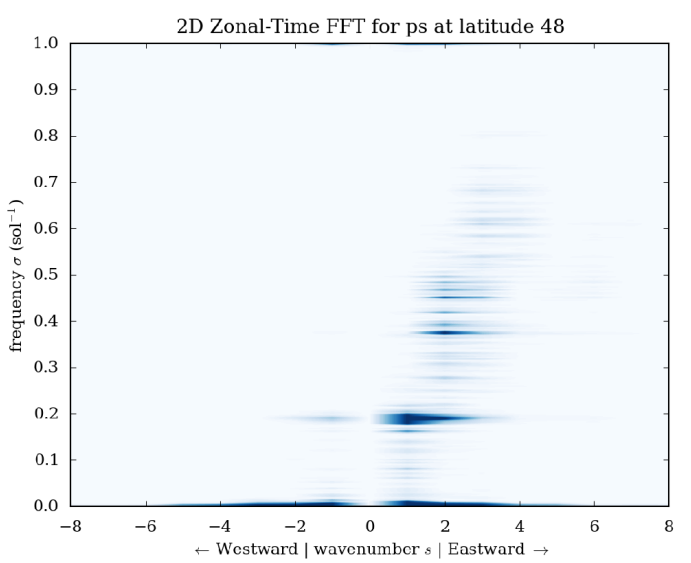

d High resolution, inactive

Figure 13: Two dimensional Fourier transform of the surface pressure variable (Pa) for the period $\mathrm{L}_{\mathrm{s}}=180^{\circ}-360^{\circ}$, colorbar $^{\circ}$ limits are $[$ mean $\pm 20 \sigma]$, latitude $48^{\circ} \mathrm{N}$. 


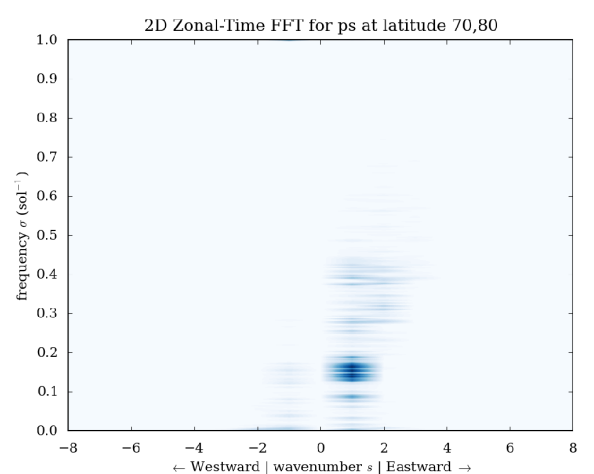

a Low resolution

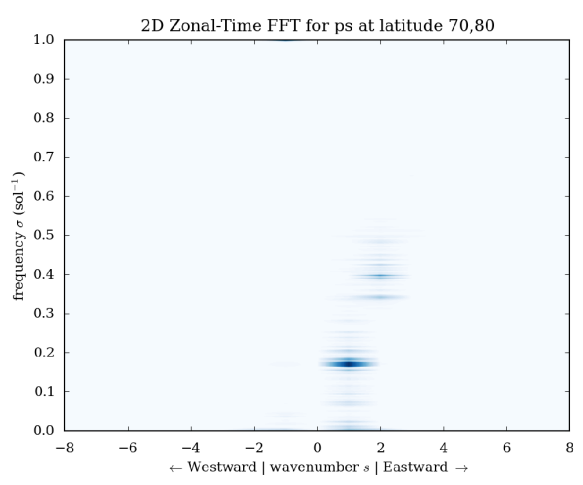

c Low resolution, inactive

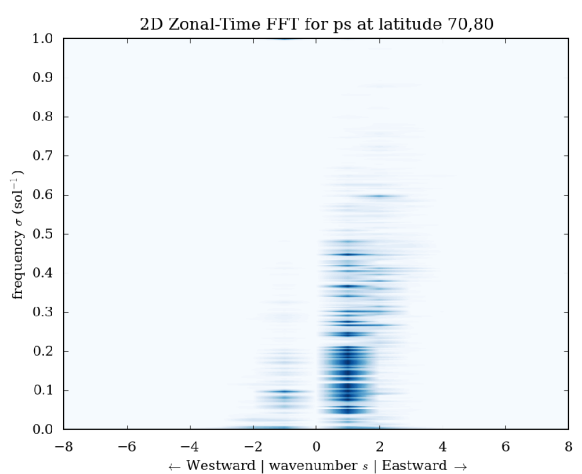

b High resolution

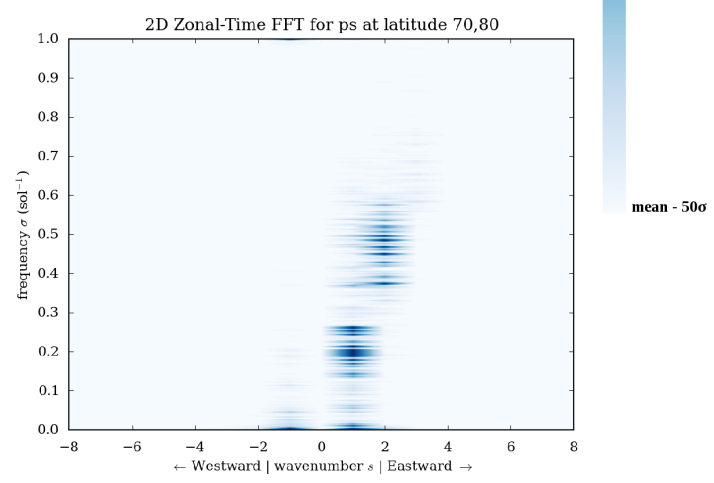

d High resolution, inactive

Figure 14: Two dimensional Fourier transform of the surface pressure variable $(\mathrm{Pa})$ for the period $\mathrm{L}_{\mathrm{s}}=180^{\circ}-360^{\circ}$, colorbar limits are $[$ mean $\pm 50 \sigma]$, latitude $70-80^{\circ} \mathrm{N}$ 
this wider variety of waves. Differences in wind shear can also emerge from large-scale circulation differences such as the Hadley cell strengthening described earlier in this paper (see also next subsection).

\subsection{Effect of wave propagation on cloud structures and water vapor}

The use of Hovmöller plots (Hovmöller, 1949) reveals how the underlying wave patterns affect cloud structures. We describe thereafter Hovmöller plots as excursion from the zonal mean for different variables, mostly clouds, that show baroclinic wave propagation. The effect of the baroclinic instability on the clouds is stronger than the diurnal cycle, although the diurnal cycle is known for triggering mode fluctuations (Collins et al., 1996). Figures 15 and 16 in this section are representative of wave activity at all seasons. These focus on times when the transient eddy activity is maximal.

Looking at a span of five days around the northern fall equinox, total cloud column (Figure not shown here) and total water vapor column show the eastward baroclinic wave patterns (the steep, upwards slope) intersecting the diurnal cycle (the less steep, nearly horizontal stripes). At this time of year, the northern fall equinox, the waves are present from latitude $50^{\circ} \mathrm{N}$ to $90^{\circ} \mathrm{N}$ (see section 5.3). They are less developed at low resolution. Not surprisingly, there is a difference between IC and RAC models: the IC waves are weaker, and not as clearly marked. The non-linear effect of RAC enhances the signature of waves in the cloud column. Active runs show an eastward propagation of baroclinic waves with a wavenumber of 2 , and a period of 5 to 6 sols (figures not shown here). Propagation is slower at high resolution. Inactive clouds result in less baroclinic activity. Plots (not shown here) show a wavenumber 1 stationary wave for that time span. The water vapor graphs (not shown here) confirm this diagnosis.

Hovmöller graphs for northern fall, at $\mathrm{L}_{\mathrm{s}}=220^{\circ}$, show a peak of baroclinic wave activity for active clouds (see also section 5.3). Looking at the water vapor variable (not shown), the signature of an eastward propagating wavenumber 2 wave with a period of about 5 sols is visible. The HRIC run shows a strengthened amplitude (by 0.5 pr. $\mu \mathrm{m}$ on average, occasionally as much as by 2 pr. $\mu \mathrm{m}$ ). RAC graphs show the baroclinic waves mixed with a stationary component which, we hypothesize, is topographic in nature, with a maximum at a longitude of around $50^{\circ} \mathrm{E}$, and a wavenumber of 1 to 2 . Looking at the baroclinic waves in water ice cloud column data (Fjgure 15), the signal of the 5-6 sol period is striking, with an amplitude of about 4 pr. $\mu \mathrm{m}$, and a wavenumber 2, for low resolution. The HRRAC model run clearly shows a wavenumber of 3 and slower waves: quite different from the HRIC case. The amplitude of the waves in terms of cloud content seems to be the same for all simulations. Surface pressure data show a wavenumber 2 to 3 stationary wave, with a maximum at longitude $50^{\circ} \mathrm{W}$, which is due to the impact of topography. The surface temperature evolves similarly.

$\mathrm{L}_{\mathrm{s}}=330^{\circ}$ in the Martian northern winter marks the onset of the last period with many waves following the solsticial pause (see section 5.3). During the winter period, there is a general destabilization of the polar vortex which generates storms and cyclonic cells (Read et al., 2015) and affects middle and high latitude 


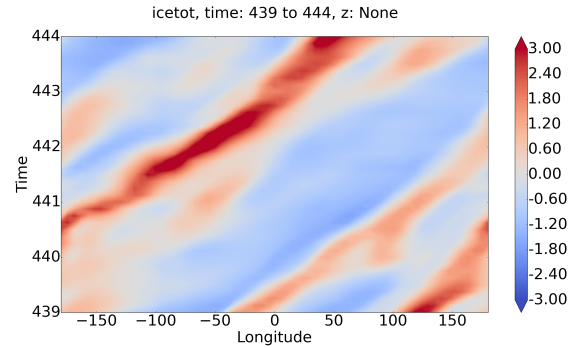

a Low resolution, active clouds

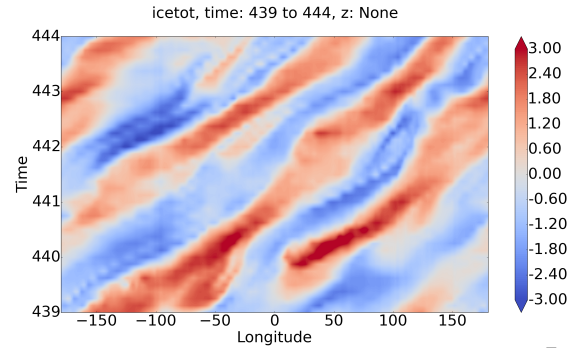

b High resolution, active clouds

Figure 15: Hovmöller plots of deviation of water ice column (pr. $\mu \mathrm{m}$ ) from zonal mean, for latitude $60^{\circ}$, sol 439 to 444 , beginning of fall in the northern hemisphere. $\mathrm{L}_{\mathrm{S}}=220^{\circ}$.

climate. Looking at the water vapor excursion from zonal mean, waves have more amplitude with RAC, and even more at high resolution. The eastward propagation of the baroclinic waves is similar to the pre-solstice period, but is not as marked. It can be understood as a result of the air being drier in winter (less in active runs than in inactive ones). The plots of the non-zonal component of ice clouds (Figure 16) show a propagation with a period of 5 to $6 \mathrm{sol}$ for the low resolution run which becomes wavenumber 3 with cloud activity. The propagation of the wave is not as clear at high resolution, there is a cloud fragmentation and finely structured higher harmonic waves. The HRRAC run especially shows lots of irregularities. A wavenumber 2-3 wave is discernable, but with cloud fragmentation, generating streaks of clouds. The waves seem a bit slower when clouds are active. At the end of the northern winter winter season $\left(\mathrm{L}_{\mathrm{s}}=360^{\circ}\right)$ there is still a peak in baroclinic wave instability and activity. IC runs show a wavenumber 2 wave at low resolution and a wavenumber 3 one at high resolution. RAC runs host bursts of water (Figure not shown here), are much less regular, with an approximate wavenumber of 1 . There is fragmentation, instability, in clouds, and a phase shift between high and low resolution. RAC induce more irregularities and wave transition throughout wintertime.

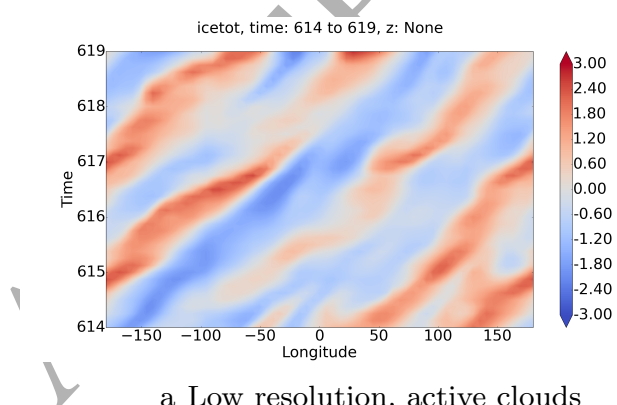

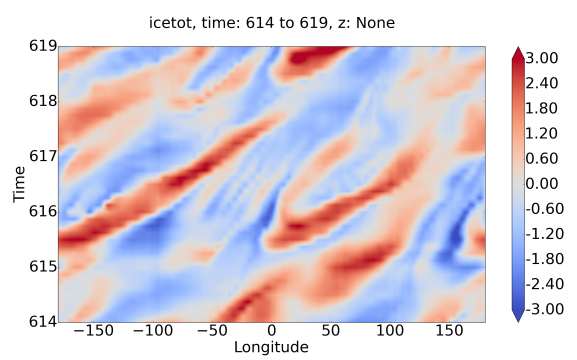

b High resolution, active clouds

Figure 16: Hovmöller plots of deviation of water ice column (pr. $\mu \mathrm{m}$ ) from zonal mean, for latitude $60^{\circ}$, sol 614 to 619 , beginning of fall in the northern hemisphere. $\mathrm{L}_{\mathrm{s}}=330^{\circ}$.

The $\mathrm{L}_{\mathrm{s}}=220^{\circ}$ to $290^{\circ}$ time period (Figures 17 and 18) corresponds to the transition between late fall 

but it also comprises the solsticial pause, which is a relative minimum of wave activity. Wilson et al. (2002) presented TES observations and MGCM simulations that show a transition between a slow wave which is a large amplitude Rossby wave and faster waves that have a 6.5 sol period, from baroclinic instability (both have zonal numbers one). The increase in wave speed occurs around the winter solstice. There is an increase in wave peak-to-peak amplitude and we confirm the increase in wave speed after $L_{s}=260^{\circ}$. This behavior is even more marked and present in the HRRAC simulation. Wave amplitude exceeds 2.5 pr. $\mu$ m which is not the case for the other runs. Looking at water cloud data during this midfall to midwinter period (Figure 17), in IC runs, there is a stronger contrast in wave peaks for the HR case than for the LR one. There are transitions between wavenumber 2 and 1 over intervals of time. At high resolution, wavenumber 2 is present almost everywhere. The HRRAC run shows very clearly, after $L_{\mathrm{s}}=260^{\circ}$, a wavenumber 1 stationary wave. For the active runs, the wavenumber is clearly higher at high resolution compared to low resolution. There is an increase in phase speed with a transition between $\mathrm{L}_{\mathrm{s}}=247^{\circ}$ and $\mathrm{L}_{\mathrm{s}}=260^{\circ}$. The gradual increase appears slightly earlier at low resolution (between $L_{s}=234^{\circ}$ and $L_{s}=247^{\circ}$ ). And the predominance of a zonal wavenumber 1 wave around the solstice matches previous studies as it is in the higher wavenumbers that the solsticial pause is most visible (Lewis et al., 2016). The water vapor data (Figure 18) shows is a wavenumber 2 stationary wave (forced by topography), that is more pronounced than in total cloud column Hovmöller plots. The amplitude of the waves is larger in RAC runs and in HR runs. For IC runs, the decrease in wave propagation speed seems to appear earlier at low resolution than for the high-resolution run. Temperature and pressure variables (not shown here) mostly corroborate the previous 480 observations.

At high resolution higher wavenumbers are produced and the phase speed increases closer to winter solstice. This can be correlated with the overall increase in Hadley circulation in the HR runs, and perhaps also with various changes in wind shear from various sources (cloudiness, topography...). The mechanism behind wave development and resonance deserves further study. Furthermore, Wang et al. (2013) find a link between traveling waves and traveling dust storms before and after the northern winter solstice. Interranual variability is seen in the distribution of wave amplitude and wavenumber, see for example Figure 1 of Wang $\&$ Toigo (2016). This is an incentive to further investigate waves in future simulations intercomparing forcing dust scenarios.

\subsection{Effect of the baroclinic waves on the polar hood}

At $L_{\mathrm{s}}=200^{\circ}$, there is a temporary reduction of the northern polar hood at low resolution that is clearly less marked at high resolution (compare Figure 10b to Figure 10a). In the HR runs, the thick clouds of that period can be explained by stronger baroclinic waves, which transport water into the polar regions, and that is what is analyzed in this section. Baroclinic wave signature in surface pressure peak-to-peak amplitude is 


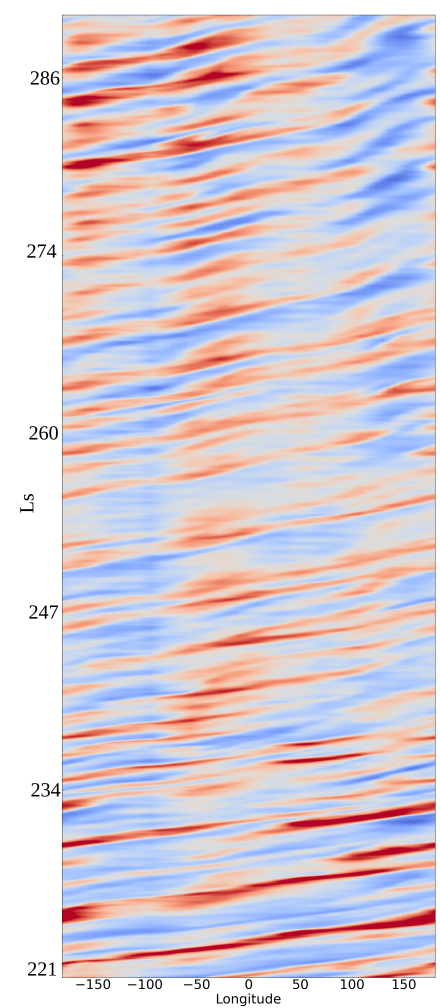

a Low resolution, active clouds

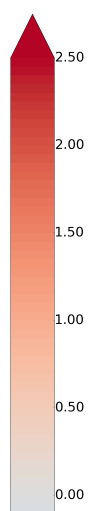

13

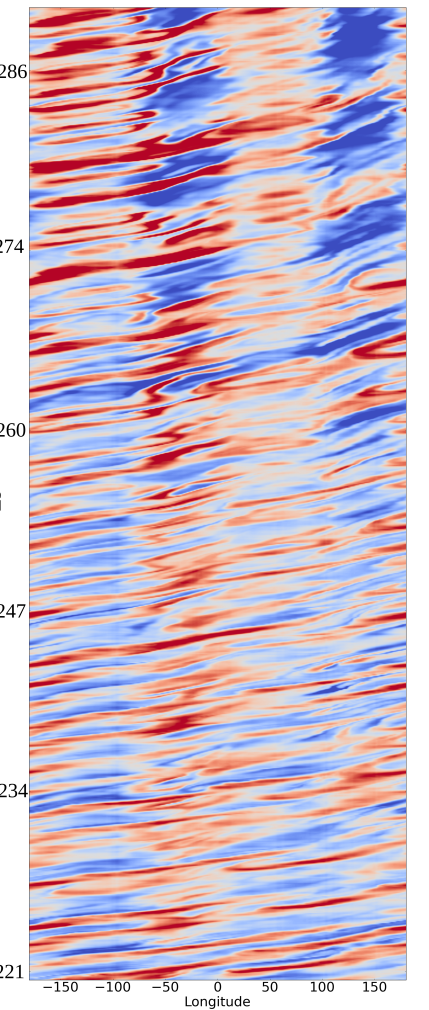

b High resolution, active clouds

Figure 17: Hovmöller plots of deviation of water ice column (pr. $\mu \mathrm{m}$ ) from zonal mean, for latitude $60^{\circ}$, sol 439 to 547 , beginning of fall in the northern hemisphere. $\mathrm{L}_{\mathrm{S}}=220-290^{\circ}$.

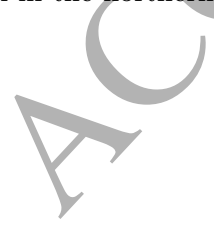




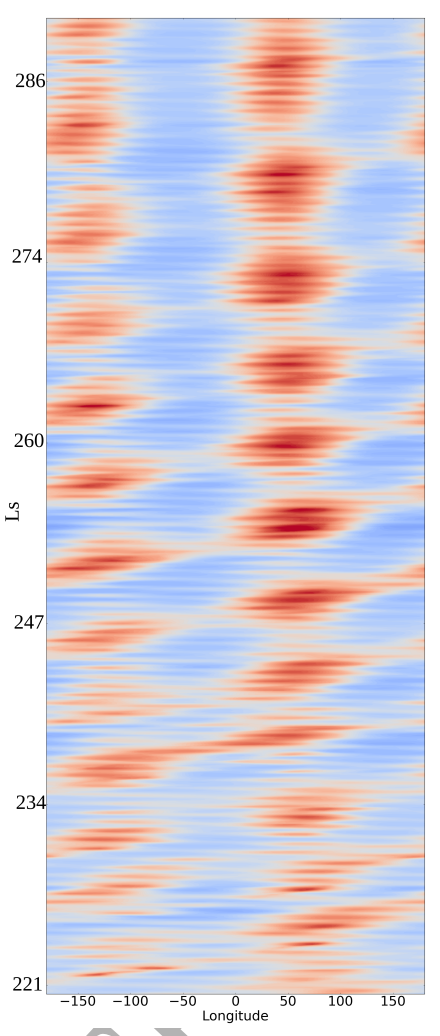

Low resolution, active clouds

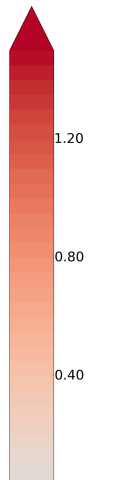

0.00

286

274
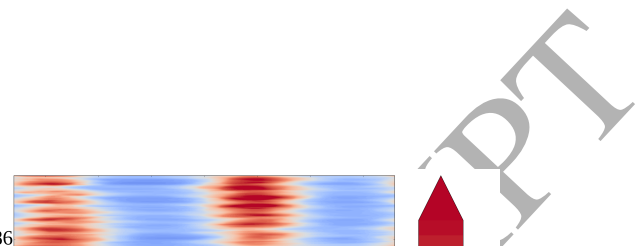

24

247

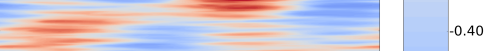

221

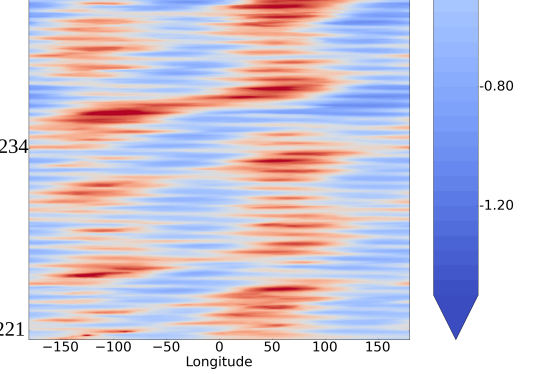

b High resolution, active clouds

Figure 18: Hovmöller plots of deviation of water vapor column (pr. $\mu \mathrm{m}$ ) from zonal mean, for latitude $60^{\circ}$, sol 439 to 547 , end of winter in the northern hemisphere. $\mathrm{L}_{\mathrm{s}}=220-290^{\circ}$.

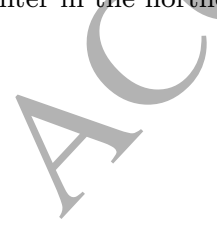


given in Figure 19. The signature of baroclinic waves (Figures 19a and 19b) shows that baroclinic waves are stronger for $\mathrm{L}_{\mathrm{s}}=180-200^{\circ}$ at high latitudes. The vertical extension of the waves is also different (Figures 19c and 19d): at the altitude of the cloud $(8 \mathrm{~km})$, the $\mathrm{L}_{\mathrm{s}}=170-200^{\circ}$ period holds waves with increased amplitude in temperature at the edges of the seasonal caps (receding in the south and expanding in the north). At $8 \mathrm{~km}$, in RAC runs, baroclinic waves have a larger amplitude at high resolution than at low resolution. There is no local minimum of waves between $\mathrm{L}_{\mathrm{s}}=180^{\circ}$ and $220^{\circ}$ at high resolution. And at low resolution the maximum amplitude of the waves happens at $\mathrm{L}_{\mathrm{s}}=160^{\circ}$, i.e. $20^{\circ}$ of solar longitude earlier than at high resolution. The mid-fall polar hood break is affected by this difference in phasing and strength of the waves and almost disappears in the high resolution runs.

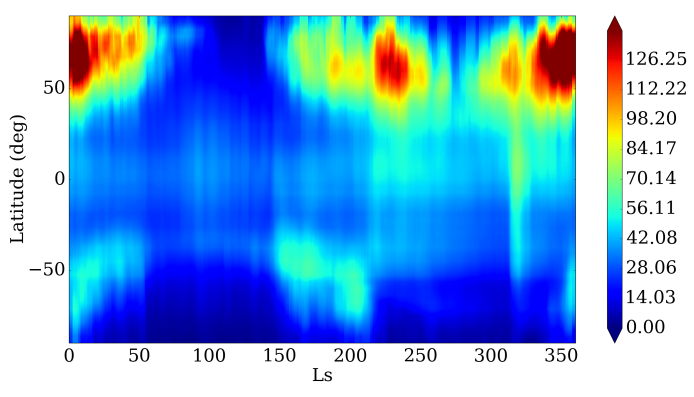

a Low resolution, active

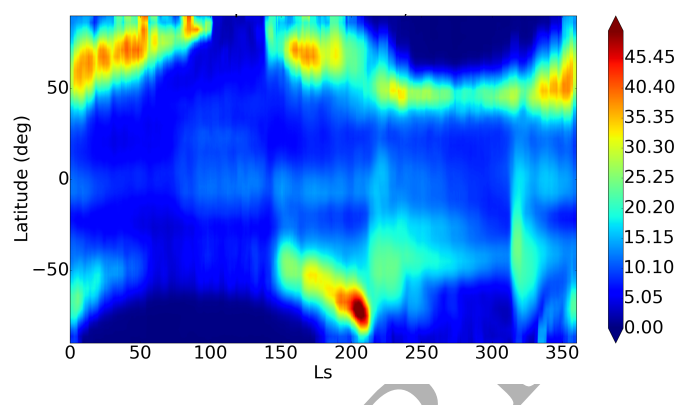

c Low resolution, T at $8 \mathrm{~km}$, active

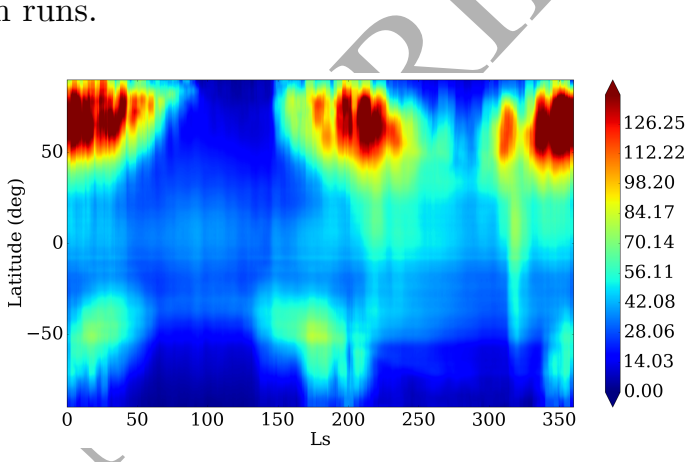

b High resolution, active

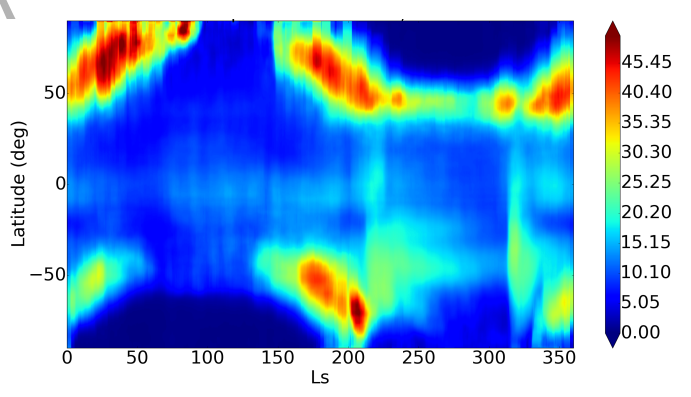

d High resolution, $\mathrm{T}$ at $8 \mathrm{~km}$, active

Figure 19: Baroclinic wave peak-to-peak intensity diagnostic (in surface pressure units - $\mathrm{Pa}$ - , computed with $<\mathrm{Max}_{\Delta \mathrm{t}}\left(\mathrm{Ps}_{\mathrm{t}}-\right.$ $\left.\overline{\mathrm{Ps}_{\Delta \mathrm{t}}}\right)-\operatorname{Min}_{\Delta \mathrm{t}}\left(\mathrm{Ps}_{\mathrm{t}}-\overline{\mathrm{Ps}_{\Delta \mathrm{t}}}\right)>>_{\text {zonal }}$, with $\Delta \mathrm{t}=10 \mathrm{sol}$ here.). Figures 19c and 19d, same diagnostic, but with temperature (K) at $8 \mathrm{~km}$ (the height of clouds in active clouds simulations).

The weakening of the baroclinic waves around $\mathrm{L}_{\mathrm{s}}=270 \pm 10^{\circ}$ is present in RAC runs and not in IC ones. For IC runs, baroclinic waves signals in terms of temperature change are much weaker at altitudes from 4 to $10 \mathrm{~km}$ than when clouds are radiatively active. At an altitude of $20 \mathrm{~km}$, where clouds reside in the polar hood in IC runs, there is a relative increase in wave activity $\left(\Delta \mathrm{T}=40 \mathrm{~K}\right.$ for $\left.\mathrm{L}_{\mathrm{s}}=240^{\circ}\right)$, but it is still weaker than in RAC runs. This demonstrates the role of RAC in this decrease.

This phenomenon is called the solsticial pause, as introduced by Lewis et al. (2016) and analyzed further in Mulholland et al. (2016), who link it to the capacity of ice clouds to decrease wind shear at middle and 
high latitudes, decreasing baroclinic growth rates. MGCM simulations (Wilson et al., 2006) with analysis of eddy activity have shown that, apart from the sensitivity to RAC, Hadley cell intensification and increased dust loading can impact surface stresses and suppress baroclinic wave activity. The precise origin of waves and their generation is beyond the scope of this article. Processes at play are clearly non-linear. Generation of these atmospheric waves can be affected by a modification of convection, shear generation. Topography of course plays a significant role in the triggering and development of waves and the better resolved topograpy plays a role in the appearance of more harmonics and a wider range of wavenumbers. The increased Hadley circulation present in high-resolution runs can increase wind shear and instabilities in the baroclinic waves.

\section{Focus on the polar regions}

The North polar cap is the main reservoir of water in the Martian water cycle (Kieffer et al., 1976; Toon et al., 1980). Refining the resolution results in a more realistic surface ice coverage (Figure 1) and topography for the polar regions.

\subsection{Cloud morphology and polar hood dynamics}

The main source of the martian water cycle are the Northern polar layered deposits, as reviewed by Byrne (2009), which consist of a $\mathrm{CO}_{2}-\mathrm{H}_{2} \mathrm{O}$ ice seasonal cap, that covers a residual $\mathrm{H}_{2} \mathrm{O}$ ice cap itself sitting on top of a layered deposit of older $\mathrm{H}_{2} \mathrm{O}$ ice mixed with dust. In contrast, the South residual ice cap is covered with carbon dioxyde ice (or dry ice) above $\mathrm{H}_{2} \mathrm{O}$ ice. The shape of the residual caps could be the result of years of interaction with atmospheric global and regional circulations. This is the case e.g. of spiral troughs on the northern polar residual ice cap (Smith et al., 2013). High resolution models can help understand how water vapor is advected from the poles, and particularly from the North Pole, to form the main source of the entire water cycle. Hereafter we explore the role played by horizontal resolution on the predictions of instabilities, transient eddies and storms at the edge of the seasonal cap.

Spiralling patterns of elouds or dust are commonly observed in orbiter data. Figure 20 shows remarkable examples of such occurences. In Wang \& Ingersoll (2002), a spiral cloud is described (their Figure 12, $\mathrm{L}_{\mathrm{s}}=160^{\circ}$ to $185^{\circ}$ ). Others are described in Hunt \& James (1979) and reprinted in Figures 20a and 20c . Such spiralling patterns are not resolved by LR run; HR runs are required. Figure 21 shows a typical spiral storm, in a view of the north pole of Mars at $\mathrm{L}_{\mathrm{s}}=151^{\circ}$. The cloud structure simulated by HR runs is more complex and shows a spiralling pattern of clouds and winds centered on $-20^{\circ} \mathrm{E}, 80^{\circ} \mathrm{N}$. A southward flux of air and clouds comes down from the pole via Chasma Boreale.

Temperature maps help track the air masses at the origin of the formation of these spiral storms. Cold air (about $170 \mathrm{~K}$ ) flows from the pole, going down over the edge of Chasma Boreale. At $-20^{\circ} \mathrm{E}$, there is an upward flow of warmer air ( 180 to $190 \mathrm{~K}$ ) next to a relatively colder band of airflow to the west. The 


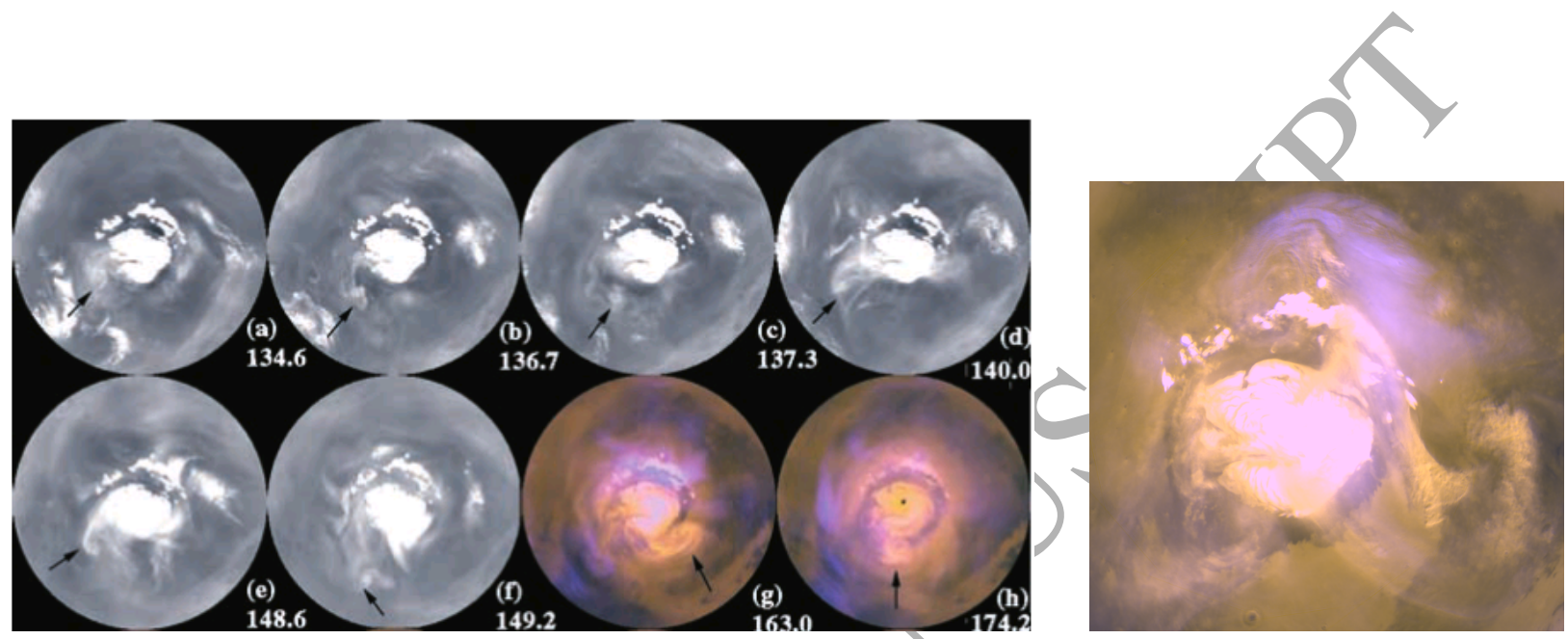

a MOC, various examples

b MOC, $L_{s}=152.03^{\circ}$
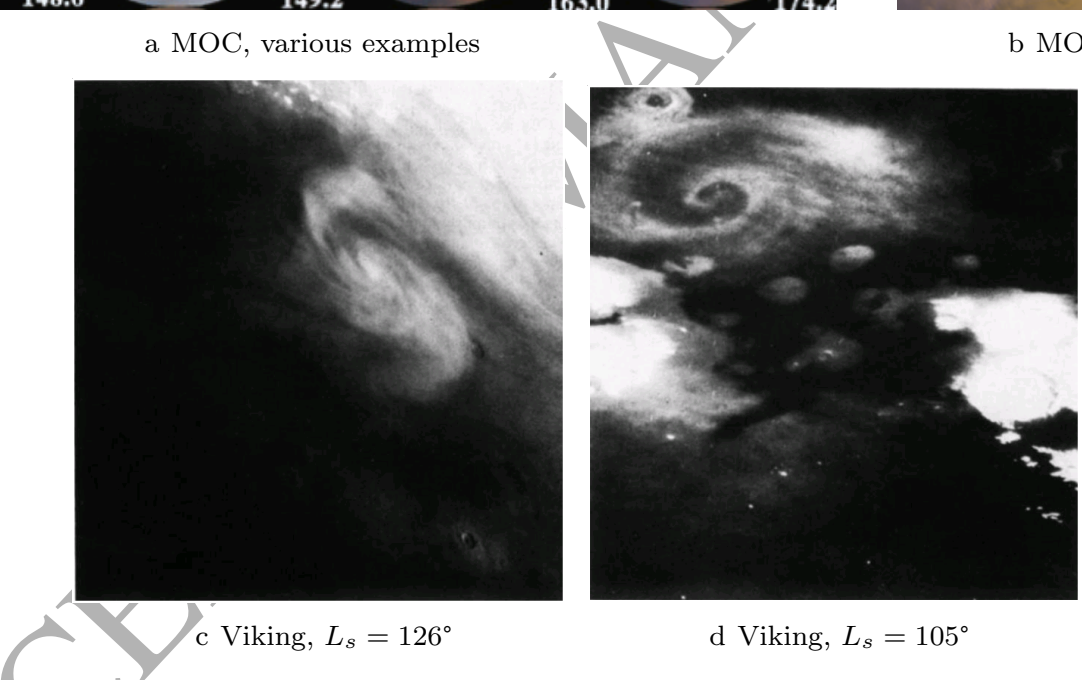

d Viking, $L_{s}=105^{\circ}$

Figure 20: Orbiter pictures of spiral storms on Mars in the Northern hemisphere (Hunt \& James, 1979; Wang \& Ingersoll, 2002). Reprinted by/permission from Macmillan Publishers Ltd: Nature, Hunt \& James (1979), copyright 1979.

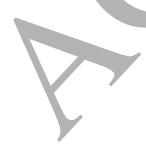




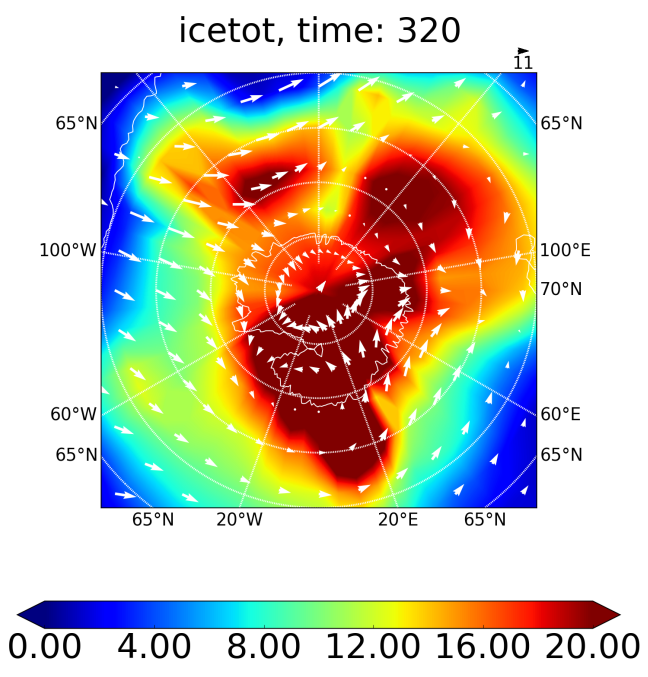

a Low resolution, active clouds

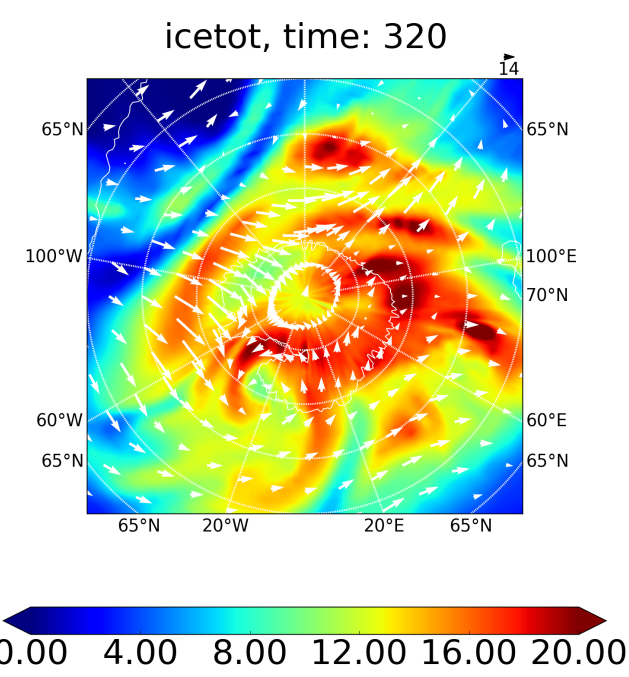

b High resolution, active clouds

Figure 21: Views of the north pole's water total cloud ice column ( $\mathrm{pr}, \mu \mathrm{m})$ and winds (horizontal component in $\mathrm{m} \mathrm{s}^{-1}$ ) at $0 \mathrm{~km}$, $\mathrm{L}_{\mathrm{s}}=151^{\circ}$, poleward of $70^{\circ} \mathrm{N}$. The color scale shows the total cloud column, and arrows are a subset of the wind vectors for clarity (one in two in longitude for the low resolution map, one in ten in longitude and one in three in latitude for the high resolution map).

whirlwind originates where the two air masses collide. In fact we note that, a few sols before the spiral cloud formation, there was a burst of cold air coming down from the pole. This isolated cold air mass, at the altitude of the clouds ( 5 to $10 \mathrm{~km}$ ), spirals counterclockwise from the pole and around it. The origin of this cold air mass is topographical (Chasma Boreale). One day before the snapshot of the storm, cold air from the pole sliding down Chasma Boreale meets relatively warmer air bound eastwards from lower latitudes $\left(75^{\circ} \mathrm{N}\right)$. The spiral storm breaks out at the meeting point, with relatively warmer air trapped in the center.

Other types of spiralling pattern happen in winter according to Wang \& Ingersoll (2002). These are streak clouds, shown in Figure 8 in Wang \& Ingersoll (2002). They tend to spiral in toward the pole, turning counterclockwise. They are mostly present between the middle of the northern fall and winter. Their estimated lifetime is at least several hours. Such large scale systems of atmospheric phenomena also exist in our HR runs (Figure 22). The polar hood exhibits a peculiar morphology with filamentation spiralling outward from the pole. Some snapshots of one of these phenomena are shown in Figures 22c and $22 \mathrm{~d}$. The main bulks of clouds spiral counterclockwise for a few sols around $\mathrm{L}_{\mathrm{s}}=286^{\circ}$. A single streak of thicker clouds crosses the pole at longitudes $60^{\circ} \mathrm{E}$ and $120^{\circ} \mathrm{W}$. From this inflexion point its extremities spiral eastward and dislocate. Figure $22 \mathrm{a}$ and $22 \mathrm{~b}$ shows the thicker polar hood during northern fall. Spirals of relatively clearer air travel southward from the pole. 

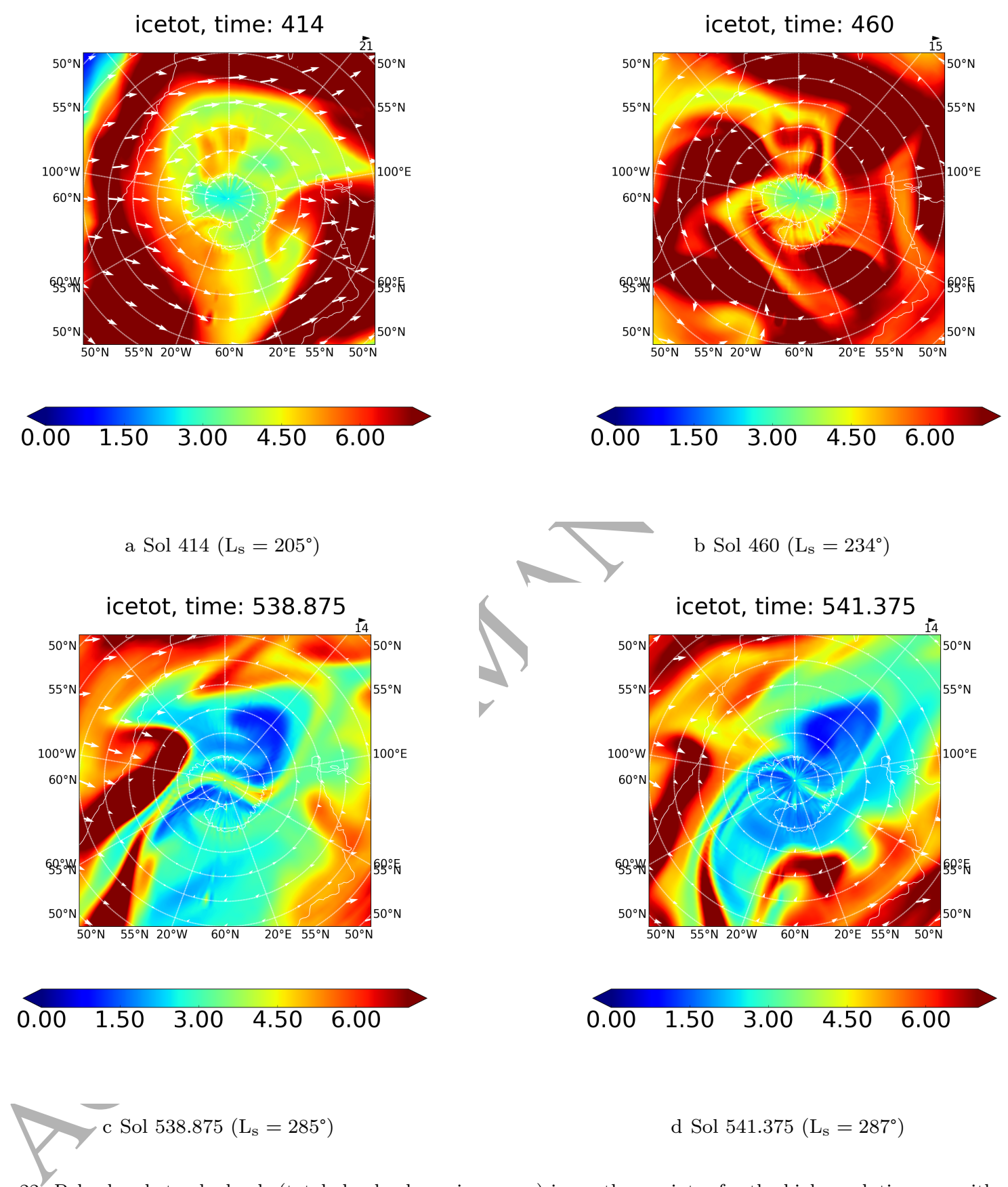

d Sol $541.375\left(\mathrm{~L}_{\mathrm{s}}=287^{\circ}\right)$

Figure 22: Polar hood streak clouds (total cloud column in pr. $\mu \mathrm{m}$ ) in northern winter for the high-resolution run with active water ice clouds, poleward of $60^{\circ} \mathrm{N}$. Wind vectors are plotted for a subset of grid points for clarity (horizontal component of the wind in $\mathrm{ms}^{-1}$ at $0 \mathrm{~km}$ ). Northern fall (sol 414, 460) and winter (sol 539, 541). 
The high-resolution modeling greatly improves the representation of polar hood dynamics and reproduces cloud formations commonly observed in satellite data. The role of dust scenarios in the triggering of such storms shall be studied in future work. Storm zones are well defined, but the precise triggering location of storms is subject to interannual variability.

\subsection{Vertical structure of the outward flux from the pole}

The key phenomenon controlling the martian water cycle is the sublimation of ice from the northern polar region during spring and summer (Richardson \& Wilson, 2002a). There is a cycle of sublimation and recondensation at that time while the seasonal cap recedes (Houben et al., 1997): released water vapor recondenses again northward and the water ice cap thickness increases. In summer, there is a period devoid of any seasonal frost (which has smaller grain size). This period begins in early summer for the central polar region and in late summer for the edges of the permanent ice cap (Langevin et al,, 2005). Higher resolution runs can resolve with more accuracy latitudinal retreat, the topographical features of this retreating polar cap and the baroclinic waves responsible for the poleward transport of water. They also improve the accuracy of the representation of the polar dome. Indeed, mesoscale modeling studies of the north polar region during summertime showed that a realistic modeling of the polar circulation requires a sufficiently high resolution (15 km in Tyler \& Barnes (2014)). Tyler \& Barnes,(2014) suggested that a $1^{\circ}$ resolution is appropriate to obtain a realistic polar circulation. However, polar mesoscale models have similar grid cells regardless of their location, or use more convenient polar projections, while the $1^{\circ} \times 1^{\circ}$ longitude-latitude grid cells of the GCM are smaller closer to the pole (see Table 1). Thus, a high-latitude polar Fourier-space operator filtering higher frequency fluctuations (called polar filter) is necessary for the stability of numerical integrations in the GCM. Its non-physical wave dampening could affect polar circulation.

Figures 23 and 24 show cross-sections of the total water content (the sum of water vapor and ice mixing ratios) in the north polar area of Mars, for high and low resolutions respectively, at $\mathrm{L}_{\mathrm{s}}=90^{\circ}$. The polar profile is far better resolved at high resolution and the water activity is stronger, with overall more ice and vapor. Wind vectors show distinct areas of water sublimation and deposition. The vertical water gradient is stronger at high resolution and the vertical wind structure is more complex at $\mathrm{L}_{\mathrm{s}}=130^{\circ}$ (Figure not included). On the west side of the polar dome, water vapor is more abundant near the slopes. The lowresolution simulation with active clouds is much less active in terms of water transport from the pole in the end of spring and beginning of summer. The circulation is very different, especially over the western side of the poleaway from Chasma Boreale.

A seasonal average of these variables from $\mathrm{L}_{\mathrm{s}}=90^{\circ}$ to $\mathrm{L}_{\mathrm{s}}=120^{\circ}$ filters out transient events and helps understand which recurring summertime features are affected by the change in resolution and how. According to Tyler \& Barnes (2014) the northernmost parts of the atmosphere of the polar dome are permanently in saturation conditions, and sublimation rates are low. Indeed most of the water vapor sublimation and 


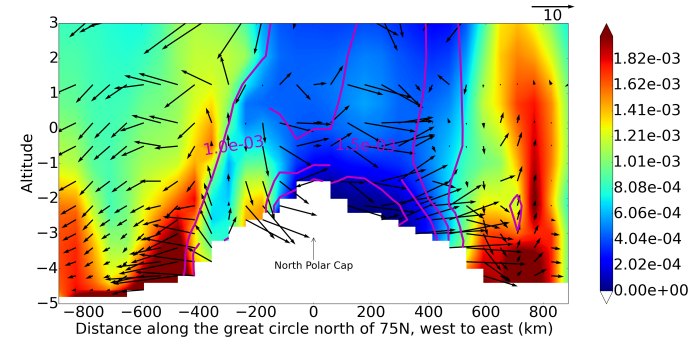

a $45^{\circ} \mathrm{E}$

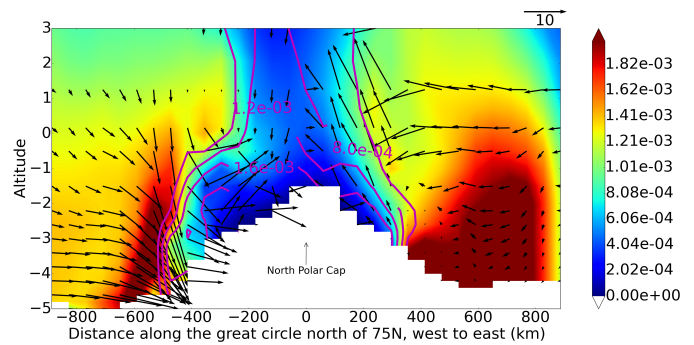

b $107^{\circ} \mathrm{E}$

Figure 23: Cross-section of the north pole along different meridians, at high resolution. Colours: mixing ratio of water vapor, contours: mixing ratio of water ice, mol/mol. Wind vectors ( $v$ and $w$ components, in $\mathrm{m} / \mathrm{s}) . \mathrm{L}_{\mathrm{s}}=90^{\circ}, 06: 00 \mathrm{AM}$ at longitude 0 .

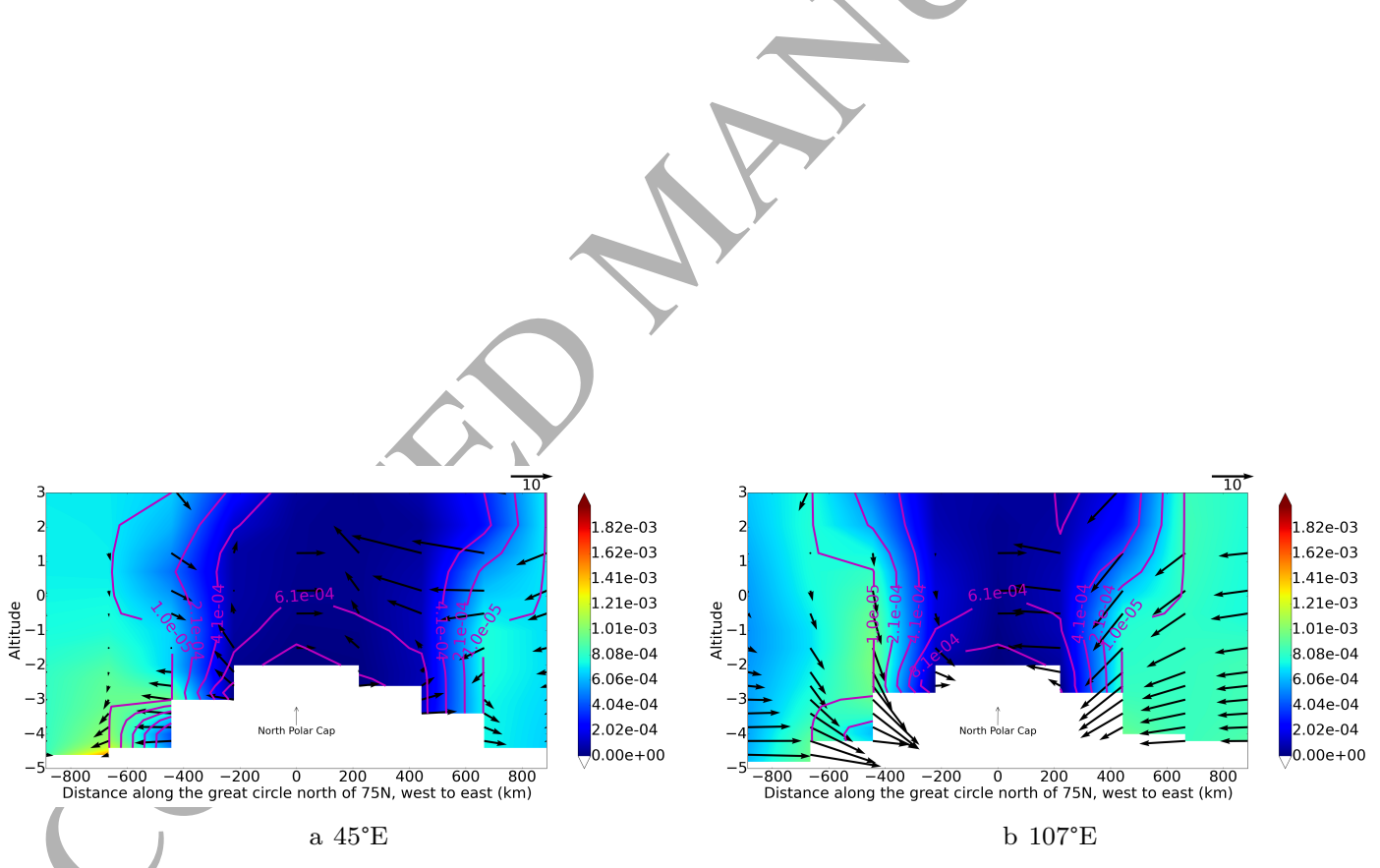

Figure 24: Cross-section of the north pole along different meridians, at low resolution. Colours: mixing ratio of water vapor, contours: mixing ratio of water ice, mol/mol. Wind vectors ( $\mathrm{v}$ and $\mathrm{w}$ components, in $\mathrm{m} / \mathrm{s}$ ). $\mathrm{L}_{\mathrm{s}}=90^{\circ}, 06: 00 \mathrm{AM}$ at longitude 0 . 
uplifting happens at the edge of the caps (Figures 23 and 24). Here winds are supposed to be stronger in the downslope (equatorward) direction (Tyler \& Barnes, 2014). These averaged diagnostics also show that cloudy events like the one shown on Figure 23 are quite transient.

One fairly notable effect of the high resolution employed in our GCM runs is the enhancement of the polar slope winds. Indeed, at longitudes $62^{\circ} \mathrm{E}, 73^{\circ} \mathrm{E}, 90^{\circ} \mathrm{E}, 107^{\circ} \mathrm{E}, 135^{\circ} \mathrm{E}$ (Figure 25 ), $152^{\circ} \mathrm{E}$, winds close to the polar dome surface are strong compared to higher above the dome, and blow downslope rather than upslope. In some cases (the $118^{\circ} \mathrm{W}, 90^{\circ} \mathrm{W}$ cuts) slope winds blow upslope on average. This inversion can be explained by recurring transient events (Tyler \& Barnes, 2005) affecting the winds and dynamical state of the atmosphere, like storms (which may appear in HR runs, as we saw earlier)
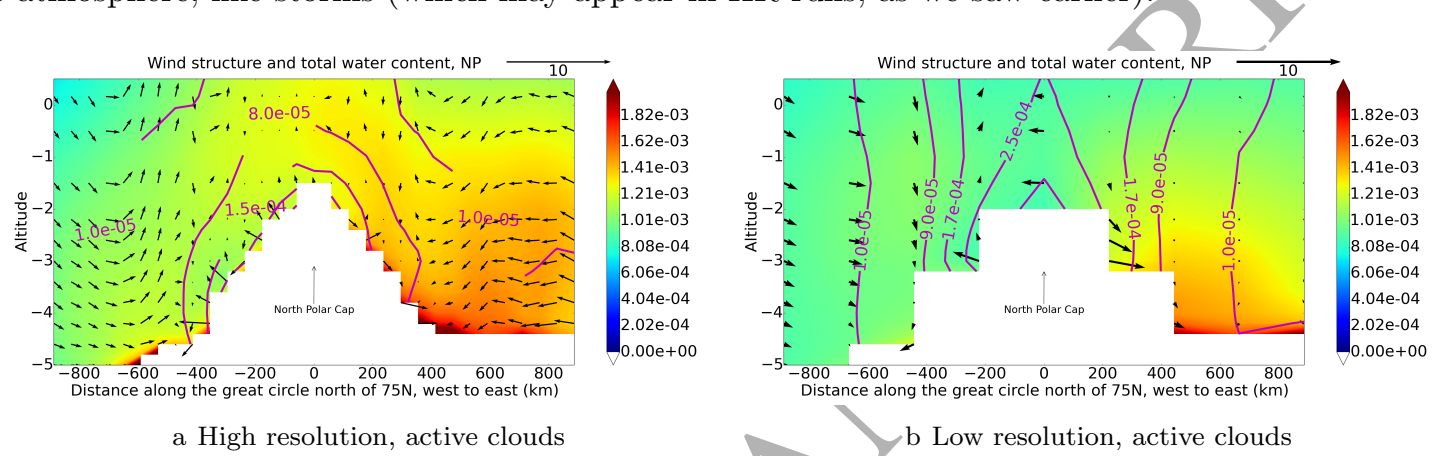

a High resolution, active clouds

Figure 25: Cross-section of the north pole along meridian $135^{\circ} \mathrm{E}$, averaged over the $\mathrm{L}_{\mathrm{s}}=90-120^{\circ}$ time span, northern summer. Clouds in contours, vapor in colored scale.

In the zonal wind, there is an increase of the circumpolar winds above the polar dome with RAC, at least temporarily. The LRRAC run shows stronger eastward jets at $1 \mathrm{~km}$ of altitude, while the LRIC run exhibits weaker and lower jets (centered on $1 \mathrm{~km}$ below areoid). The HRRAC simulation follows the same trend (Figure 26), with stronger winds than the HRIC one. High resolution jets tend to flow more southward than the ones observed in the LR simulations. A small westward wind for the longitude $45^{\circ} \mathrm{E}$ cross-section blows again more to the north at low resolution and is a bit weaker. We conclude that near-surface westward winds are increased in HRRAC runs as compared to LRRAC ones. The low-altitude eastward polar jet $(>=1 \mathrm{~km})$ in northern summer is weakened in HRRAC runs compared to LRRAC and its maximum is localized lower in altitude and more to the south. These changes are quite significant.

According to the average cross-sections, at high resolution, active clouds are confined within about $1 \mathrm{~km}$ of the surface in the northern part of it, very close to the pole itself. This is not the case for the clouds simulated in low-resolution GCM runs. We saw in section 4 that such clouds are transient during summertime. The polar hood disappears for a longer period of time in HRRAC runs. However, the atmosphere is not always as clear as at low resolution due to these transient summer clouds. Our model tends to simulate a too extensive polar hood which extends for a shorter period of time, according to, for example, TES observations (Tamppari et al., 2008), thus a longer clear time period is an improvement over LR. However the modeled 


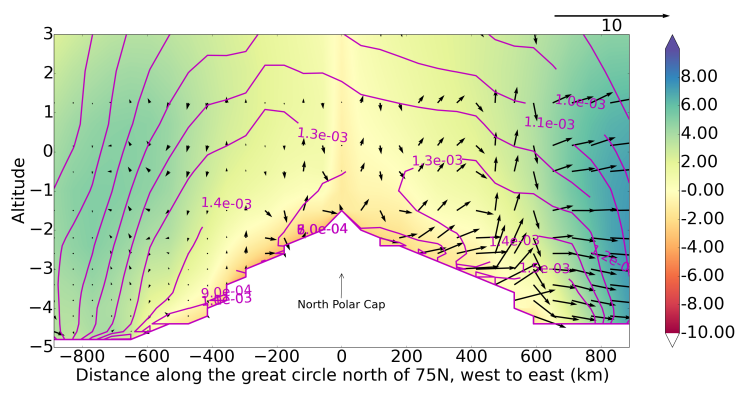

a High resolution, active clouds

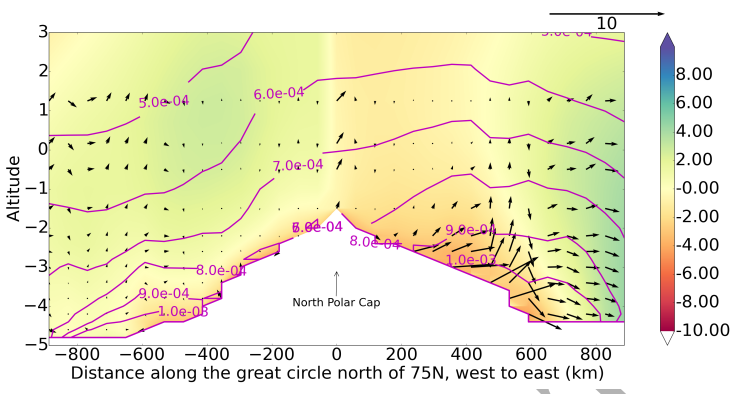

b High resolution, inactive clouds

Figure 26: Cross-section of the north pole along meridian $45^{\circ} \mathrm{E}$, averaged over the $\mathrm{L}_{\mathrm{s}}=90-120^{\circ}$ time span, northern summer. Water vapor in contours, zonal mean $\mathrm{u}$ in colored scale.

transient polar clouds are probably too thick.

Along the $62^{\circ} \mathrm{E}$ cross-section, there is an upward motion at a latitude of $83^{\circ} \mathrm{N}$ in the HRRAC model, which is not seen in the HRIC run. Average winds tend to be stronger farther above the surface at low resolution whereas high resolution winds exhibit stronger variability and tend to be stronger near the ground. Indeed, Chasma Boreale tends to show strong winds pushing downslope into its center at high resolution, this behavior does not exist at low resolution (Figures not shown). On the $28^{\circ} \mathrm{E}$ averaged cross-section, the high resolution models exhibits strong surface winds along the plateau at $80^{\circ} \mathrm{N}$ and southwards, downslope. The upwelling of air above the plateau appears. At low resolution the upwelling effect is only apparent with active clouds, yet remains very weak.

To summarize, high-resolution runs predict a more versatile circulation over the north pole and the development of complex structures of wind and clouds formed out of the vapor sublimated from the edge of the cap. Active clouds, with their effect on ground temperature and their feedback, complicate the wind structure even more and tend to allow intense, transient events. Some redeposition areas are highlighted in the dynamics of the winds, the most remarkable one being Chasma Boreale.

\subsection{Flux of water from the pole}

To better quantify some of the phenomena described in the previous subsection, the poleward and equatorward fluxes of water along a latitudinal circle are computed. Doing so, geographical features are smoothed out, and the main corridors where winds sweep water from and to the pole are highlighted.

$$
\begin{aligned}
\frac{\mathrm{d} m_{\mathrm{H}_{2} \mathrm{O}}}{\mathrm{d} t} & =\int_{0}^{2 \pi} \int_{0}^{z_{\mathrm{top}}} \rho_{\text {air }} q_{\mathrm{H}_{2} \mathrm{O}} v R \cos (\theta) \mathrm{d} \phi \mathrm{d} z \\
& =\int_{0}^{2 \pi} \int_{P_{\text {surf }}}^{0}\left(\frac{-q_{\mathrm{H}_{2} \mathrm{O}} v R \cos (\theta)}{g}\right) \mathrm{d} P \mathrm{~d} \phi
\end{aligned}
$$


A northward flux is positive. In Equation 1, $\frac{\mathrm{d} m_{\mathrm{H}_{2} \mathrm{O}}}{\mathrm{d} t}$ is the flux of $\mathrm{H}_{2} \mathrm{O}$ mass, $\rho_{\text {air }}$ is the air density, $q_{\mathrm{H}_{2} \mathrm{O}}$ is the mass mixing ratio of water, $v$ is the meridional wind, $R$ is the radius of the planet, $z$ is the altitude, $P$ is the pressure, $\phi$ is the longitude and $\theta$ the latitude.

At the equinoxes, the Martian Hadley circulation causes a zonally-averaged influx of air from the equator towards the polar regions. Conversely, when the circulation situation is not symmetrical between hemispheres, e.g. at solstices, there is a planet-wide dominant cell from the midlatitudes of the summer hemisphere to the winter one. Even then, there is an asymmetry caused by the topographical dichotomy (Richardson \& Wilson, 2002a,b) between low northern plains and high southern cratered plateaus. The southern summer Hadley circulation is stronger than the northern summer one (see Figures 11g-j and 12g-j), leading to water stabilization in the northern hemisphere. Water is advected along these main circulation patterns (Montmessin et al., 2004). The annual mean circulation shows that the symmetrical equinox cells are of secondary importance and that the solstice pattern is dominant in the yearly-averaged flux. In addition to the global hemisphere-to-hemisphere transport, waves, particularly at the edge of the seasonal cap, are responsible for the intrahemispheric water transport. For example, in spring, baroclinic waves are mainly responsible for the transport of water vapor at the edge of the seasonal cap towards lower latitudes (and the redeposition of frost at higher latitudes). In fall, they also drive the cap extension, along with the global condensation flux of the $\mathrm{CO}_{2}$ atmosphere. What is expected is thus reproduced by our runs (for example Figure 27): an outgoing flux during the warmer seasons, with a peak during northern summer. It is interesting to correlate this information with the global water budget described in Figure 8.

Figures $27 \mathrm{a}$ and $27 \mathrm{~b}$ show the northward flux towards the north pole crossing two given latitude circles, for both HRRAC and LRRAC simulations. The impact of the retreat of the seasonal cap can be noticed on a variety of similar graphs at different latitudes. Water is transported southward mainly between $\mathrm{L}_{\mathrm{s}}=50^{\circ}$ and $150^{\circ}$ for the $79^{\circ} \mathrm{N}$ latitude circle(Figure $27 \mathrm{~b}$ ). The flux of water becomes negative starting from a solar longitude of $40^{\circ}$ (a bit later at low resolution) at $68^{\circ} \mathrm{N}$ (Figure 27a). An interesting feature is also the relative bump of northward flux on Figure $27 \mathrm{~b}$ early in the year, beginning around $\mathrm{L}_{\mathrm{s}} \sim 50^{\circ}$, with local maxima at $\mathrm{L}_{\mathrm{S}}=65^{\circ}$ in the high resolution simulation and $\mathrm{L}_{\mathrm{s}}=75^{\circ}$ in the low resolution simulation. This stems from the sublimation/redeposition process, driven by eddies at the edge of the cap, being more regular at high resolution: the smallest unit of potential surface area of frost is indeed smaller (because of the refined resolution), and the sublimation/redeposition is more gradual. The low-resolution GCM runs are not sufficient to simulate the processes at play in the sublimation and redeposition of ice correctly: the model has too few grid cells at the poles.

\subsection{Ice accumulation in the North polar region}

As stated in the introduction, the state of equilibrium of the Martian water cycle is still unknown. A slow transfer of water from the north to the south pole seems to occur, over decades (Richardson \& Wilson, 


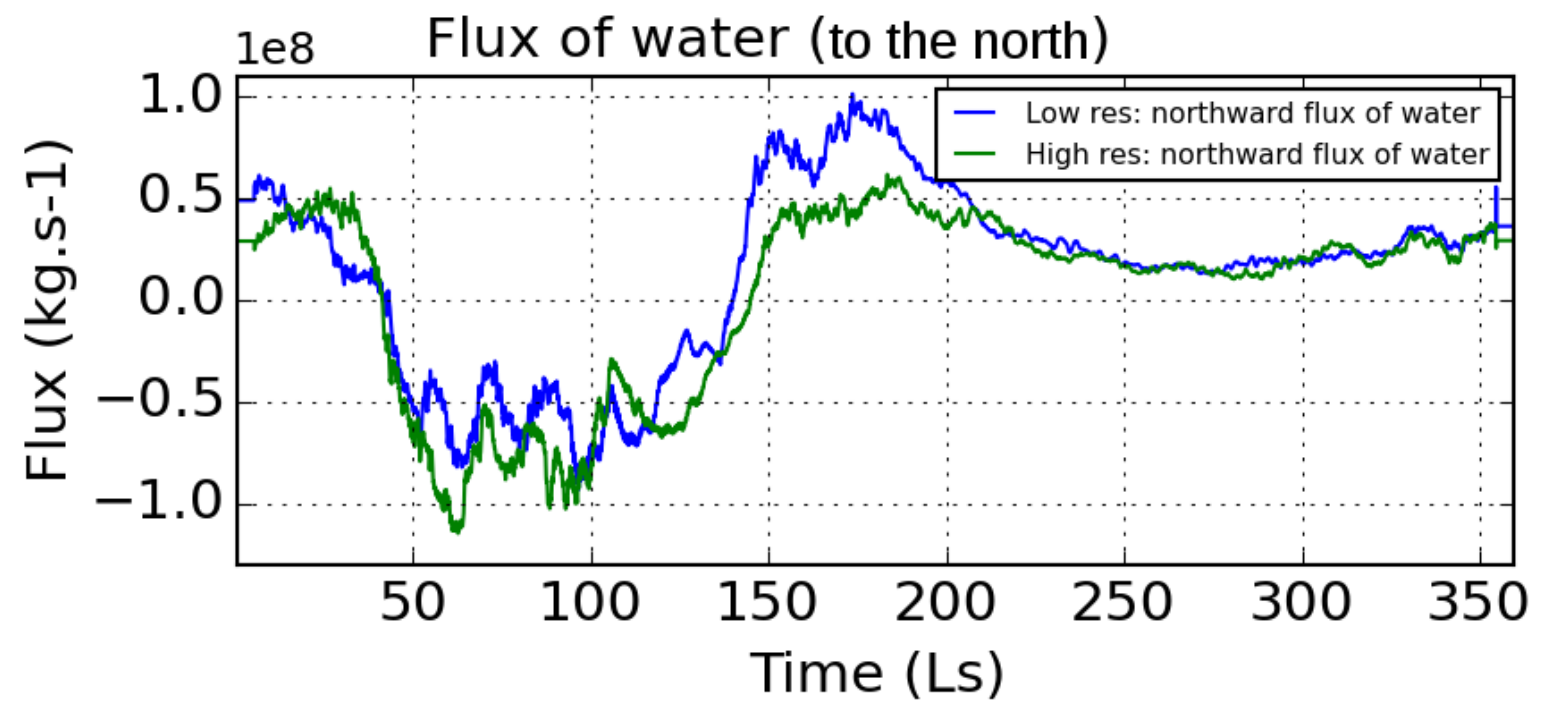

a $68^{\circ} \mathrm{N}$

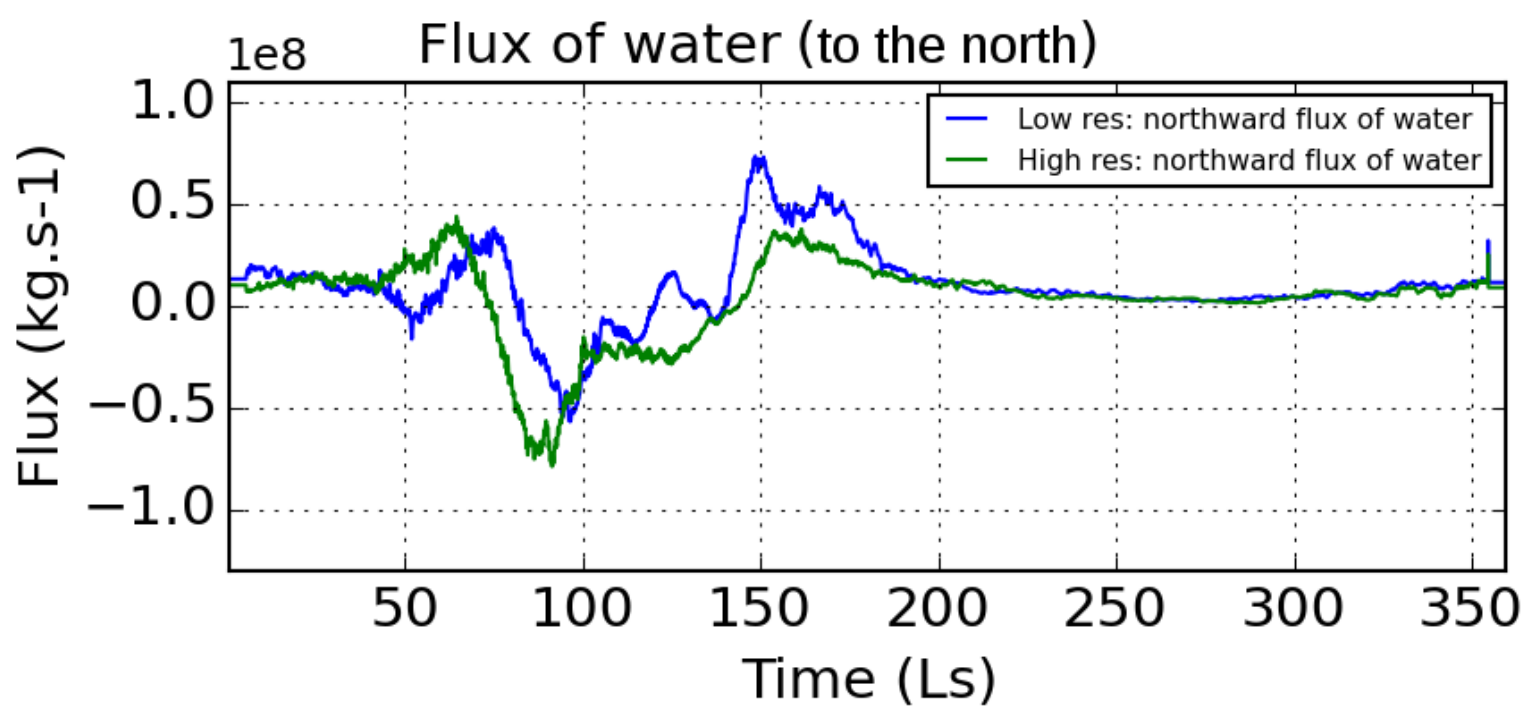

b $79^{\circ} \mathrm{N}$

Figure 27: Northward flux crossing the $68^{\circ} \mathrm{N}$ and $79^{\circ} \mathrm{N}$ latitude circle (or $67.5^{\circ} \mathrm{N}$ and $78.75^{\circ} \mathrm{N}$ at low resolution). Results are averaged over 10 days. 
2002a; Houben et al., 1997; Jakosky \& Farmer, 1982). During winter, fall and spring, the North polar area undergoes a net deposition of water. Water is transported out of the pole during northern summer only (Figure 27b for clouds and vapor). Figure 28 shows surface ice when it is winter at the north polar cap. At high resolution, the peak area of deposition is more restricted: the Chasma Boreale depression is a preferred area of frost deposition. Figure 28a (high resolution), as compared to Figure 28b (low resolution), has only one maximum area of surface ice, which is centered on Chasma Boreale (whereas the low resolution one has three maxima, one at Chasma Boreale, one at $120^{\circ} \mathrm{E}$, and one at $120^{\circ} \mathrm{W}$ ). While the LR case predicts an annulus of surface ice deposition around the northern perennial cap, the HR run predicts a preferential deposition on the western side of the cap.

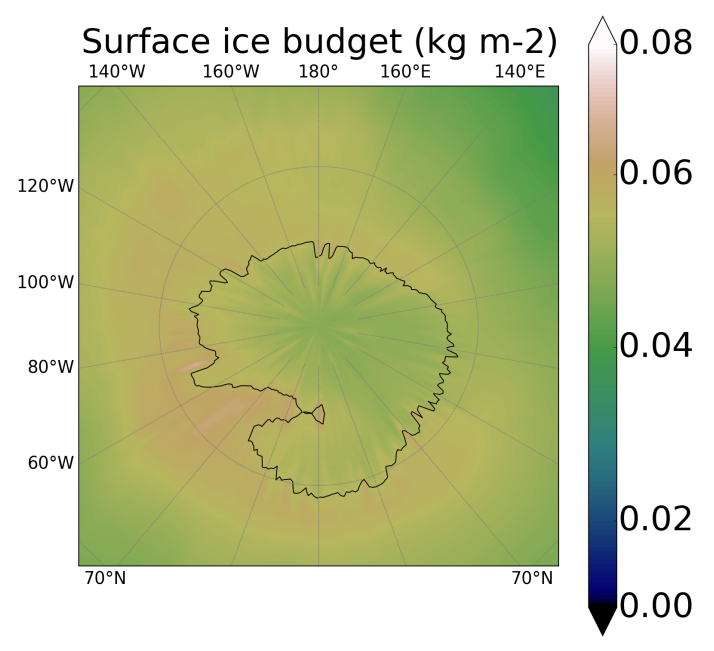

a High resolution

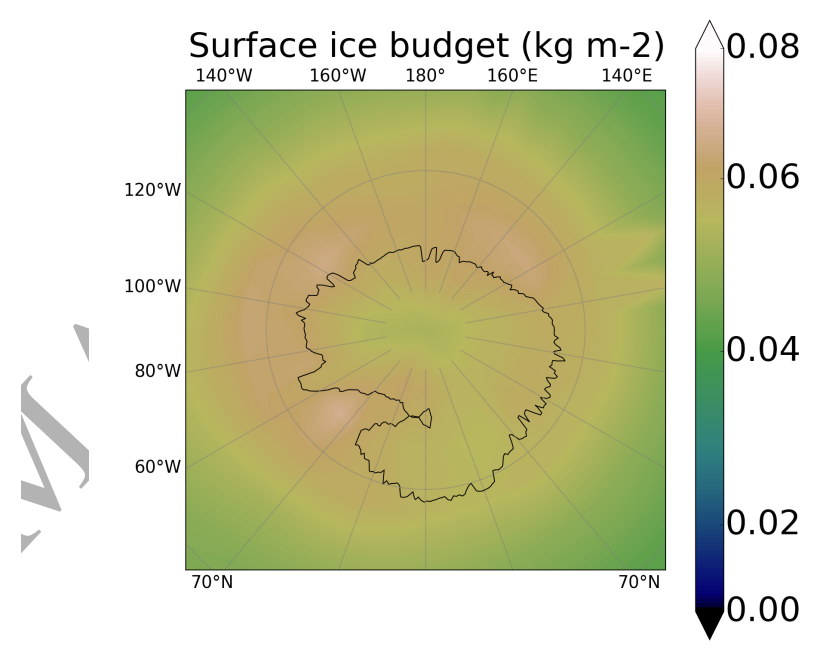

b Low resolution

Figure 28: Deposits of surface ice $\left(\mathrm{kg} \mathrm{m}^{-2}\right)$ during northern winter $\left(\mathrm{L}_{\mathrm{s}}=270-360^{\circ}\right)$, high resolution (left) versus low resolution (right)

\subsection{Frost deposition in the South polar region}

A specific season is the focus here: southern fall/winter. Frost deposition, as seen before, is affected by the refinement in resolution. These maps are comparable to frost measurements around the south pole acquired with the OMEGA instrument aboard Mars express (Langevin et al., 2007; Appéré et al., 2011). The frost spatial pattern is presented for solar longitude $188^{\circ}$ on Figure 29 and for solar longitude $220^{\circ}$ on Figure 30. The agreement between model and observations is better at high resolution than at low resolution.

Between the low- and high-resolution figures, the peak of the frost distribution is shifted by $40^{\circ}$ to the 


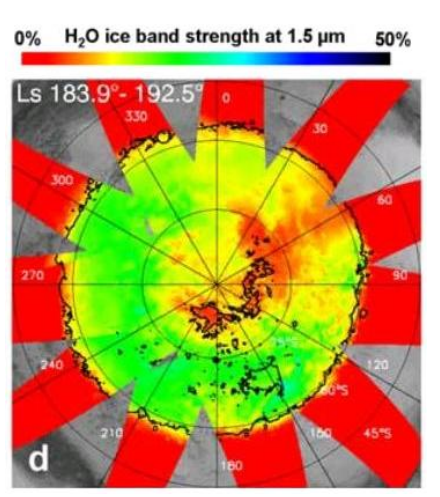

a Frost data

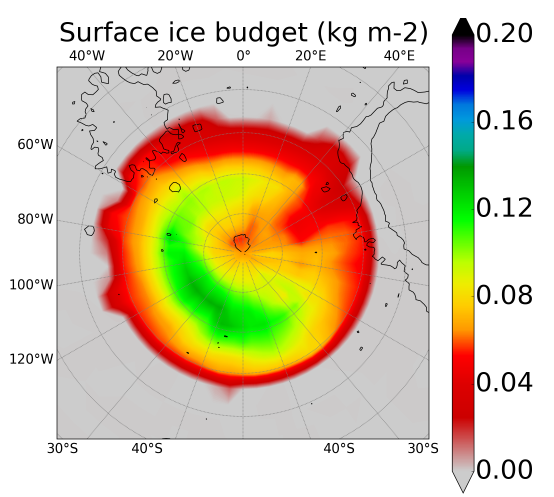

b Low resolution model

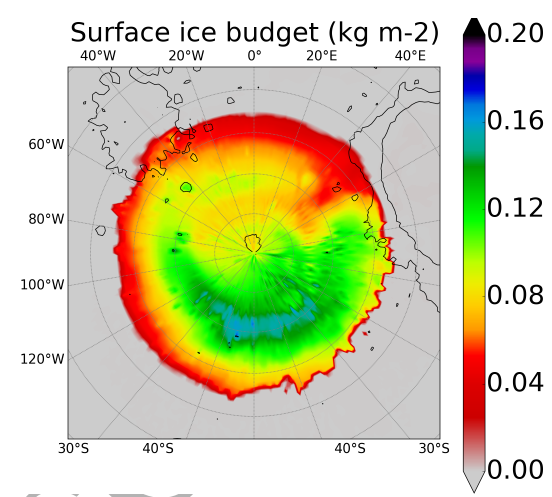

c High resolution model

Figure 29: Surface deposition of frost for $\mathrm{L}_{\mathrm{s}}=188^{\circ}\left(\mathrm{kg} \mathrm{m}^{-2}\right)$, comparisons with Langevin et al. (2007).

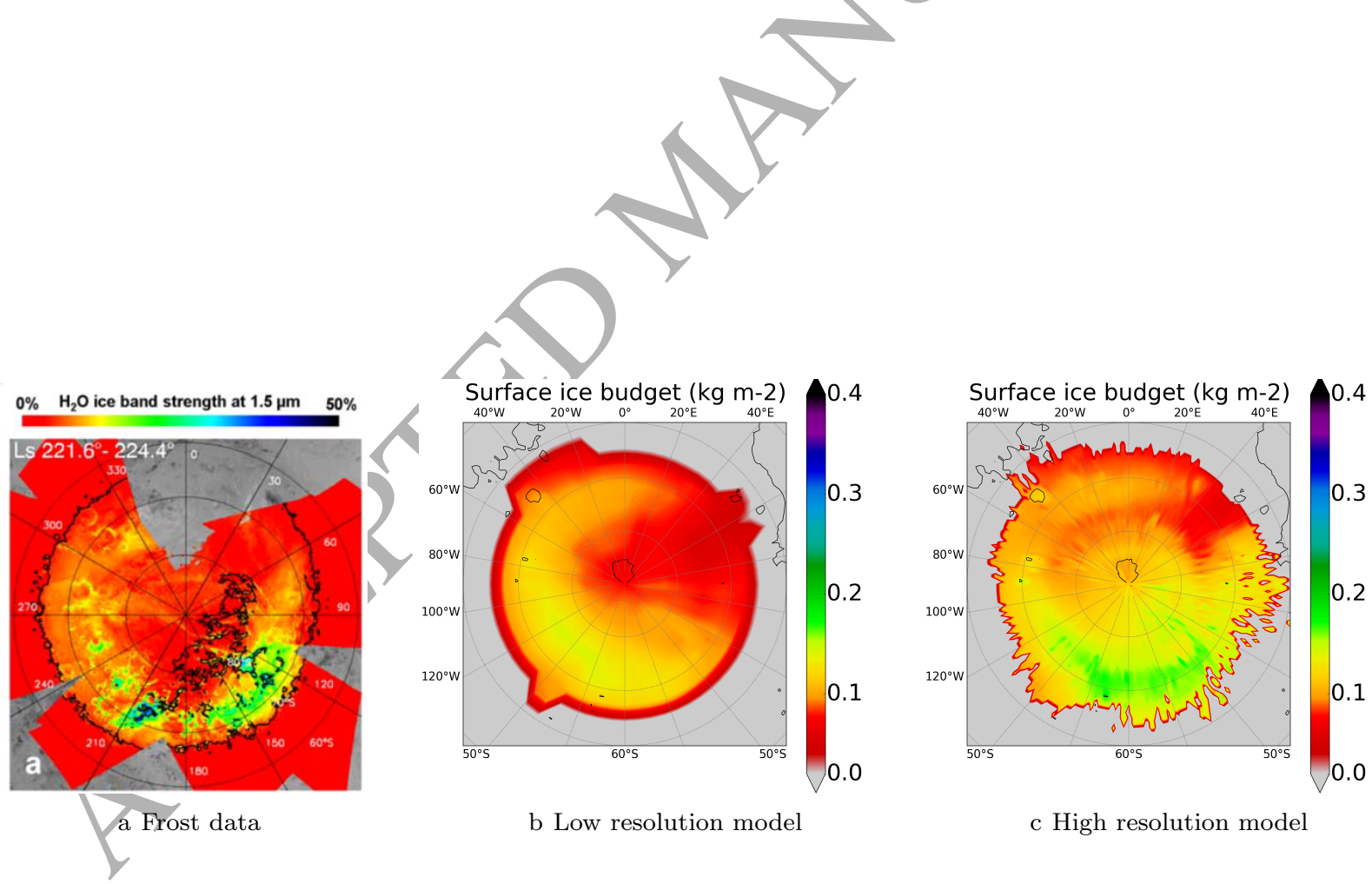

Figure 30: Surface deposition of frost for $\mathrm{L}_{\mathrm{s}}=220^{\circ}\left(\mathrm{kg} \mathrm{m}^{-2}\right)$, comparisons with Langevin et al. (2007). 


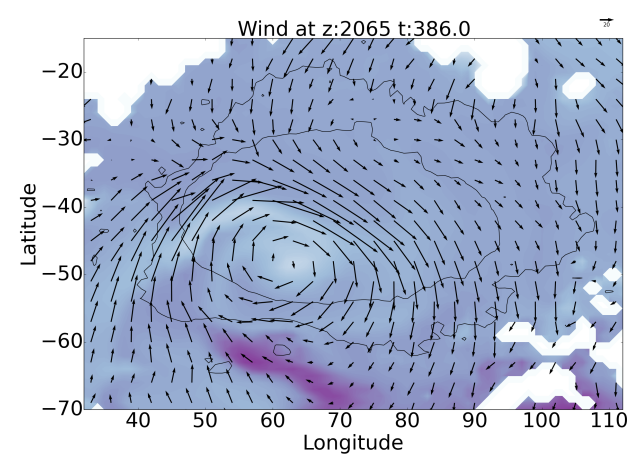

a High resolution, $L_{s}=188^{\circ}$

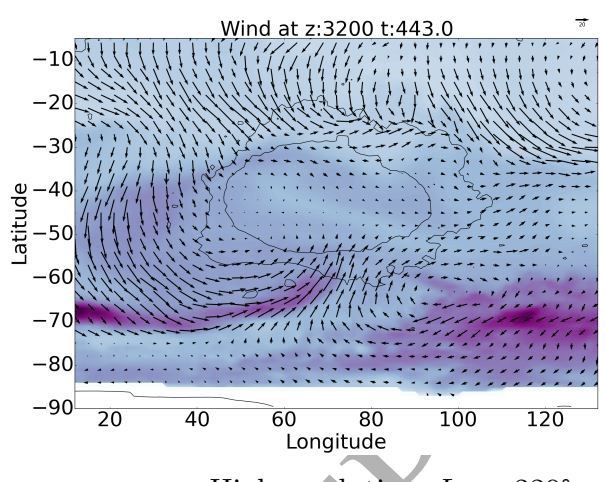

c High resolution, $L_{s}=220^{\circ}$
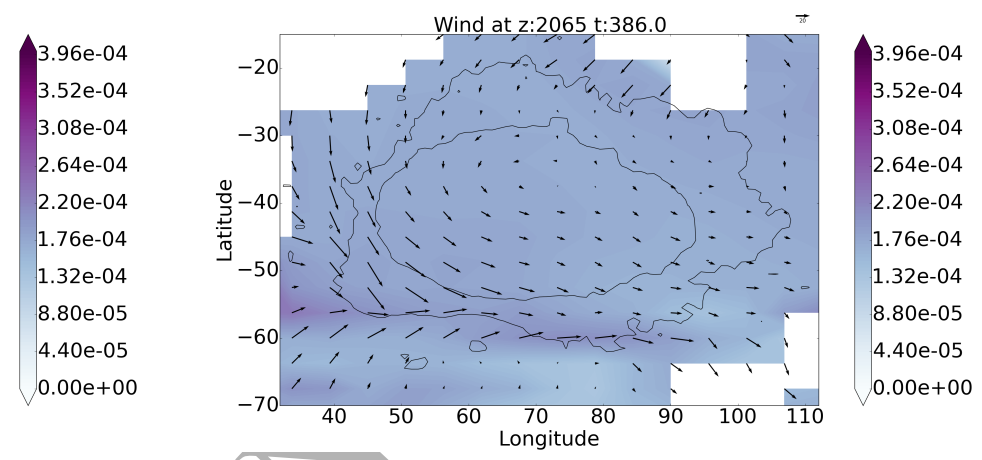

b Low resolution, $L_{s}=188^{\circ}$

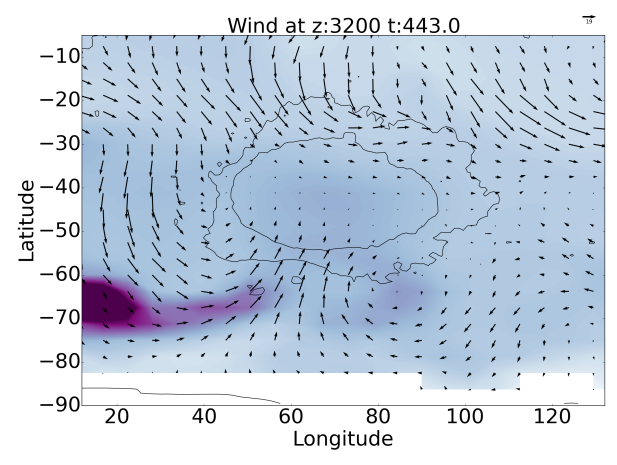

4.95e-04

$4.40 \mathrm{e}-04$

$3.85 \mathrm{e}-04$

3.30e-04

2.75e-04

2.20e- 04

$1.65 \mathrm{e}-04$

$1.10 \mathrm{e}-04$

5.50e- 05

$0.00 e+00$

d Low resolution, $L_{s}=220^{\circ}$

Figure 31: Hellas Planitia, wind vectors for wind and color levels for total water mixing ratio, both at 2 (figures a and b) or $3 \mathrm{~km}$ (figures c and d). Low resolution vectors are plotted at their underlying resolution, and high resolution vectors have been subsampled by a factor of 3 . Same vector scale for all figures. 
west. To understand this, a study of circulation and water advection near Hellas Planitia was conducted. Figure 31 shows the horizontal wind and total water mixing ratio (clouds and vapor) corresponding to the early- to middle-spring periods shown in the frost maps (Figures 29 and 30). The altitude has been adapted to zoom in on the most interesting and representative phenomena for each time period, and the longitude and latitude ranges have been changed accordingly to remove blank space (for the lower altitude). The result is that for $\mathrm{L}_{\mathrm{s}}=188^{\circ}$, at low resolution there is a wide longitudinal band of increased water content at $60^{\circ} \mathrm{S}$. At high resolution stronger winds enhance the advection of water inside Hellas. At an altitude of $8.9 \mathrm{~km}$ (figure not shown), the vertical maximum of a transient wave advecting moist air near its edges and with its peak holding drier air is linked to the relative lack of frost deposition from 20 to $40^{\circ} \mathrm{E}$ in figures of frost deposition. At low resolution there is no evidence for this wave; the circulation is more symmetric, with the zonal jet located along the south border of Hellas. At $\mathrm{L}_{\mathrm{s}}=220^{\circ}$, the water at low altitude is confined to the west of Hellas Planitia under $3 \mathrm{~km}$, and water is advected by southerly winds going towards the north-east. Winds surround Hellas and decrease inside the lowlands. At low resolution, the water content in the south is more longitudinally confined compared to high resolution. Stronger winds advect water and clouds in the $20-40^{\circ} \mathrm{E}$ band from $70^{\circ} \mathrm{S}$ to the Hellas edge. There is almost no wind activity inside Hellas, unlike the storm observed at $\mathrm{L}_{\mathrm{s}}=188^{\circ}$. Winds circle around Hellas, going eastward north of the lowlands, and following its curve southwardsin the west, with an ascending branch to the northeast afterwards. The moisture is brought northwards with the same overall structure as at low resolution with an enhancement of wind strength. This is due to the circulation above the two main topographical features of the southern hemisphere of Mars, Hellas Planitia and Argyre Planitia, with the addition of the southern low to midlatitudes Tharsis bulge. The wavenumber 1 stationary eddy is prominent in the southern winter high latitude circulation pattern, due to the same wavenumber topography component at midlatitudes (Hellas and Tharsis). Wavenumbers 2 and 3 are also present, though being of smaller importance, with the added effect of Argyre. The winds at 2 and $3 \mathrm{~km}$ above the ground (Figure 31), show a stronger circulation pattern inside Hellas Planitia in the high-resolution run. Winds are able to channel water vapor away from the circumpolar area (Figure 31a), especially in the $60^{\circ} \mathrm{W}-80^{\circ} \mathrm{E}$ latitude range. The overall wetter atmosphere in the high-resolution simulations allows more frost deposition outside this latitude range, especially over the better resolved topographical features, producing the $60^{\circ} \mathrm{S}$ band of thicker frost. But inside this latitude range $\left(60^{\circ} \mathrm{W}-80^{\circ} \mathrm{E}\right)$ there is a frost depletion, caused by the increased outgoing flux leaving the polar area that is a result of the increased water transport of the Hellas-Argyre circulation. The frost distribution over the south polar area becomes in better agreement with OMEGA observations as a result. 


\section{Conclusion}

Higher resolution global simulations of the martian water cycle give promising results, as computer power and storage possibilies increase. They bring changes both significant and of lesser importance in profiles of dust, water vapor and cloud content. The mean effect is a warming of levels of altitude 20 to $80 \mathrm{~km}$, a wetter and cloudier atmosphere, and dustier at high altitudes (and dust-depleted in lower ones). Apart from some high-frequency perturbations in RAC runs, higher horizontal resolution does not affect strongly thermal tides.

The main water cycle features are still present at high resolution. The global water budget follows the same trends for both hemispheres, even if the released water vapor is more abundant due to a better resolved cap. The polar hood and aphelion cloud belt are thicker on average, as are southern hemisphere wintertime clouds. During the growth of the northern seasonal polar cap in fall, the polar hood is thicker, while baroclinic wave activity is stronger. Differences in cloud cover and temperature profiles can be explained with the effect of this increased water content on the atmospheric circulation.

Atmospheric waves important to water sublimation, condensation and transport are affected in a major way. At high resolution, there are both higher frequency harmonics of baroclinic waves and increased atmospheric instability. These transient eddies are responsible for intrahemispheric water advection, and thus the water cycle, cloud formation, frost deposition, condensation/sublimation cycle are impacted.

Circumpolar phenomena are more realistically simulated, due to, in part, the improved representation of regional scale circulation, which impacts water transport, and frost deposition. Spiral clouds near the north pole appear at this level of resolution. This level of detail also allows the model to reproduce observations of spiral storms on Mars. The retreat of the seasonal polar cap in the North is predicted to occur more smoothly and realistically than at low resolution during northern spring and summer.

\section{Acknowledgments}

This work was granted access to the HPC resources of the Institute for Scientific Computing and Simulation financed by region/lle de France and the project Equip@Meso (reference ANR-10-EQPX-29-01) overseen by the French National Research Agency (ANR) as part of the "investissements d'avenir" program.

All my thanks to Jeremy Foulon and René Ernenwein who helped with the use of the Mesu supercomputer and provided computer time and enough storage space for these studies. François Forget thanks the UPWARDS project for support. 


\section{References}

Appéré, T., Schmitt, B., Langevin, Y., Douté, S., Pommerol, A., Forget, F., Spiga, A., Gondet, B., \& Bibring, J.-P. (2011). Winter and spring evolution of northern seasonal deposits on Mars from OMEGA on Mars Express. Journal of Geophysical Research, 116, E05001. URL: http://doi.wiley.com/10.1029/2010JE003762. doi:10.1029/2010JE003762.

Guzewich, S. D., Talaat, E. R., \& Waugh, D. W. (2012). Observations of planetary waves and nonmigrating tides by the Mars Climate Sounder. Journal of Geophysical Research, 117, E03010. URL: http://doi.wiley.com/10.1029/2011JE003924. doi:10.1029/2011JE003924.

Hinson, D. P., \& Wang, H. (2010). Further observations of regional dust storms and baroclinic eddies in the northern hemisphere 
of Mars. Icarus, 206, 290-305. URL: http://adsabs.harvard.edu/abs/2010Icar. .206. .290H. doi:10.1016/j.icarus.2009. 08.019.

Hinson, D. P., Wang, H., \& Smith, M. D. (2012). A multi-year survey of dynamics near the surface in the northern hemisphere of Mars: Short-period baroclinic waves and dust storms. Icarus, 219, 307-320. URL: http://linkinghub.elsevier.com/ retrieve/pii/S0019103512000863. doi:10.1016/j.icarus.2012.03.001.

Houben, H., Haberle, R. M., Young, R. E., \& Zent, A. P. (1997). Modeling the Martian seasonal water cycle. Journal of Geophysical Research, 102, 9069. URL: http://doi.wiley.com/10.1029/97JE00046. doi:10.1029/97JE00046.

Hovmöller, E. (1949). The Trough-and-Ridge Diagram. Tellus, 1. URL: http://adsabs.harvard.edu/abs/1949Tell....1b. $.62 \mathrm{H}$.

Hunt, G. E., \& James, P. B. (1979). Martian extratropical cyclones. Nature, 278, 531-532. URL: http://dx.doi.org/10. 1038/278531a0. doi:10.1038/278531a0.

Jakosky, B. M., \& Farmer, C. B. (1982). The seasonal and global behavior of water vapor in the Mars atmosphere: Complete global results of the Viking Atmospheric Water Detector Experiment. Journal of Geophysical Research, 87, 2999. URL: http://doi.wiley.com/10.1029/JB087iB04p02999. doi:10.1029/JB087iB04p02999.

Jaquin, F., Gierasch, P., \& Kahn, R. (1986). The vertical structure of limb hazes in the Martian atmosphere. Icarus, 68, 442461. URL: http://www.sciencedirect.com/science/article/pii/0019103586900503. doi:10.1016/0019-1035(86)90050-3.

Kahre, M., Hollingsworth, J., Haberle, R., \& Wilson, R. (2015). Coupling the Mars dust and water cycles: The importance of radiative-dynamic feedbacks during northern hemisphere summer. Icarus, 260, 477-480. URL: http://www.sciencedirect. com/science/article/pii/S0019103514003832. doi:10.1016/j.icarus.2014.07.017.

Kieffer, H. H., Chase, S. C., Martin, T. Z., Miner, E. D., \& Palluconi, F. D. (1976). Martian north pole summer temperatures: dirty water ice. Science (New York, N.Y.), 194, 1341-4. URL: http://www.sciencemag.org/content/194/4271/1341. abstract. doi:10.1126/science.194.4271.1341.

Kleinböhl, A., Schofield, J. T., Kass, D. M., Abdou, W. A., Backus, C. R., Sen, B., Shirley, J. H., Lawson, W. G., Richardson, M. I., Taylor, F. W., Teanby, N. A., \& McCleese, D. J. (2009). Mars Climate Sounder limb profile retrieval of atmospheric temperature, pressure, and dust and water ice opacity. Journal of Geophysical Research (Planets), 114, 10006. doi:10.1029/ 2009JE003358.

Kleinböhl, A., Wilson, R. J., Kass, D., Schofield, J. T., \& McCleese, D. J. (2013). The semidiurnal tide in the middle atmosphere of Mars. Geophysical Research Letters, 40,1952-1959. URL: http://doi.wiley.com/10.1002/grl.50497. doi:10.1002/grl. 50497.

Langevin, Y., Bibring, J.-P., Montmessin, F., Forget, F., Vincendon, M., Douté, S., Poulet, F., \& Gondet, B. (2007). Observations of the south seasonal cap of Mars during recession in 2004-2006 by the OMEGA visible/near-infrared imaging spectrometer on board Mars Express. Journal of Geophysical Research, 112, E08S12. URL: http://doi.wiley.com/10. 1029/2006JE002841. doi:10.1029/2006JE002841.

Langevin, Y., Poulet, F., Bibring, J.-P., Schmitt, B., Douté, S., \& Gondet, B. (2005). Summer evolution of the north polar cap of Mars as observed by OMEGA/Mars Express. Science (New York, N.Y.), 307, 1581-4. URL: http://adsabs.harvard. edu/abs/2005Sci...307.1581L. doi:10.1126/science.1109438.

Lee, C., Lawson, W. G., Richardson, M. I., Heavens, N. G., Kleinböhl, A., Banfield, D., McCleese, D. J., Zurek, R., Kass, D., Schofield, J. T., Leovy, C. B., Taylor, F. W., \& Toigo, A. D. (2009). Thermal tides in the Martian middle atmosphere as seen by the Mars Climate Sounder. Journal of Geophysical Research, 114, E03005. URL: http://doi.wiley.com/10.1029/ 2008JE003285. doi:10.1029/2008JE003285.

Lewis, S. R., \& Montabone, L. (2008). Mars Climate Database and Physical Models (ESA-11369/95/NL/LvH - CNES: Base de donnes atmosphriques martiennes), High resolution simulations of the Martian atmosphere. WP11.2 technical note, .

Lewis, S. R., Mulholland, D. P., Read, P. L., Montabone, L., Wilson, R. J., \& Smith, M. D. (2016). The solsticial pause on 
Mars: 1. A planetary wave reanalysis. Icarus, 264, 456-464. URL: http://adsabs.harvard.edu/abs/2016Icar. .264. .456L. doi:10.1016/j.icarus.2015.08.039.

Lindzen, R. S. (1970). The Application and Applicability of Terrestrial Atmospheric Tidal Theory to Venus and Mars. Journal of the Atmospheric Sciences, 27, 536-549. URL: http://journals.ametsoc.org/doi/abs/10.1175/1520-0469(1970)027\% 3C0536\%3ATAAAOT\%3E2.0.CO\%3B2. doi:10.1175/1520-0469(1970)027<0536: TAAAOT>2.0.CO; 2.

Madeleine, J.-B., Forget, F., Millour, E., Montabone, L., \& Wolff, M. J. (2011). Revisiting the radiative impact of dust on Mars using the LMD Global Climate Model. Journal of Geophysical Research, 116, E11010. URL: http://doi.wiley.com/ 10.1029/2011JE003855. doi:10.1029/2011JE003855.

Madeleine, J.-B., Forget, F., Millour, E., Navarro, T., \& Spiga, a. (2012a). The influence of radiatively active water ice clouds on the Martian climate. Geophysical Research Letters, 39. URL: http://doi.wiley.com/10.1029/2012GL053564. doi:10.1029/2012GL053564.

Madeleine, J.-B., Forget, F., Spiga, a., Wolff, M. J., Montmessin, F., Vincendon, M., Jouglet, D., Gondet, B., Bibring, J.-P., Langevin, Y., \& Schmitt, B. (2012b). Aphelion water-ice cloud mapping and property retrieval using the OMEGA imaging spectrometer onboard Mars Express. Journal of Geophysical Research, 117, E00J07. URL: http://doi.wiley.com/10.1029/ 2011JE003940. doi:10.1029/2011JE003940.

McCleese, D. J., Heavens, N. G., Schofield, J. T., Abdou, W. A., Bandfield, J. L., Calcutt, S. B., Irwin, P. G. J., Kass, D. M., Kleinböhl, A., Lewis, S. R., Paige, D. A., Read, P. L., Richardson, M. I., Shirley, J. H., Taylor, F. W., Teanby, N., \& Zurek, R. W. (2010). Structure and dynamics of the Martian lower and middle atmosphere as observed by the Mars Climate Sounder: Seasonal variations in zonal mean temperature, dust, and water ice aerosols. Journal of Geophysical Research, 115, 1-16. URL: http://onlinelibrary.wiley.com/doi/10.1029/2010JE003677/full. doi:10.1029/2010JE003677.

Mellon, M. T., Jakosky, B. M., Kieffer, H. H., \& Christensen, P. R. (2000). High-Resolution Thermal Inertia Mapping from the Mars Global Surveyor Thermal Emission Spectrometer.Icarus, 148, 437-455. URL: http://adsabs.harvard.edu/abs/ 2000Icar. .148. .437M. doi:10.1006/icar.2000.6503.

Montabone, L., Forget, F., Millour, E., Wilson, R., Lewis, S., Cantor, B., Kass, D., Kleinböhl, A., Lemmon, M., Smith, M., \& Wolff, M. (2015). Eight-year climatology of dust optical depth on Mars. Icarus, 251, 65-95. URL: http://www. sciencedirect.com/science/article/pii/S0019103515000044. doi:10.1016/j.icarus.2014.12.034.

Montmessin, F., Forget, F., Rannou, P., Cabane, M., \& Haberle, R. M. (2004). Origin and role of water ice clouds in the Martian water cycle as inferred from a general circulation model. Journal of Geophysical Research, 109, E10004. URL: http://doi.wiley.com/10.1029/2004JE002284. doi:10.1029/2004JE002284.

Montmessin, F., Forget, F., Rannou, P., Cabane, M., \& Haberle, R. M. (2004). Origin and role of water ice clouds in the Martian water cycle as inferred from a general circulation model. Journal of Geophysical Research (Planets), $109,10004$. doi:10.1029/2004JE002284.

Montmessin, F., Rannou, P., \& Cabane, M. (2002). New insights into Martian dust distribution and water-ice cloud microphysics. Journal of Geophysical Research, 107, 5037. URL: http://doi.wiley.com/10.1029/2001JE001520. doi:10.1029/ 2001 JE001520.

Mulholland, D. P. Lewis, S. R., Read, P. L., Madeleine, J.-B., \& Forget, F. (2016). The solsticial pause on Mars: 2 modelling and investigation of causes. Icarus, 264, 465-477. URL: http://www.sciencedirect.com/science/article/pii/ S0019103515004169. doi:10.1016/j.icarus.2015.08.038.

Navarro, T., Madeleine, J.-B., Forget, F., Spiga, A., Millour, E., Montmessin, F., \& Määttänen, A. (2014). Global climate modeling of the Martian water cycle with improved microphysics and radiatively active water ice clouds. Journal of Geophysical Research: Planets, 119, 1479-1495. URL: http://doi.wiley.com/10.1002/2013JE004550. doi:10.1002/2013JE004550.

Pankine, A. A., Tamppari, L. K., Bandfield, J. L., McConnochie, T. H., \& Smith, M. D. (2013). Retrievals of martian atmospheric opacities from MGS TES nighttime data. Icarus, 226, 708-722. URL: http://www.sciencedirect.com/science/ 
article/pii/S0019103513002893. doi:10.1016/j.icarus.2013.06.024.

Pearl, J. C., Smith, M. D., Conrath, B. J., Bandfield, J. L., \& Christensen, P. R. (2001). Observations of Martian ice clouds by the Mars Global Surveyor Thermal Emission Spectrometer: The first Martian year. Journal of Geophysical Research, 106, 12325. URL: http://doi.wiley.com/10.1029/1999JE001233. doi:10.1029/1999JE001233.

Read, P. L., Lewis, S. R., \& Mulholland, D. P. (2015). The physics of Martian weather and climate: a review. Reports on progress in physics. Physical Society (Great Britain), 78, 125901. URL: http://iopscience.iop.org/article/10.1088/ 0034-4885/78/12/125901. doi:10.1088/0034-4885/78/12/125901.

Richardson, M. I., \& Wilson, R. J. (2002a). A topographically forced asymmetry in the martian circulation and climate. Nature, 416, 298-301. URL: http://dx.doi.org/10.1038/416298a. doi:10.1038/416298a.

Richardson, M. I., \& Wilson, R. J. (2002b). Investigation of the nature and stability of the Martian seasonal water cycle with a general circulation model. Journal of Geophysical Research, 107, 5031. URL: http://doi.wiley.com/10.1029/ 2001JE001536. doi:10.1029/2001JE001536.

Smith, D. E., Zuber, M. T., Frey, H. V., Garvin, J. B., Head, J. W., Muhleman, D. O., Pettengill, G. H., Phillips, R. J., Solomon, S. C., Zwally, H. J., Banerdt, W. B., Duxbury, T. C., Golombek, M. P., Lemoine, F. G., Neumann, G. A., Rowlands, D. D., Aharonson, O., Ford, P. G., Ivanov, A. B., Johnson, C. L., McGovern, P. J., Abshire, J. B., Afzal, R. S., \& Sun, X. (2001a). Mars Orbiter Laser Altimeter: Experiment summary after the first year of global mapping of Mars. Journal of Geophysical Research, 106, 23689. URL: http://doi.wiley.com/10.1029/2000JE001364. doi:10.1029/2000JE001364.

Smith, I. B., Holt, J. W., Spiga, A., Howard, A. D., \& Parker, G. (2013). The spiral troughs of Mars as cyclic steps. Journal of Geophysical Research: Planets, 118, 1835-1857. URL: http://doi.wiley.com/10.1002/jgre.20142. doi:10.1002/jgre. 20142.

Smith, M. D. (2002). The annual cycle of water vapor on Mars as observed by the Thermal Emission Spectrometer. Journal of Geophysical Research, 107, 5115. URL: http://adsabs.harvard.edu/abs/2002JGRE. 107.5115S. doi:10.1029/ 2001JE001522.

Smith, M. D., Pearl, J. C., Conrath, B. J., \& Christensen, P. R. (2001b). Thermal Emission Spectrometer results: Mars atmospheric thermal structure and aerosol distribution. Journal of Geophysical Research: Planets, 106, 23929-23945. URL: http://doi.wiley.com/10.1029/2000JE001321. doi:10.1029/2000JE001321.

Takahashi, Y. O., Hayashi, Y.-Y., Odaka, M., \& Ohfuchi, W. (2006). High resolution simulations of the martian atmosphere with a general circulation model. Second workshop on Mars atmosphere modelling and observations, . URL: http://adsabs. harvard.edu/abs/2006mamo. conf. .116T.

Takahashi, Y. O., Hayashi, Y.-Y., Odaka, M., \& Ohfuchi, W. (2011). High Resolution General Circulation Model Experiments of the Martian Atmosphere: Resolution Dependence of Disturbance and Surface Stress. "The Fourth International Workshop on the Mars Atmosphere: Modelling and observation, . URL: http://adsabs.harvard.edu/abs/2011mamo.conf ...74T.

Tamppari, L., Smith, M., Bass, D., \& Hale, A. (2008). Water-ice clouds and dust in the north polar region of Mars using MGS TES data. Planetary and Space Science, 56, 227-245. URL: http://www.sciencedirect.com/science/article/pii/ S0032063307002115. doi:10.1016/j.pss.2007.08.011.

Tamppari, L. K. (2003). Viking-era diurnal water-ice clouds. Journal of Geophysical Research, 108, 5073. URL: http: //cdsads.u-strasbg.fr/abs/2003JGRE. . 108.5073T. doi:10.1029/2002JE001911.

Toigo, A. D., Lee, C., Newman, C. E., \& Richardson, M. I. (2012). The impact of resolution on the dynamics of the martian global atmosphere: Varying resolution studies with the MarsWRF GCM. Icarus, 221, 276-288. URL: http://www.sciencedirect.com/science/article/pii/S0019103512002965. doi:10.1016/j.icarus.2012.07.020.

915 Toon, O. B., Pollack, J. B., Ward, W., Burns, J. A., \& Bilski, K. (1980). The astronomical theory of climatic change on Mars. Icarus, 44, 552-607. URL: http://www.sciencedirect.com/science/article/pii/001910358090130X. doi:10.1016/ 0019-1035(80) 90130-X. 
Trokhimovskiy, A., Fedorova, A., Korablev, O., Montmessin, F., Bertaux, J.-L., Rodin, A., \& Smith, M. D. (2015). Mars water vapor mapping by the SPICAM IR spectrometer: Five martian years of observations. Icarus, 251, 50-64. doi:10.1016/j . icarus.2014.10.007.

Tyler, D., \& Barnes, J. R. (2005). A mesoscale model study of summertime atmospheric circulations in the north polar region of Mars. Journal of Geophysical Research, 110, E06007. URL: http://adslabs.org/adsabs/abs/2005JGRE..110.6007T/. doi:10.1029/2004JE002356.

Tyler, D., \& Barnes, J. R. (2014). Atmospheric mesoscale modeling of water and clouds during northern summer on Mars. Icarus, 237, 388-414. URL: http://www.sciencedirect.com/science/article/pii/S0019103514002127. doi:10.1016/j . icarus. 2014.04.020.

Urata, R. A., \& Toon, O. B. (2013). Simulations of the martian hydrologic cycle with a general circulation model: Implications for the ancient martian climate. Icarus, 226, 229-250. URL: http://www.sciencedirect.com/science/article/pii/ S0019103513002145. doi:10.1016/j.icarus.2013.05.014.

Wang, H., \& Ingersoll, A. P. (2002). Martian clouds observed by Mars Global Surveyor Mars Orbiter Camera. Journal of Geophysical Research, 107, 5078. URL: http://doi.wiley.com/10.1029/2001JE001815. doi:10.1029/2001JE001815.

Wang, H., Richardson, M. I., Toigo, A. D., \& Newman, C. E. (2013). Zonal wavenumber three traveling waves in the northern hemisphere of Mars simulated with a general circulation model. Icarus, 223, 654-676. URL: http://adsabs.harvard.edu/ abs/2013Icar..223. .654W. doi:10.1016/j.icarus.2013.01.004.

Wang, H., \& Toigo, A. D. (2016). The variability, structure and energy conversion of the northern hemisphere traveling waves simulated in a Mars general circulation model. Icarus, 271, 207-221. doi:10.1016/j.icarus.2016.02.005.

Wilson, R. J. (2011). Dust Cycle Modeling with the GFDL Mars General Circulation Model. The Fourth International Workshop on the Mars Atmosphere: Modelling and observation, Paris, France., (pp. 147-150). URL: http://www-mars. lmd.jussieu.fr/paris2011/abstracts/wilson_rj3_paris2011.pdf.

Wilson, R. J., Banfield, D., Conrath, B. J., \& Smith, M. D. (2002). Traveling waves in the Northern Hemisphere of Mars. Geophysical Research Letters, 29, 29-1-29-4. URL: http://doi.wiley.com/10.1029/2002GL014866. doi:10.1029/2002GL014866.

Wilson, R. J., \& Guzewich, S. D. (2014). Influence of water ice clouds on nighttime tropical temperature structure as seen by the Mars Climate Sounder. Geophysical Research Letters, 41, 3375-3381. URL: http://doi . wiley.com/10.1002/2014GL060086. doi:10.1002/2014GL060086.

Wilson, R. J., Hinson, D., \& Smith, M. D. (2006). GCM simulations of transient eddies and frontal systems in the martian atmosphere. Second workshop on Mars atmosphere modelling and observations, Granada, Spain., (p. 154). URL: http: //www-mars.lmd.jussieu,fr/granada2006/abstracts/Wilson3_Granada2006.pdf.

Wilson, R. J., Lewis, S. R., Montabone, L., \& Smith, M. D. (2008). Influence of water ice clouds on Martian tropical atmospheric temperatures. Geophysical Research Letters, 35, L07202. URL: http://doi . wiley.com/10.1029/2007GL032405. doi:10.1029/2007GL032405.

Wilson, R. J., Millour, E., Navarro, T., Forget, F., \& Kahre, M. (2014). GCM Simulations of aphelion season tropical cloud and temperature structure. The Fifth International Workshop on the Mars Atmosphere: Modelling and Observation, held on January 13-16 2014, in Oxford, U.K. Edited by F. Forget and M. Millour, id.1304, . URL: http://www-mars.Imd.jussieu. fr/oxford2014/abstracts/wilson_clouds_oxford2014.pdf.

Wilson, R. J., Neumann, G. A., \& Smith, M. D. (2007). Diurnal variation and radiative influence of Martian water ice clouds. Geophysical Research Letters, 34, L02710. URL: http://doi.wiley.com/10.1029/2006GL027976. doi:10.1029/ 2006GL027976.

Zasova, L., Formisano, V., Moroz, V., Grassi, D., Ignatiev, N., Giuranna, M., Hansen, G., Blecka, M., Ekonomov, A., Lellouch, E., Fonti, S., Grigoriev, A., Hirsch, H., Khatuntsev, I., Mattana, A., Maturilli, A., Moshkin, B., Patsaev, D., Piccioni, G., Rataj, M., \& Saggin, B. (2005). Water clouds and dust aerosols observations with PFS MEX at Mars. Planetary and Space 
Science, 53, 1065-1077. URL: http://www.sciencedirect.com/science/article/pii/S0032063305000735. doi:10.1016/j. pss.2004.12.010.

Zurek, R. (1976). Diurnal tide in the Martian atmosphere. Journal of the Atmospheric Sciences, 33. URL: http://journals. ametsoc.org/doi/abs/10.1175/1520-0469(1976)033<0321: DTITMA>2.0.C0; 2.

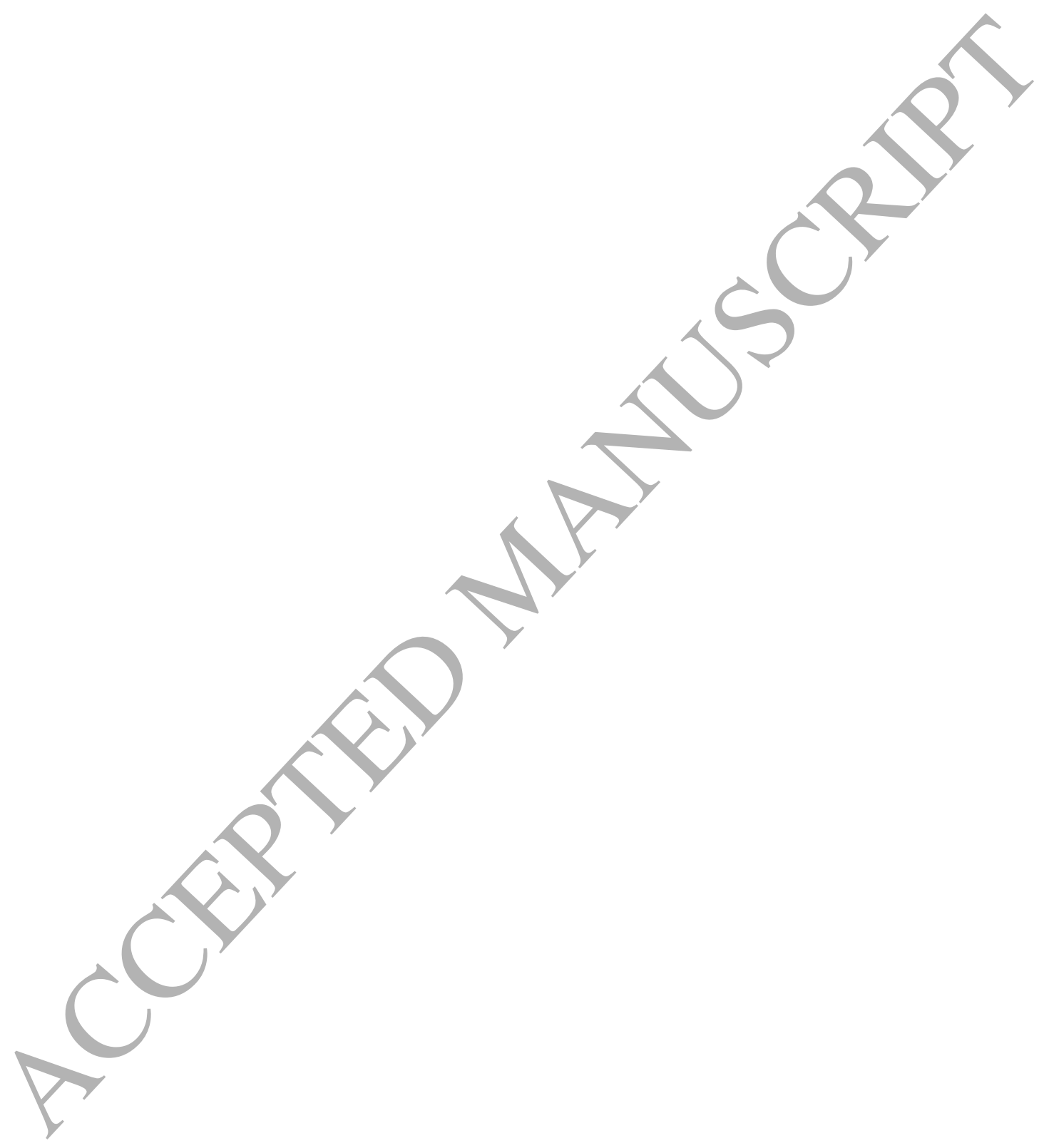

